OAK RIDGE

NATIONAL LABORATORY

MANAGED BY UT-BATTELLE

FOR THE DEPARTMENT OF ENERGY

\title{
Status of Preconceptual Design of the Advanced High-Temperature Reactor (AHTR)
}

\author{
D. T. Ingersoll \\ L. J. Ott \\ C. W. Forsberg \\ J. P. Renier \\ D. F. Williams \\ S. J. Ball \\ D. F. Wilson \\ W. R. Corwin \\ L. Reid \\ G. D. Del Cul \\ Oak Ridge National Laboratory \\ P. F. Peterson H. Zhao \\ University of California, Berkeley \\ $\begin{array}{ll}\text { P. S. Pickard } & \text { E. J. Parma }\end{array}$ \\ M. Vernon \\ Sandia National Laboratories
}

May 2004

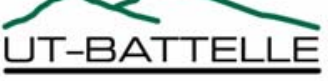




\title{
DOCUMENT AVAILABILITY
}

Reports produced after January 1, 1996, are generally available free via the U.S. Department of Energy (DOE) Information Bridge:

Web site: http://www.osti.gov/bridge

Reports produced before January 1, 1996, may be purchased by members of the public from the following source:

\author{
National Technical Information Service \\ 5285 Port Royal Road \\ Springfield, VA 22161 \\ Telephone: 703-605-6000 (1-800-553-6847) \\ TDD: 703-487-4639 \\ Fax: 703-605-6900 \\ E-mail: info@ntis.fedworld.gov \\ Web site: http://www.ntis.gov/support/ordernowabout.htm
}

Reports are available to DOE employees, DOE contractors, Energy Technology Data Exchange (ETDE) representatives, and International Nuclear Information System (INIS) representatives from the following source:

Office of Scientific and Technical Information

P.O. Box 62

Oak Ridge, TN 37831

Telephone: 865-576-8401

Fax: 865-576-5728

E-mail: reports@adonis.osti.gov

Web site: http://www.osti.gov/contact.html

\begin{abstract}
This report was prepared as an account of work sponsored by an agency of the United States Government. Neither the United States government nor any agency thereof, nor any of their employees, makes any warranty, express or implied, or assumes any legal liability or responsibility for the accuracy, completeness, or usefulness of any information, apparatus, product, or process disclosed, or represents that its use would not infringe privately owned rights. Reference herein to any specific commercial product, process, or service by trade name, trademark, manufacturer, or otherwise, does not necessarily constitute or imply its endorsement, recommendation, or favoring by the United States Government or any agency thereof. The views and opinions of authors expressed herein do not necessarily state or reflect those of the United States Government or any agency thereof.
\end{abstract}


ORNL/TM-2004/104

\section{Status of Preconceptual Design of the Advanced High-Temperature Reactor (AHTR)}

D. T. Ingersoll, C. W. Forsberg, L. J. Ott, D. F. Williams, J. P. Renier,

D. F. Wilson, S. J. Ball, L. Reid, W. R. Corwin, G. D. Del Cul

Oak Ridge National Laboratory

P. F. Peterson, H. Zhao

University of California, Berkeley

P. S. Pickard, E. J. Parma, M. Vernon

Sandia National Laboratories

Date Published: May 2004

The submitted manuscript has been authored by a contractor of the U.S. Government under contract DE-AC05-00OR22725.

Accordingly, the U.S. Government retains a nonexclusive, royalty-free license to publish or reproduce the published form of this contribution, or allow others to do so, for U.S. Government purposes.

Prepared by

OAK RIDGE NATIONAL LABORATORY

Oak Ridge, Tennessee 37831-6285

managed by

UT-BATTELLE, LLC

for the

U.S. DEPARTMENT OF ENERGY

under contract DE-AC05-00OR22725 



\section{CONTENTS}

LIST OF FIGURES

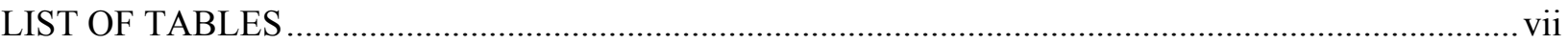

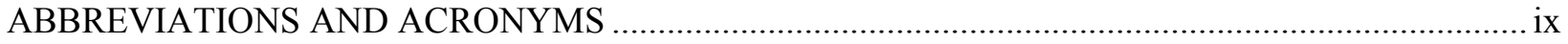

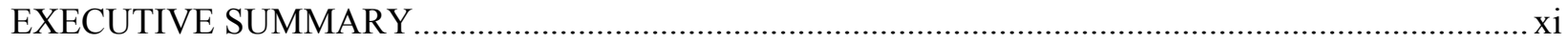

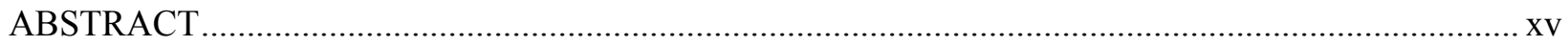

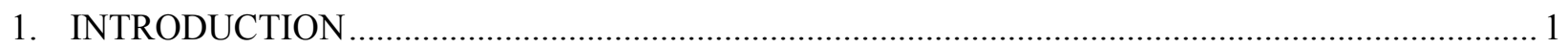

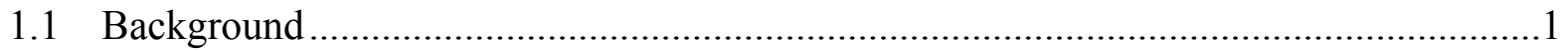

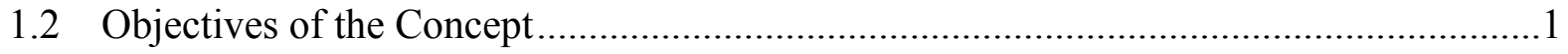

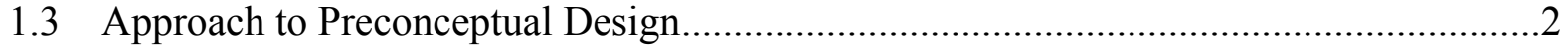

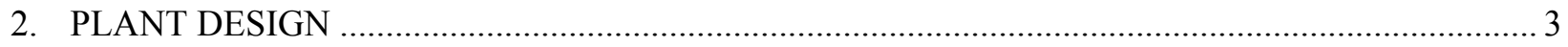

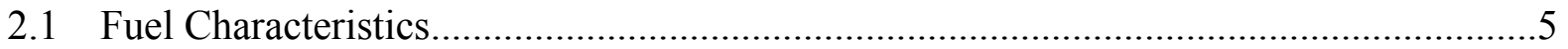

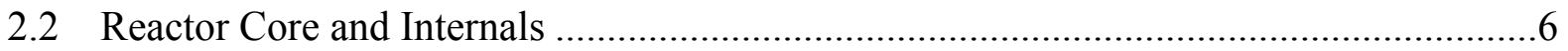

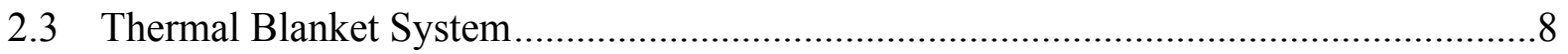

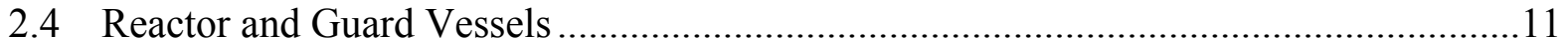

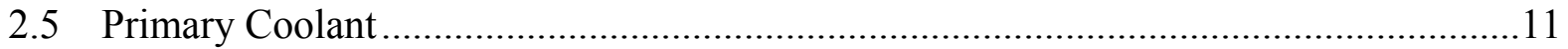

2.6 Decay Heat Removal Systems ............................................................................ 11

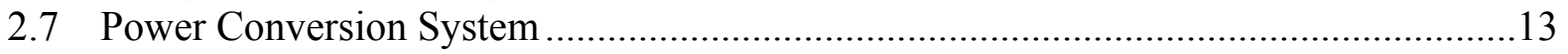

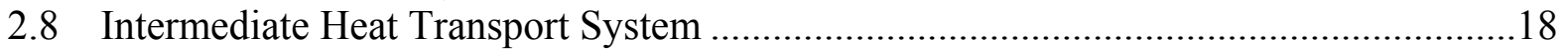

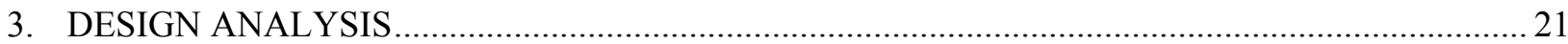

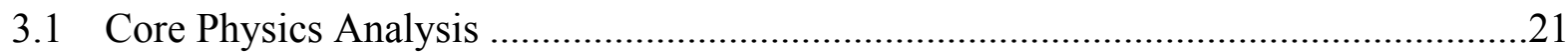

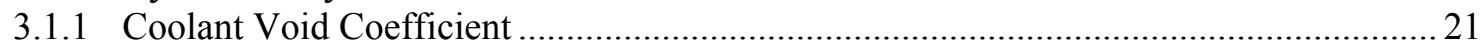

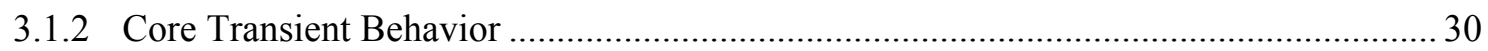

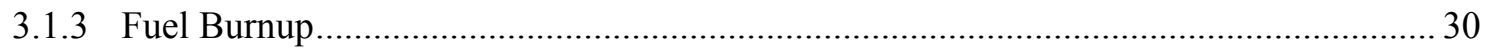

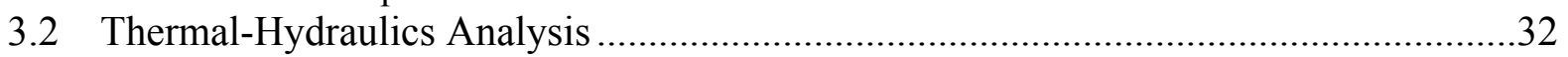

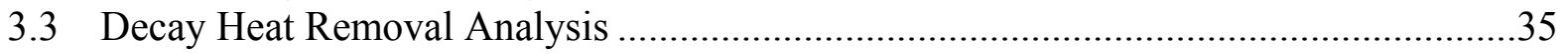

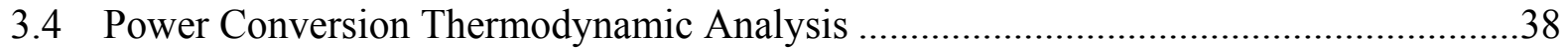

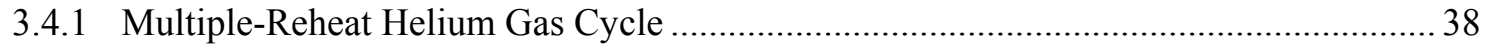

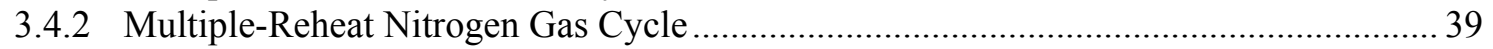

3.4.3 Vertical vs Horizontal Turbomachinery ..................................................................... 41

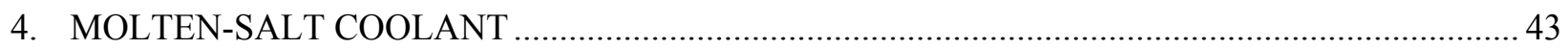

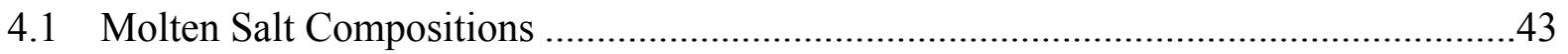

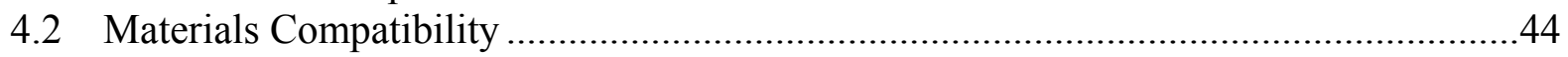

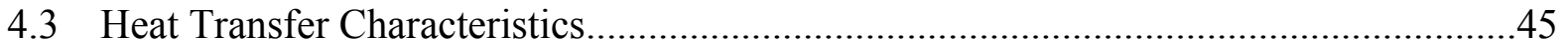

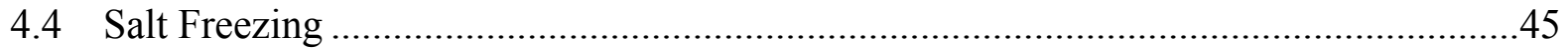

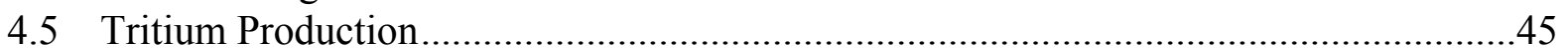

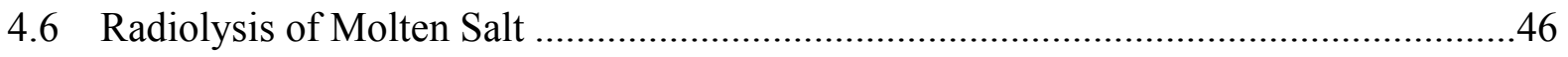

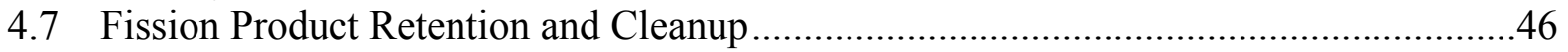




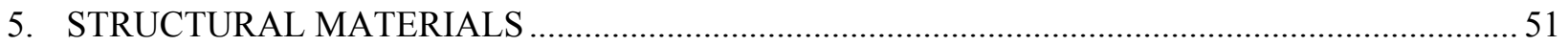

5.1 Graphite and Carbon-Carbon Composites ...............................................................51

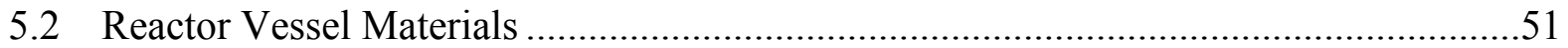

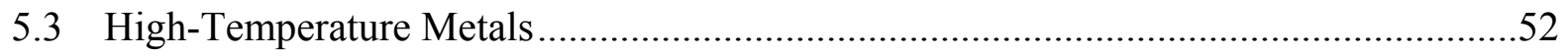

5.4 High-Temperature Melt-Infiltrated Composites ...................................................55

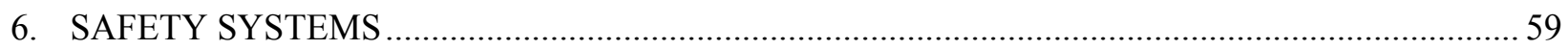

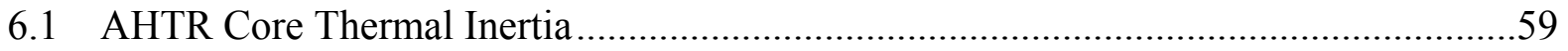

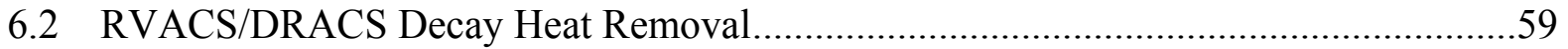

6.3 Beyond-Design-Basis Accidents ........................................................................60

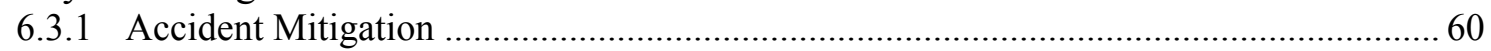

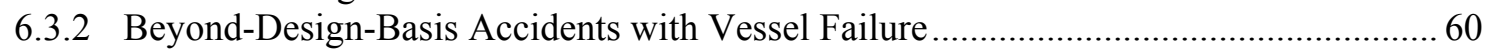

6.4 Intermediate Heat Transport Loop......................................................................63

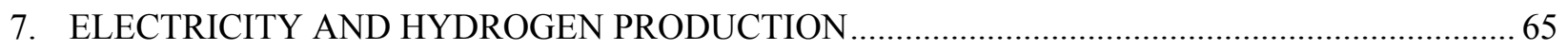

7.1 Thermal Characteristics for Energy Conversion ....................................................65

7.2 Electricity Production ........................................................................................65

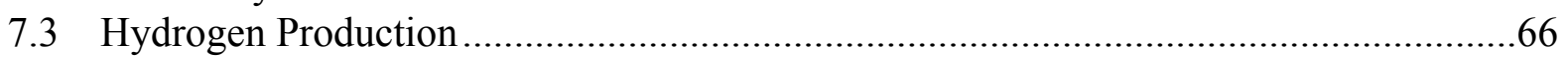

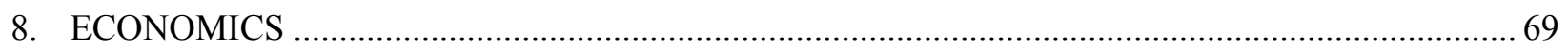

8.1 Comparison-Based Capital Cost Estimate ...........................................................69

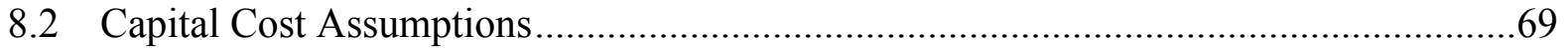

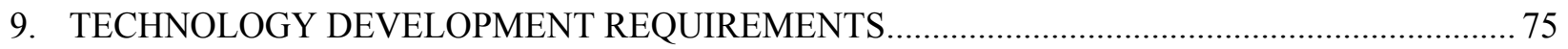

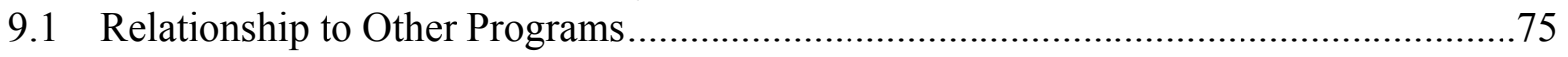

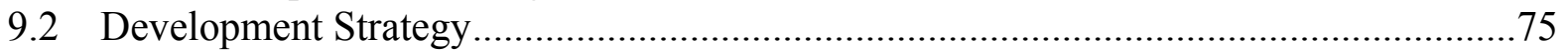

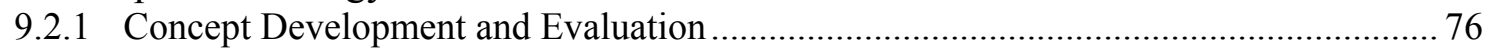

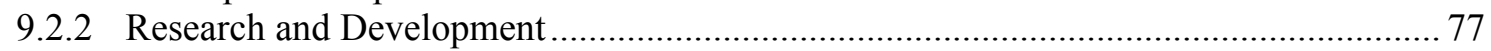

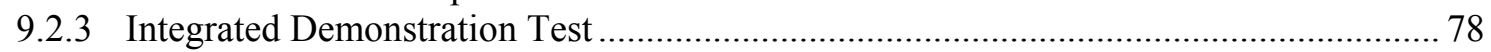

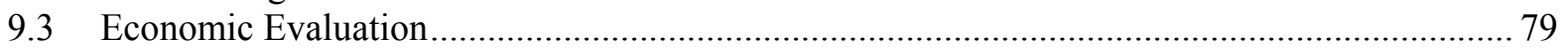

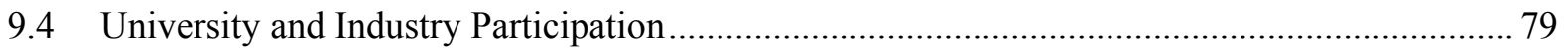

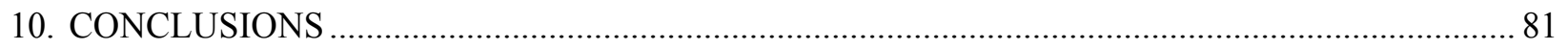

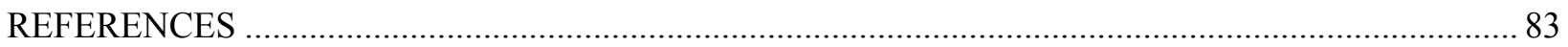




\section{LIST OF FIGURES}

Figure $\quad$ Page

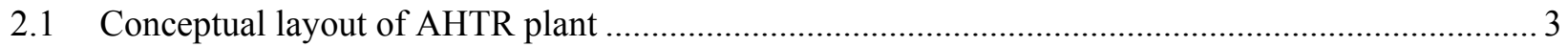

2.2 Functional layout of AHTR for electricity production.................................................................. 4

2.3 Diagram and photographs of high-temperature, TRISO-coated particle fuel .................................. 5

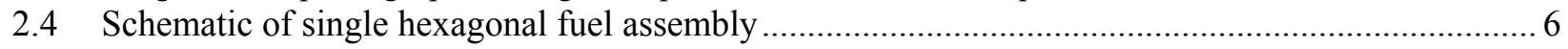

2.5 Plan view of AHTR core showing 324 columns of fuel assemblies ............................................. 7

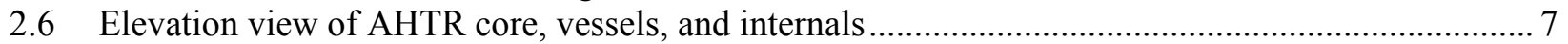

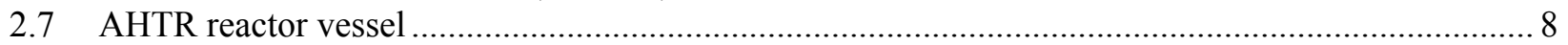

2.8 Schematic showing a vertical cross-section for an AHTR thermal blanket system ......................... 9

2.9 Schematic showing how controlled leakage occurs through a hollow double-wrapped

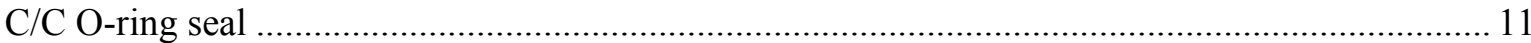

2.10 Illustration of a combined RVACS/DRACS system for the AHTR …....................................... 13

2.11 Schematic flow diagram for the reference three-expansion-stage MCGC, using three PCU modules [high pressure (HP), middle pressure (MP), and low pressure (LP)] each containing a generator $(\mathrm{G})$, turbine $(\mathrm{T})$, compressor $(\mathrm{C})$, and heater and cooler heat exchangers, with

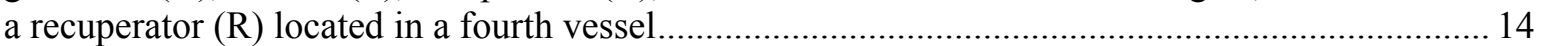

2.12 Cross section of the GT-MHT PCU, with changes required for MCGC indicated on left.............. 15

2.13 Hot- and cold-leg configurations for the MCGC based on three (HP, MP, and LP) PCUs and

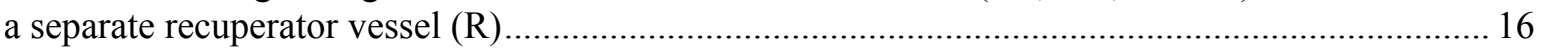

2.14 Stress and temperature distributions in a plate-type LSI composite heat exchanger currently under development at UCB................................................................................. 16

2.15 Total pumping power $\mathrm{P}$ (dashed) and the total volume $\mathrm{V}_{\mathrm{HX}}$ (solid) for a $600 \mathrm{MW}(\mathrm{t}$ ) compact intermediate heat exchanger as a function of LMTD for three combinations of helium

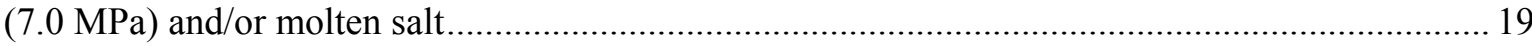

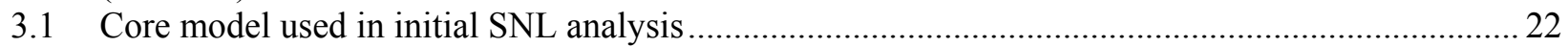

3.2 Variation of coolant void coefficient with fuel volume fraction ............................................... 24

3.3 Capture cross section for candidate salt constituents (and carbon) ............................................2.

3.4 Scattering cross section for candidate salt constituents (and carbon) ...........................................25

3.5 Sensitivity of void coefficient (whole core voiding) on erbium loading in BP rods (14 per assembly)

3.6 SNL model of the reference AHTR fuel/coolant geometry (left) and a revised annular

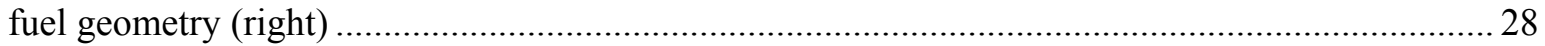

3.7 Variation of $\mathrm{k}_{\text {eff }}$ with fuel fraction for reference AHTR core model..........................................29

3.8 Sensitivity of void coefficient to fuel fraction (left) and uranium enrichment (right) ................... 29

3.9 Thermal power and average core temperature following a $\$ 0.4$ reactivity insertion ....................... 30

3.10 Fuel burnup predictions for $10 \%{ }^{235} \mathrm{U}$ enriched core .............................................................. 31

3.11 Fuel burnup predictions for $20 \%{ }^{235} \mathrm{U}$ enriched core ................................................................ 32

3.12 Comparison of ORNL (lines) and INEEL (points) calculations of hot channel temperatures for

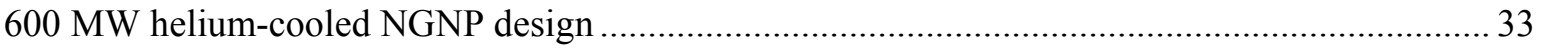

3.13 Pumping power as function of coolant channel size and core inlet temperature ........................... 33

3.14 Axial temperature profiles in hot channel of $600 \mathrm{MW}(\mathrm{t}) \mathrm{NGNP}$ and $2400 \mathrm{MW}(\mathrm{t})$ AHTR ............. 34

3.15 Radial temperature profiles from coolant channel centerline to fuel compact centerline

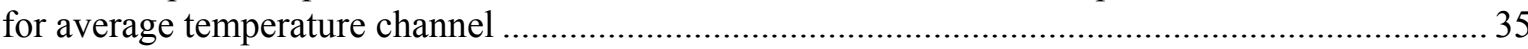

3.16 Comparison of RVACS heat removal capacity and heat load generated after an LOFC

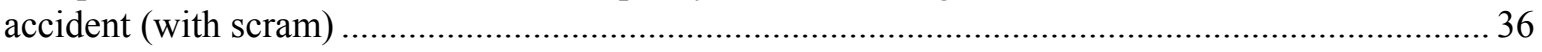

3.17 Maximum core temperature as a function of time after an LOFC accident (with scram) ............... 37

3.18 Maximum reactor vessel temperature as a function of time after an LOFC accident (with scram) .. 37 
3.19 Temperature (T) — entropy (S) diagram for the MCGC very high-temperature reference case........ 38

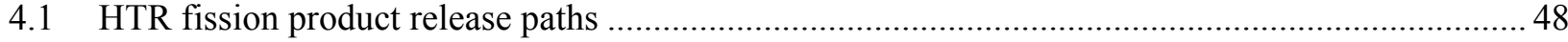

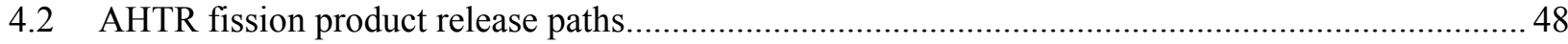

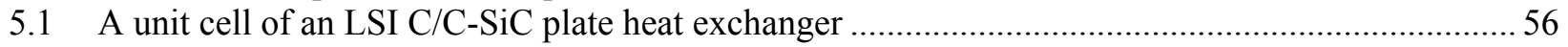

5.2 Photos of numerically controlled milling being performed on carbon-carbon green-body material

5.3 Pressed plate of short-fiber carbon-carbon composites showing the fabrication of flow channels using molds for application to fuel cells

5.4 Photo of chemical vapor infiltration-deposited carbon layer on a carbon-carbon composite plate.. 57

6.1 Normal and beyond-design-basis accident states for the AHTR 61 


\section{LIST OF TABLES}

Table

Page

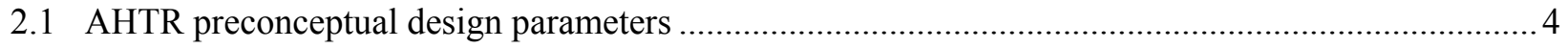

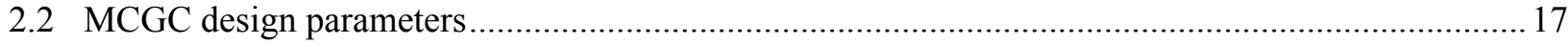

2.3 Comparison of $600 \mathrm{MW}(\mathrm{t})$ compact intermediate heat exchanger designs (the molten salt is $\left.0.42 \mathrm{LiF}-0.29 \mathrm{NaF}-0.29 \mathrm{ZrF}_{4}\right)$

3.1 Void coefficient of reactivity for different salt compositions (initial SNL model) ........................23

3.2 Specifications for ORNL AHTR fuel assembly model .........................................................26

3.3 High-temperature helium MCGC heat exchanger design parameters ............................................. 39

3.4 Very high-temperature helium MCGC preliminary turbomachinery design parameters ...................39

3.5 Very high-temperature nitrogen MCGC heat exchanger design parameters ....................................40

3.6 Very high-temperature nitrogen MCGC preliminary turbomachinery design parameters .................41

4.1 Thermophysical properties common reactor coolants ................................................................. 44

5.1 Coated F-M or stainless steels, or monolithic alloys potentially suitable for AHTR reactor

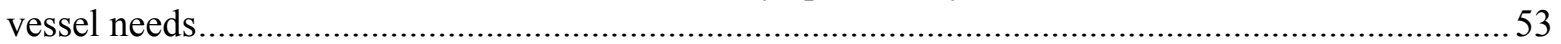

5.2 Coated high-temperature alloys or monolithic alloys potentially suited for AHTR needs................ 54

6.1 Thermodynamic equilibrium $\left(850^{\circ} \mathrm{C} ; 1 \mathrm{~atm}\right)$ between 200 moles of sulfuric acid $\left(\mathrm{H}_{2} \mathrm{SO}_{4}\right)$ and 100 moles of the molten salt: NaF-KF-ZrF 4 (10-48-42)....

8.1 Comparison of the estimated overnight capital cost (2002 \$) of the AHTR-IT and AHTR-VT, as a percentage of the costs of the S-PRISM and GT-MHR [with 1145 MW(e) output]..................69

8.2 Comparison of parameters for AHTR-VT, AHRT-IT, S-PRISM, and GT-MHR ........................... 70

8.3 Detailed results for AHTR comparative cost estimate................................................................... 71 


\section{ABBREVIATIONS AND ACRONYMS}

\begin{tabular}{|c|c|}
\hline $3-\mathrm{D}$ & three-dimensional \\
\hline AHTR & Advanced High-Temperature Reactor \\
\hline AHTR-IT & Advanced High-Temperature Reactor-intermediate temperature \\
\hline AHTR-VT & Advanced High-Temperature Reactor-very high temperature \\
\hline ALMR & advanced liquid-metal (-cooled) reactor \\
\hline ARE & Aircraft Reactor Experiment \\
\hline BP & burnable poisons \\
\hline $\mathrm{C} / \mathrm{C}$ & carbon-carbon (composite) \\
\hline $\mathrm{C} / \mathrm{U}$ & carbon-to-uranium ratio \\
\hline CANDU & Canadian Deuterium Uranium Reactor \\
\hline CVD & chemical vapor deposition \\
\hline CVI & chemical vapor infiltration \\
\hline DOE & U.S. Department of Energy \\
\hline DRACS & direct reactor auxiliary cooling system \\
\hline EBR-II & Experimental Breeder Reactor II \\
\hline EPRI & Electric Power Research Institute \\
\hline GA & General Atomic \\
\hline GE & General Electric \\
\hline GRSAC & Graphite Reactor Severe Accident Code \\
\hline GT-MHR & Gas-Turbine Modular High-Temperature Reactor \\
\hline $\mathrm{HP}$ & high pressure \\
\hline HTTR & High-Temperature Test Reactor \\
\hline HWR & heavy-water reactor \\
\hline $\mathrm{HX}$ & heat exchanger \\
\hline IAEA & International Atomic Energy Agency \\
\hline $\mathrm{IHX}$ & intermediate heat exchanger \\
\hline INEEL & Idaho National Energy and Engineering Laboratory \\
\hline LMTD & log-mean temperature difference \\
\hline LOFC & loss of forced cooling \\
\hline LP & low pressure \\
\hline LSI & liquid-silicon infiltrated \\
\hline LWR & light-water reactor \\
\hline MCGC & molten coolant gas cycle \\
\hline MCNP & Monte Carlo N-Particle \\
\hline MHTGR & modular high-temperature gas-cooled reactor \\
\hline MP & medium pressure \\
\hline MS & molten salt \\
\hline MSBR & Molten Salt Breeder Reactor \\
\hline MSR & Molten Salt Reactor \\
\hline MSRE & Molten Salt Reactor Experiment \\
\hline $\mathrm{NE}$ & Office of Nuclear Energy, Science and Technology \\
\hline NGNP & Next Generation Nuclear Plant \\
\hline ORNL & Oak Ridge National Laboratory \\
\hline PBMR & Pebble Bed Modular Reactor \\
\hline PCU & power conversion unit \\
\hline RCCS & reactor cavity cooling system \\
\hline RVACS & reactor vessel auxiliary cooling system \\
\hline
\end{tabular}


SNL Sandia National Laboratories

S-PRISM Super Power Reactor Inherently Safe Module

TBS thermal blanket system

UCB

University of California at Berkeley

UNLV

University of Nevada at Las Vegas

VHTR very high-temperature reactor 


\section{EXECUTIVE SUMMARY}

The Next Generation Nuclear Plant (NGNP) Project being conducted by the U.S. Department of Energy Office of Nuclear Energy, Science and Technology seeks to develop and demonstrate advanced nuclear reactor technology to produce electricity and hydrogen in a highly efficient, passively safe, and economical manner. The NGNP functional requirements will necessitate very-high-temperature operation $\left(1000^{\circ} \mathrm{C}\right)$ compared with conventional systems. The traditional choice of coolant for a very-hightemperature reactor has been helium, and several helium-cooled designs have been built or are being developed. However, an alternative option for future high-temperature reactors is to use a molten salt as the primary coolant; this offers several advantages over gas coolants, owing to the superior thermophysical properties of liquids, but also introduces a different set of technological and engineering challenges.

A new reactor plant concept has been proposed that uses clean, high-temperature, low-pressure molten salt as the primary coolant. The Advanced High-Temperature Reactor (AHTR) concept is a collaboration of Oak Ridge National Laboratory, Sandia National Laboratories, and the University of California at Berkeley. The purpose of the concept is to provide an advanced design capable of satisfying the top-level functional requirements of the NGNP, while also providing a technology base that is sufficiently robust to allow a growth path to higher power output and higher temperatures, and offering the potential for highly competitive economics. Although it creates some unique technology challenges of its own, the AHTR has many strong advantages over gas-cooled reactors and provides an alternative development path to some of the more challenging technology issues encountered by gas-cooled hightemperature plants. Primary advantages include lower reactor fuel temperatures, higher-temperature delivered heat, and better economics.

This report summarizes the status of the AHTR preconceptual design. It captures the results from an intense effort over a period of 3 months to (1) screen and examine potential feasibility concerns with the concept; (2) refine the conceptual design of major systems; and (3) identify research, development, and technology requirements to fully mature the AHTR design. All of the goals of the study were accomplished.

The AHTR plant represents a unique merging of design features from several other reactor systems. At the heart of the plant is the reactor core, which is strikingly similar to graphite-moderated, heliumcooled reactor systems such as Fort St. Vrain and the Gas-Turbine Modular High-Temperature Reactor (GT-MHR). It uses the same coated particle fuel, cylindrical fuel compacts, and hexagonal graphite fuel assemblies as these reactors. A large number of fuel assemblies $(>3000)$ are stacked and formed with similar nonfueled graphite blocks into a large annular core with internal and external reflectors. However, because the molten salt coolant operates at low pressure, the vessel enclosure system and facility design is more similar to designs developed for atmospheric-pressure, pool-type, sodium-cooled reactors, especially the Super Power Reactor Inherently Safe Module (S-PRISM) developed by General Electric (GE). In the AHTR, the relatively thin reactor vessel is protected from the high-temperature coolant pool by a thermal blanket.

The molten salt coolant and related systems draw heavily on extensive experience gained from the earlier Molten Salt Reactor (MSR) program and associated test programs. While the primary system of the MSR used molten salt with fuel material dissolved directly in the circulating salt, the AHTR uses "clean" molten salt in combination with solid, stationary fuel. However, much of the MSR-related experience is directly relevant to the AHTR. Currently, the reference salt for AHTR is $\mathrm{Li}_{2} \mathrm{BeF}_{4}$, sometimes referred to as "Flibe." This selection is based on its thermophysical properties and its better performance in core transients. However, other promising salts are still being considered. The ultimate salt selection will be a balancing of several issues, including neutronics, toxicity, activation, compatibility, cost, etc. 
To meet the passive safety requirements of the NGNP, the AHTR uses a reactor vessel auxiliary cooling system (RVACS) similar to that of S-PRISM. It may also use a direct reactor auxiliary cooling system (DRACS) similar to what was used in the Experimental Breeder Reactor II to supplement the RVACS and reduce the reactor vessel temperature.

The primary molten salt coolant circulates through the core and is pumped to an external heat exchanger. An intermediate heat transport loop of molten salt is used either to provide heat to a thermochemical hydrogen production plant or to secondary heat exchangers that drive a closed, multireheat gas Brayton cycle generator to produce electricity. The current study suggests that the combination of these advanced features yields a plant design that is capable of generating in excess of $1300 \mathrm{MW}$ of electrical power compared with the 150-300 MW(e) produced by typical gas-cooled reactor designs.

Several analyses were performed to quantify the AHTR performance expectations and to assist in the selection of several design parameters. In particular, core physics, thermal hydraulics, decay heat removal, and power conversion analyses were performed. In the core physics analysis, the AHTR was found to share the same large negative temperature feedback as the GT-MHR (approximately $-\$ 0.01 /{ }^{\circ} \mathrm{C}$ ). However, whereas the helium coolant of the GT-MHR has a negligible coolant void coefficient of reactivity, it is possible for the AHTR to have an undesirable positive void coefficient for some salt compositions and core designs. Several analyses were performed to understand this effect. In the current core configuration, it appears that achieving a zero or negative void coefficient is possible if high-purity ${ }^{7} \mathrm{Li}$ is used (>99.99\%) in the Flibe salt and if burnable poisons are present in the core. Positive void coefficients are a characteristic of most sodium and lead-cooled fast reactors; however, experience with existing thermal-neutron reactors suggests that advanced core designs can avoid this problem. Other core performance characteristics such as fuel burnup and fuel cycle length were found to be similar to those of the GT-MHR, as was expected due to the strong similarity in fuel and assembly design.

Simplified thermal-hydraulic analyses, which were benchmarked against GT-MHR data, indicated that for a fixed core outlet temperature of $1000^{\circ} \mathrm{C}$ for the coolant, the peak fuel temperature in the AHTR during normal operation will be $110-130^{\circ} \mathrm{C}$ cooler than for the prismatic helium-cooled NGNP design, and the average fuel temperature at the core outlet will be $30-50^{\circ} \mathrm{C}$ cooler. This is a direct result of the superior heat transfer properties of the molten salt relative to helium. This is significant because the failure rate of the coated particle fuel increases with increasing temperature.

Earlier, a scaling analysis for the passive decay heat cooling system suggested that the AHTR could operate at a thermal power of $2400 \mathrm{MW}(\mathrm{t})$. A more sophisticated analysis was performed that indicates that $2400 \mathrm{MW}(\mathrm{t})$ can indeed be achieved with reasonable RVACS capacity. The analysis showed that for a loss-of-forced-cooling accident (with scram), significant natural convection of the molten salt is established and the core temperature peaks at only $1160^{\circ} \mathrm{C}$, which occurs about 30 hours after the accident. The reactor vessel temperature peaks at $\sim 750^{\circ} \mathrm{C}$ after about 40 hours. This analysis, which did not include a DRACS, indicates that a $2400 \mathrm{MW}(\mathrm{t})$ AHTR can easily survive this type of transient.

Analysis of the power conversion system to produce electricity showed that the three-stage multireheat Brayton cycle with a turbine inlet temperature of $900^{\circ} \mathrm{C}$ can yield a conversion efficiency of $54 \%$. Two options were considered - a pure helium cycle and a nitrogen-helium cycle ( $10 \%$ helium). The latter case was found to result in a power conversion system that is physically $40 \%$ larger than the helium-only case, although both cases are smaller than an equivalent steam cycle system because they avoid subatmospheric turbines and steam separators.

There is considerable experience with molten salts from previous reactor programs. A repository exists of more than 1000 reports that were generated to support the MSR program in the 1960s and early 1970s. An extensive testing program was implemented; and the Molten Salt Reactor Experiment (MSRE), an 8 -MW(t) molten salt (fueled) reactor, ran for $>9000$ full power hours during a 3-year period. The test data demonstrate conclusively that the molten salt is fully compatible with graphite and carbon-based materials and that its interactions with metal alloys are manageable with proper salt chemistry and alloy 
compositions. Also, a detailed conceptual design was developed for a 1000-MW(e) MSR plant. An important engineering challenge will be to prevent salt freezing during normal and off-normal operations due to the high melting temperature of the salt $\left(459^{\circ} \mathrm{C}\right.$ for Flibe). This will be similar, but more extreme than the case for sodium-cooled and lead/bismuth-cooled reactors. Of special concern are refueling and maintenance operations, which will require material inspection and handling at $\sim 500^{\circ} \mathrm{C}$. Salts were identified with lower melting temperatures $\left(320-380^{\circ} \mathrm{C}\right)$, but they had less desirable neutronics performance.

A technology challenge that AHTR shares with other high-temperature designs is the availability of nuclear qualified materials for operation at near $1000^{\circ} \mathrm{C}$ temperatures. The reactor internals will need to be made of carbon-carbon composites, and the vessels and metallic components will need to be superalloys or other advanced materials. The heat exchangers will be a significant challenge, especially for cases where low-pressure molten salt is on one side and high-pressure gas is on the other. Large pressure differentials occur in the power conversion heat exchangers of the AHTR and will also occur for hydrogen production in gas-cooled reactors, since the maximum pressure of the hydrogen process fluids $(<1 \mathrm{MPa})$ will be substantially lower than the primary helium pressure $(7 \mathrm{MPa})$.

The AHTR appears to have excellent safety attributes. The combined thermal capacity of the graphite core and the molten salt coolant pool offer a large time buffer to reactor transients. The effective transfer of heat to the reactor vessel increases the effectiveness of the RVACS and DRACS to remove decay heat, and the excellent fission product retention characteristic of molten salt provides an extra barrier to radioactive releases. The low-pressure, chemically nonreactive coolant also greatly reduces the potential for overpressurization of the reactor containment building and provides an important additional barrier for fission product release. The most important design and safety issue with the AHTR may be the performance and reliability of the thermal blanket system, which must maintain the vessel within an acceptable temperature range.

A comparative cost analysis was performed for the AHTR by scaling individual subsystem costs for either the GT-MHR or the S-PRISM. The result is that the AHTR overnight capital cost (without contingency) is estimated to be approximately $820 \$ / \mathrm{kW}(\mathrm{e})$ (2002 dollars), which is $50-55 \%$ of the SPRISM and GT-MHR costs for similar total output. This is a consequence of economy of scale. The AHTR electrical output is approximately four times that of these other reactors but with a similar plant size and complexity. Relative to light-water reactors, the AHTR should be more economical because of the higher power conversion efficiency, low-pressure containment, and absence of active safety systems.

In conclusion, there appear to be key performance benefits for the AHTR and no fundamental physics issues that would challenge the viability of an AHTR plant. There are several technology and engineering challenges, however. Because the AHTR shares many features with other reactor designs, it will benefit from technology and engineering solutions developed for these systems. Of the needs specific to the AHTR, first and foremost is the development and qualification of materials that can withstand $>1000^{\circ} \mathrm{C}$ temperatures for extended operation (up to 60 years). Research on and demonstration of molten salt chemistry control and cleanup will also be needed, as well as compatibility with metals at high temperatures. The major AHTR engineering challenges are (1) achieving a core design that maintains a negative or negligible coolant void coefficient, (2) designing a thermal blanket system that reliably protects the reactor vessel from exposure to very-high-temperature salt, and (3) engineering a process and equipment for economical refueling and maintenance operations. Finally, considerable design analysis and engineering, with industrial participation, will be needed to fully mature the AHTR design. 


\begin{abstract}
A new reactor plant concept is presented that combines the benefits of ceramic-coated, hightemperature particle fuel with those of clean, high-temperature, low-pressure molten salt coolant. The Advanced High-Temperature Reactor (AHTR) concept is a collaboration of Oak Ridge National Laboratory, Sandia National Laboratories, and the University of California at Berkeley. The purpose of the concept is to provide an advanced design capable of satisfying the top-level functional requirements of the U.S. Department of Energy Next Generation Nuclear Plant (NGNP), while also providing a technology base that is sufficiently robust to allow future development paths to higher temperatures and larger outputs with highly competitive economics. This report summarizes the status of the AHTR preconceptual design. It captures the results from an intense effort over a period of 3 months to (1) screen and examine potential feasibility concerns with the concept; (2) refine the conceptual design of major systems; and (3) identify research, development, and technology requirements to fully mature the AHTR design. Several analyses were performed and are presented to quantify the AHTR performance expectations and to assist in the selection of several design parameters.

The AHTR, like other NGNP reactor concepts, uses coated particle fuel in a graphite matrix. But unlike the other NGNP concepts, the AHTR uses molten salt rather than helium as the primary system coolant. The considerable previous experience with molten salts in nuclear environments is discussed, and the status of high-temperature materials is reviewed. The large thermal inertia of the system, the excellent heat transfer and fission product retention characteristics of molten salt, and the low-pressure operation of the primary system provide significant safety attributes for the AHTR. Compared with helium coolant, a molten salt cooled reactor will have significantly lower fuel temperatures $\left(150-200^{\circ} \mathrm{C}\right.$ lower $)$ for the equivalent temperature of heat delivered to either the power conversion system or a hydrogen production plant. Using a comparative cost analysis, the construction costs per unit output are projected to be 50$55 \%$ of the costs for modular gas-cooled or sodium-cooled reactor systems. This is primarily a consequence of substantially larger power output and higher conversion efficiency for the AHTR. The AHTR has a number of unique technical challenges in meeting the NGNP requirements; however, it appears to offer advantages over high-temperature helium-cooled reactors and provides an alternative development path to achieve the NGNP requirements. Primary challenges include optimizing the core design for improved response to transients, designing an internal blanket to thermally protect the reactor vessel, and engineering solutions to high-temperature refueling and maintenance.
\end{abstract}




\section{INTRODUCTION}

\subsection{BACKGROUND}

The production of hydrogen $\left(\mathrm{H}_{2}\right)$ by thermochemical processes and the highly efficient production of electricity require significant amounts of energy delivered at very high temperatures. Hydrogen production may require that heat be provided to chemical reagents at temperatures near $850^{\circ} \mathrm{C}$. Similar temperatures can produce electricity at efficiencies exceeding $50 \%$, substantially greater than current nuclear plants. In order to provide these temperatures, the reactor coolant exit temperature must exceed $850^{\circ} \mathrm{C}$ sufficiently to account for temperature drops in the intermediate heat transfer loop from the reactor to the turbines or the $\mathrm{H}_{2}$ production plant. For this reason, work is under way to develop reactors with coolant exit temperatures of $1000^{\circ} \mathrm{C}$. Specifically, the Next Generation Nuclear Power (NGNP) plant project, which is being directed by the U.S. Department of Energy (DOE) Office of Nuclear Energy, Science and Technology (NE), specifies a reactor core outlet temperature of $1000^{\circ} \mathrm{C}$ as a top level functional requirement. ${ }^{1}$ This project seeks to build a demonstration plant consisting of an advanced nuclear reactor coupled to an engineering-scale [nominally $50 \mathrm{MW}(\mathrm{t})$ ] hydrogen production facility and a commercial-scale [ 600-MW(t)] Brayton power conversion system for electricity production.

Historically, helium has been proposed as the coolant of choice for very high-temperature reactors. An alternative option is to use a molten fluoride salt as the coolant with the same fuel type that has been developed and demonstrated in gas-cooled reactors. The superior heat capacity and transport characteristics of liquids compared with gases enable delivery of high-temperature heat at a near uniform temperature with lower reactor fuel and component temperatures. This report describes the status of the preconceptual design of a reactor cooled by molten salt. The new concept, designated the Advanced High-Temperature Reactor (AHTR), uses a combination of existing technologies: (1) high-temperature, low-pressure molten-fluoride-salt reactor coolants, (2) coated-particle graphite-matrix fuel developed for high-temperature gas-cooled reactors, (3) passive safety systems developed for proposed modular gascooled and liquid-metal-cooled reactors, and (4) a high-efficiency closed Brayton power cycle for electricity production.

\subsection{OBJECTIVES OF THE CONCEPT}

The primary objective to developing the AHTR is to provide an alternative to gas-cooled reactors for high-temperature applications, especially for efficient production of electricity and thermochemical production of hydrogen. In addition to the high production efficiencies of electrical power and hydrogen afforded by the high-coolant temperature, the improved ability of the liquid coolant to hold and transport heat at low pressures results in several significant advantages over gas-cooled systems - higher power output for a similar-sized reactor vessel and containment, reduced reactor vessel thickness, cooler peak fuel temperatures for normal operation and transients, better retention of fission products released from failed fuel particles, and reduced plant footprint. All these factors translate ultimately to significantly improved economics, and some factors can lead to potential safety advantages.

The reference AHTR concept uses a core outlet temperature of $1000^{\circ} \mathrm{C}$ for the molten salt in order to respond to the functional requirement specified for the NGNP. This will sometimes be referred to as the AHTR-VT (very high temperature) concept. However, references are also made in this report to the AHTR-IT (intermediate temperature), which has a core outlet temperature of $800^{\circ} \mathrm{C}$. The AHTR-IT concept provides a nearer-term option, because the reduced outlet temperature substantially reduces deployment risk due to material qualification issues. While the AHTR-IT provides the same large thermal power [nominally $2400 \mathrm{MW}(\mathrm{t})$ ] as the AHTR-VT, the lower conversion efficiency reduces somewhat the sizable economic advantage anticipated for the AHTR-VT. Details of the various trade-offs are given in 
later sections of this report. Unless specifically qualified as -VT or -IT, references to AHTR in this report refer to the very high-temperature version $\left(1000^{\circ} \mathrm{C}\right.$ outlet $)$.

\subsection{APPROACH TO PRECONCEPTUAL DESIGN}

The three other high-temperature reactor designs that have been proposed for the NGNP demonstration plant are (1) a prismatic gas-cooled reactor with a direct Brayton cycle, which is an evolutionary version of the Gas-Turbine Modular High-Temperature Reactor (GT-MHR) developed by General Atomics (GA); (2) a prismatic gas-cooled reactor with an indirect Brayton cycle; and (3) a pebble bed gas-cooled reactor, which is an extension of the Pebble Bed Modular Reactor (PBMR) under development in South Africa. These designs have benefited from many hundred man-years of design and engineering effort. In contrast, the AHTR has been studied for only the past 3 years using primarily internal funds from the three participating organizations: Oak Ridge National Laboratory (ORNL), Sandia National Laboratories (SNL), and the University of California at Berkeley (UCB).

In order to mature the design quickly, the current conceptual design has drawn extensively from other relevant reactor designs or classes of designs. Specifically, the AHTR is based on technologies from four previously built or substantially engineered reactor designs.

1. High-temperature, low-pressure molten-fluoride-salt reactor coolants from the aircraft nuclear propulsion program ${ }^{2}$ of the $1950 \mathrm{~s}$ and the molten-salt breeder reactor (MSBR) program of the 1960s and 1970s. ${ }^{3}$ Today, development continues on these salts and associated advanced high-temperature materials for cooling fusion reactors.

2. Coated-particle graphite-matrix fuel developed for high-temperature gas-cooled reactors (HTGR) ${ }^{4}$ in the United States and Germany starting in the 1960s. These fuels have demonstrated low failure rates for temperatures up to about $1600^{\circ} \mathrm{C}$ and moderate burnup.

3. Passive safety systems similar to gas-cooled and liquid-metal-cooled reactors engineered in the 1980s and 1990s, especially the Super Power Reactor Inherently Safe Module (S-PRISM) design developed by General Electric (GE) ${ }^{5}$

4. Advanced gas turbines, including commercialization in the past 5 years of magnetic bearing systems that can permit these turbines to be used in closed helium and nitrogen cycles.

5. Graphite technology and component designs developed for the HTGR and Molten Salt Reactor (MSR) designs.

A recent focused effort, funded by DOE/NE, has permitted detailed analyses of several AHTR design features. However, frequent use continues to be made of design approaches, existing testing or operational experience, and anecdotal information from other reactor and nonreactor systems in order to qualitatively bound the expected performance of the AHTR in cases where detailed analyses have not been performed yet. 


\section{PLANT DESIGN}

The AHTR currently is defined at a preconceptual level of detail. Reference designs for the major components have been established; however, many design trade-offs have been identified and several plant features have not been addressed yet, especially for balance-of-plant systems. These design tradeoffs and gaps will be discussed in the following subsections and sections. Although a complete "point design" has not been completed, significant initial analyses have been performed to establish a plausible set of design parameters. Figure 2.1 shows the general plant layout with the reactor containment building in the center, the turbine building on the left, and the spent fuel storage building on the right. A functional diagram of the AHTR and power conversion system is given in Fig. 2.2. Table 2.1 provides a list of key design parameters associated with the current reference AHTR plant design (very high-temperature variant).

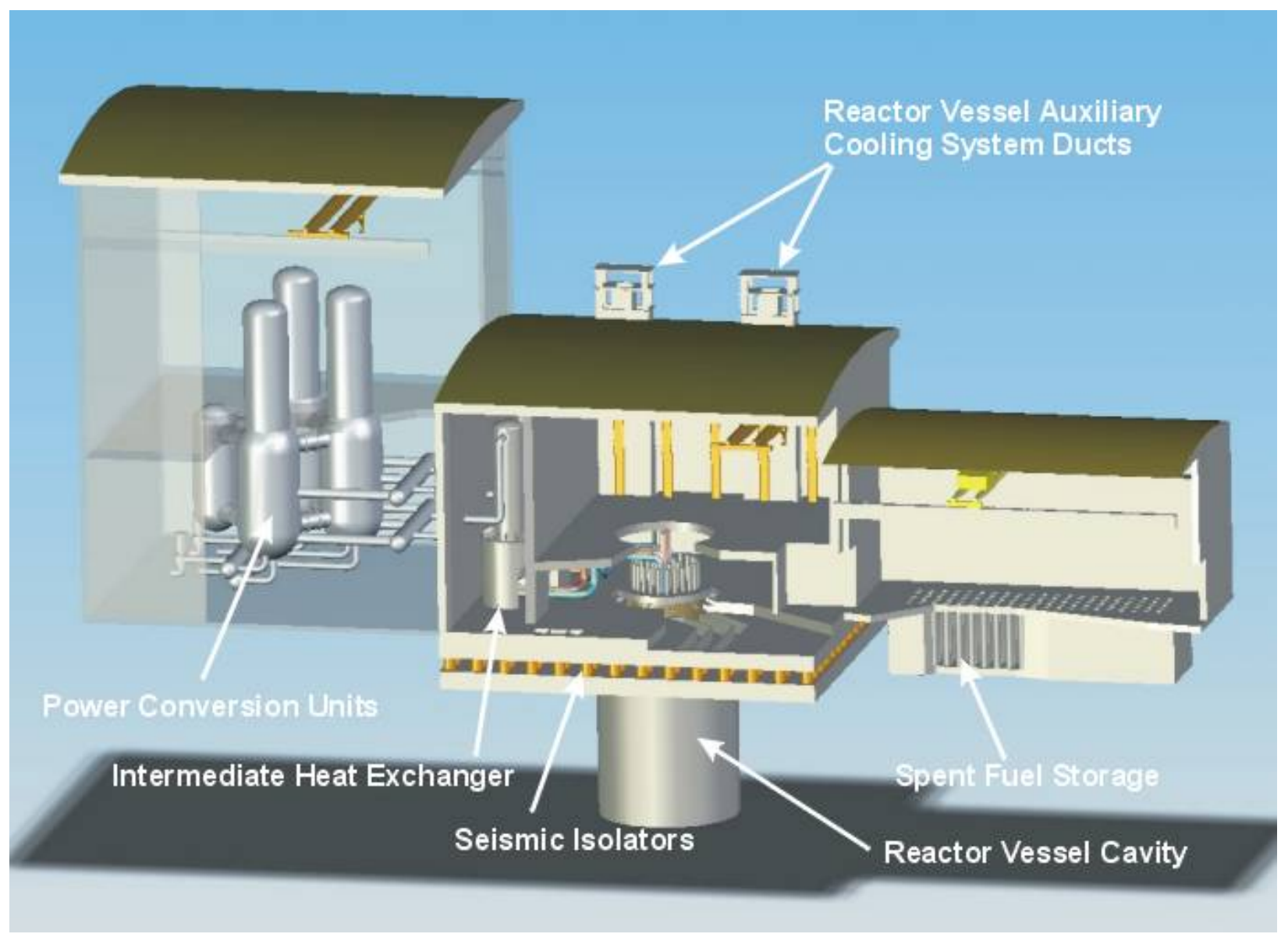

Fig. 2.1. Conceptual layout of AHTR plant. 


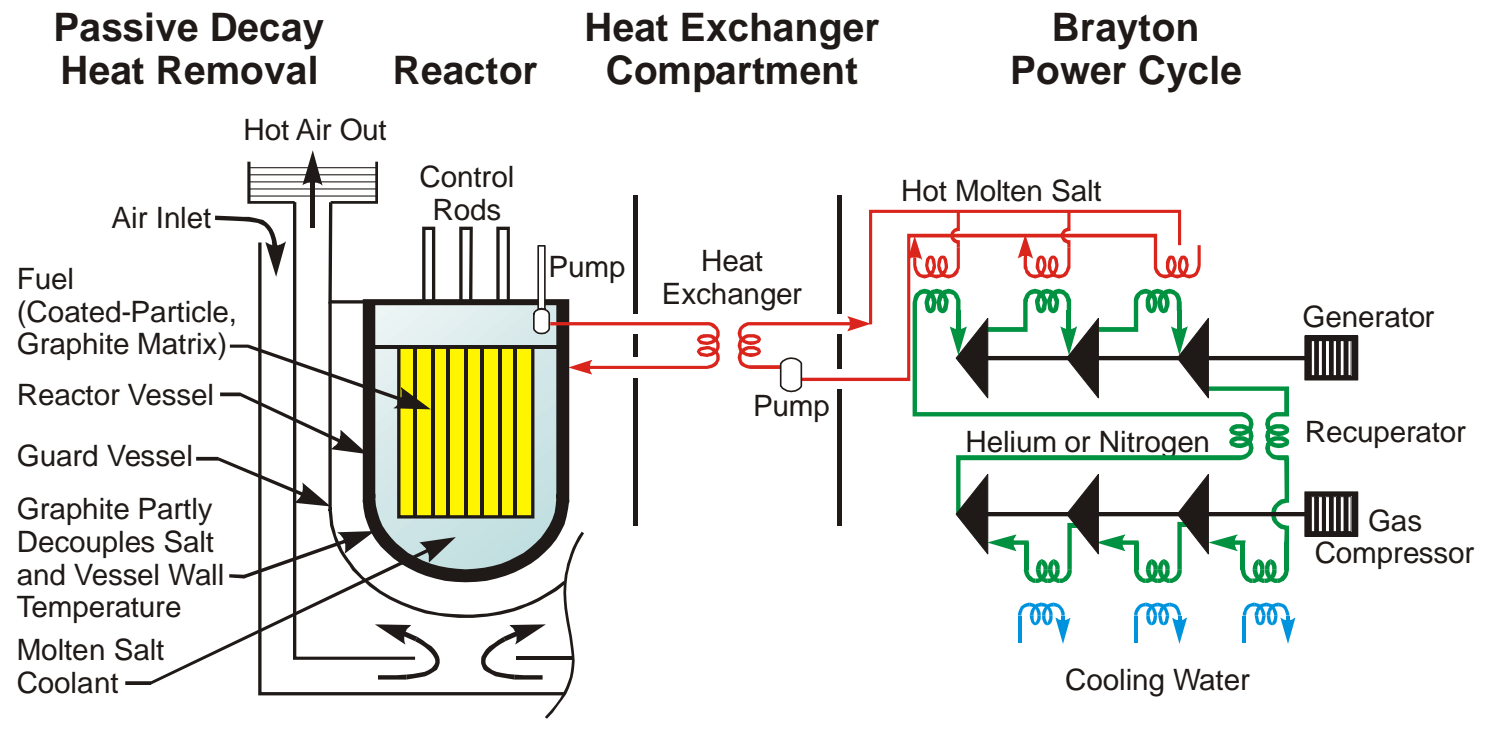

Fig. 2.2. Functional layout of AHTR for electricity production.

Table 2.1. AHTR preconceptual design parameters

\begin{tabular}{|c|c|c|c|}
\hline Power level & $2400 \mathrm{MW}(\mathrm{t})$ & Electrical output & $1300 \mathrm{MW}(\mathrm{e})$ \\
\hline Core inlet/outlet temperature & $900^{\circ} \mathrm{C} / 1000^{\circ} \mathrm{C}$ & Power cycle & $\begin{array}{l}\text { 3-stage multi-reheat } \\
\text { Brayton }\end{array}$ \\
\hline $\begin{array}{l}\text { Coolant } \\
\text { (alternate) }\end{array}$ & $\begin{array}{l}\mathrm{Li}_{2} \mathrm{BeF}_{4} \\
\left(\mathrm{NaF}-\mathrm{ZrF}_{4}\right)\end{array}$ & Power cycle working fluid & $\begin{array}{l}\text { Nitrogen (helium longer- } \\
\text { term option) }\end{array}$ \\
\hline Mass flow rate & $\begin{array}{l}12,070 \mathrm{~kg} / \mathrm{s} \\
(20 \% \text { core bypass })\end{array}$ & $\begin{array}{l}\text { Core inlet pressure } \\
\text { outlet pressure }\end{array}$ & $\begin{array}{l}0.230 \mathrm{MPa} \\
0.101 \mathrm{MPa}\end{array}$ \\
\hline Volumetric flow rate & $5.54 \mathrm{~m}^{3} / \mathrm{s}$ & Pressure drop & $0.129 \mathrm{MPa}$ \\
\hline Channel diameter & $0.95 \mathrm{~cm}$ & Core shape & Annular \\
\hline Fraction (core) & $6.56 \%$ & Core outer diameter & $7.8 \mathrm{~m}$ \\
\hline Velocity & $2.32 \mathrm{~m} / \mathrm{s}(7.6 \mathrm{ft} / \mathrm{s})$ & Core annulus & $2.3 \mathrm{~m}$ \\
\hline Fuel kernel & $\begin{array}{l}\text { Uranium } \\
\text { carbide/oxide }\end{array}$ & Core height & $7.9 \mathrm{~m}$ \\
\hline Enrichment & $10.36 \mathrm{wt} \%{ }^{235} \mathrm{U}$ & Pumping power & $716 \mathrm{~kW}$ \\
\hline Form & Prismatic & Power density & $8.3 \mathrm{~W} / \mathrm{cc}$ \\
\hline Block. diameter & $0.36 \mathrm{~m}$ (across flats) & Reflector (outer) & 138 columns \\
\hline Block height & $0.79 \mathrm{~m}$ & Reflector (inner) & 55 columns \\
\hline Columns & 324 & Vessel diameter & $9.2 \mathrm{~m}$ \\
\hline Mean temperature & $1050^{\circ} \mathrm{C}$ & Vessel height & $19.5 \mathrm{~m}$ \\
\hline Peak temperature & $1168^{\circ} \mathrm{C}$ & Vessel thickness & $10.0 \mathrm{~cm}$ \\
\hline
\end{tabular}




\subsection{FUEL CHARACTERISTICS}

The AHTR uses the same coated-particle, graphite-matrix fuel as used in all helium-cooled reactors, including the GT-MHR. ${ }^{4}$ Uranium oxycarbide fuel kernels $\left(10.4 \%{ }^{235} \mathrm{U}\right.$ in uranium) with a diameter of approximately $0.35 \mathrm{~mm}$ are coated with multiple layers of pyrolytic carbon and silicon carbide to form an 0.8-mm-diam microsphere that prevents release of radionuclides at very high temperatures. This microfuel is frequently referred to as "TRISO" fuel, whereas the consolidated form (rod or sphere) is known as a graphite-matrix fuel element. Currently available coated-particle fuels can operate for long periods at temperatures up to $1250^{\circ} \mathrm{C}$. Under off-normal conditions, fuel temperatures of $1600^{\circ} \mathrm{C}$ can be tolerated for limited periods of time ( $\sim 100$ s of hours) before fission product releases become significant.

The coated particles are incorporated into a graphite-matrix fuel compact, which, in turn, is loaded into a graphite-matrix fuel assembly. Several shapes of fuel assemblies have been used in various heliumcooled reactors: hexagonal blocks (Fort St. Vrain reactor), small spherical balls (Arbeitsgemeinschaft Versuchsreaktor-AVR), and long cylinders (Peach Bottom reactor). The different designs reflect different operational goals. Pebble bed systems allow on-line refueling by the slow movement of balls through the reactor core, while hexagonal blocks allow wide latitude in the volumetric ratio of fuel, coolant, and moderator. Figure 2.3 shows the TRISO fuel kernel and a typical fuel compact and prismatic graphite block, which is the fuel assembly shape utilized in the AHTR.

While the use of a coated-particle graphite-matrix fuel is required to obtain the desired temperatures and for compatibility with molten salt, the optimal geometry of the fuel assembly will depend upon detailed design trade-offs between performance, fuel costs, safety, and other factors. These trade-offs will be discussed in later sections of this report.

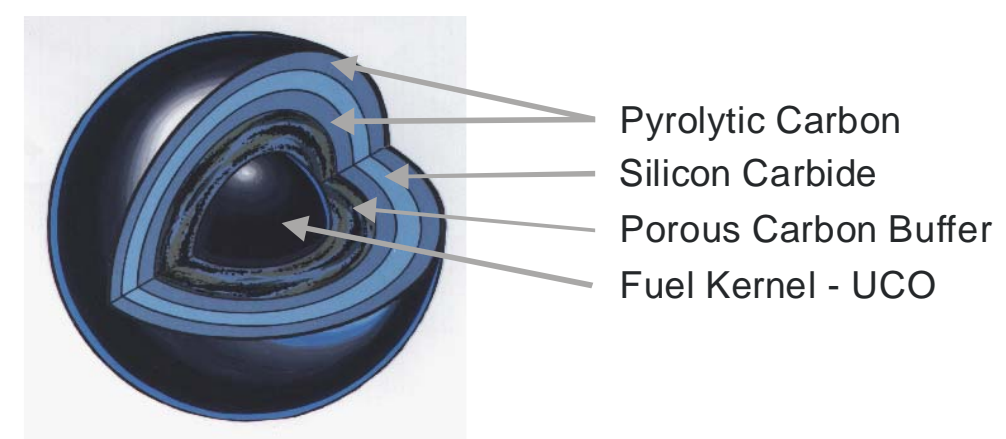

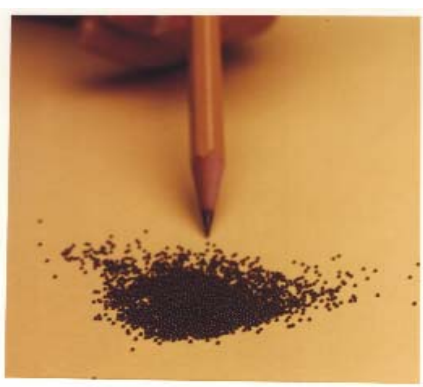

PARTICLES

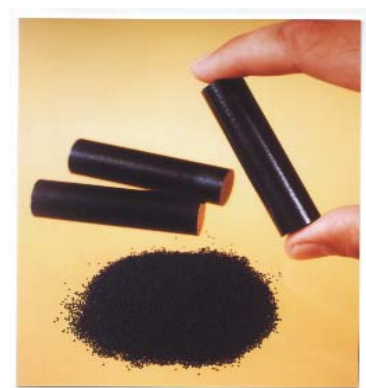

COMPACTS

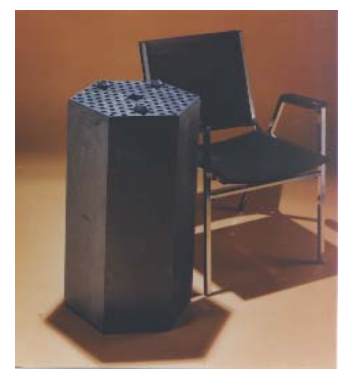

FUEL ELEMENTS

Fig. 2.3. Diagram and photographs of high-temperature, TRISO-coated particle fuel. 


\subsection{REACTOR CORE AND INTERNALS}

The hexagonal block (prismatic) fuel assembly option, rather than the pebble-bed form, was selected for the AHTR in order to provide more control of the fuel and coolant volume fractions and geometry. Figure 2.4 shows a schematic of a single graphite fuel block. The block is $36.0-\mathrm{cm}$ across flats and 79.5-cm tall. It contains 108 0.95-cm-diam coolant channels and $2161.27-\mathrm{cm}$-diam fuel channels. This design yields a coolant volume fraction of $6.9 \%$ and a fuel volume fraction of $24.4 \%$.

A total of 324 columns of fuel blocks are assembled into an annular geometry with nonfueled graphite reflector blocks filling the interior portion of the annulus and the region between the outer diameter of the core and the reactor vessel. Figure 2.5 provides a plan view of the core and reflector geometry. The core, inner reflector, and outer reflector blocks are stacked 10 blocks high with an additional layer of nonfueled graphite blocks at the top and bottom of the assembly to form axial reflectors. An elevation view schematic of the reactor core, internals, and vessels is given in Fig. 2.6. A simplified three-dimensional (3-D) model of the reactor vessel and internals is given in Fig. 2.7.

The GT-MHR uses a similar annular core design with 102 fuel block columns to generate a thermal power of $600 \mathrm{MW}$ (see Fig. 2.5). To achieve a four-fold increase in power [2400 MW(t)] for the AHTR, either the power density or the size of the core, or both, needed to be increased. With a vessel diameter of $9.2 \mathrm{~m}$, it was possible to fit a 408-column core into the vessel, but this yielded a very thin outer reflector. A compromise core configuration was selected that uses 324 fuel block columns and a power density of $8.3 \mathrm{MW} / \mathrm{cm}^{3}$, which is $26 \%$ higher than the GT-MHR.

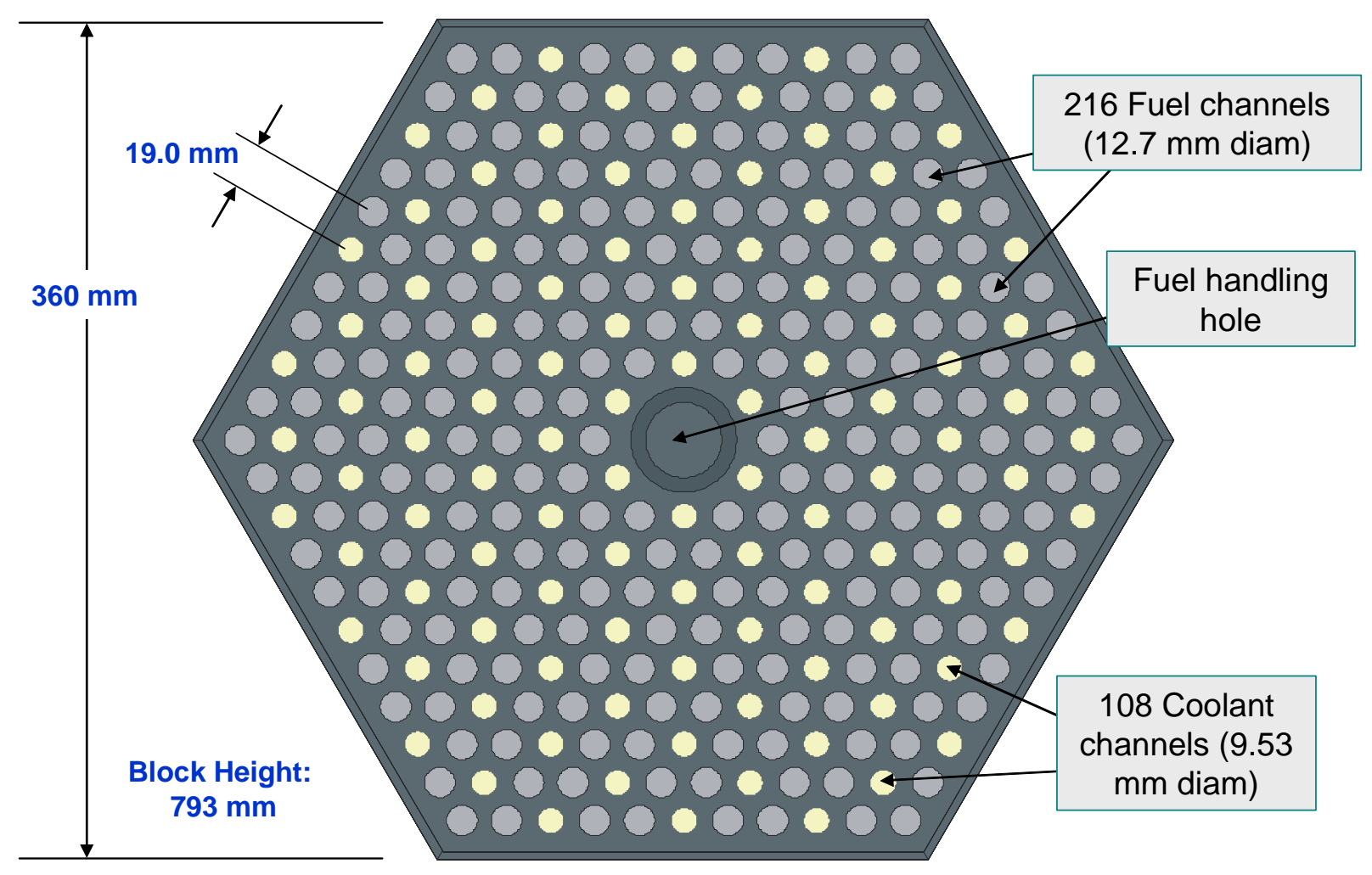

Fig. 2.4. Schematic of single hexagonal fuel assembly. 


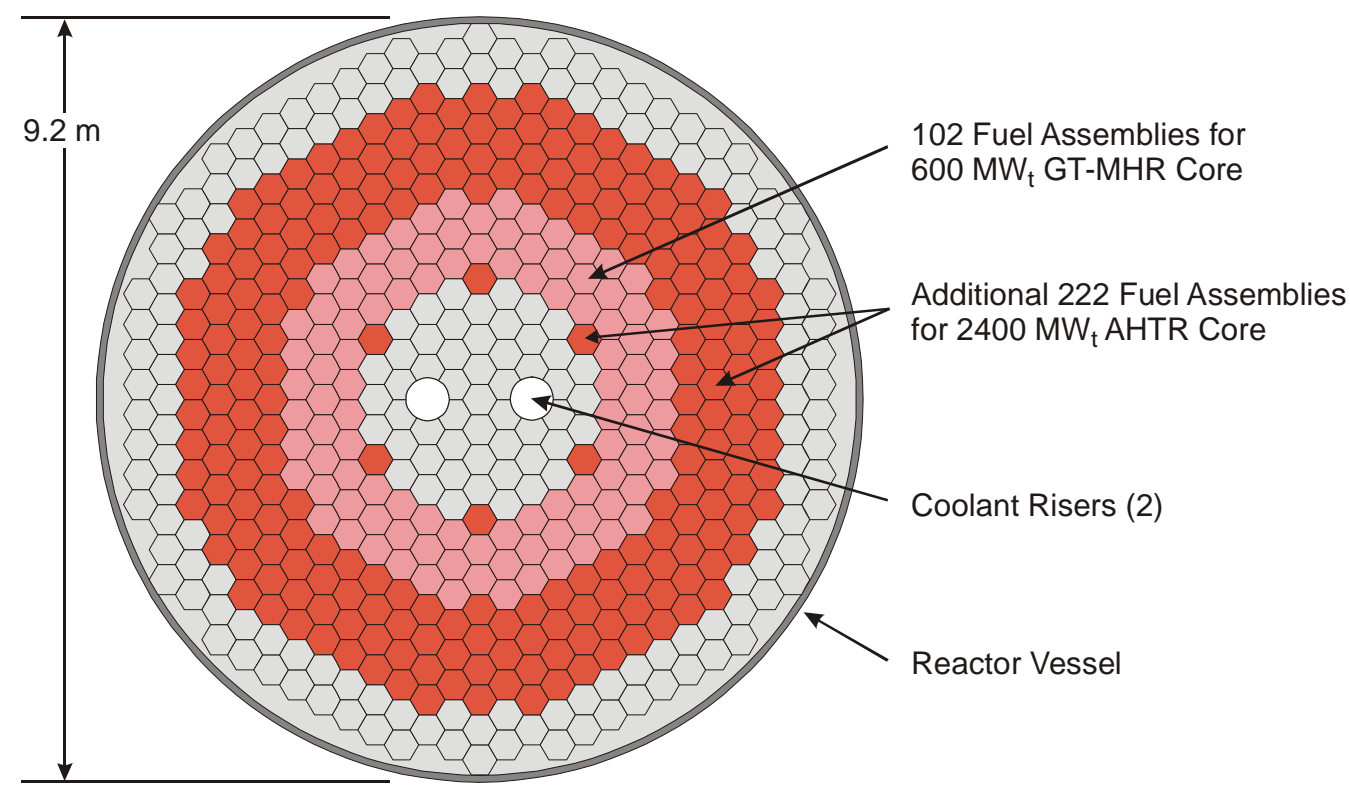

Fig. 2.5. Plan view of AHTR core showing 324 columns of fuel assemblies.

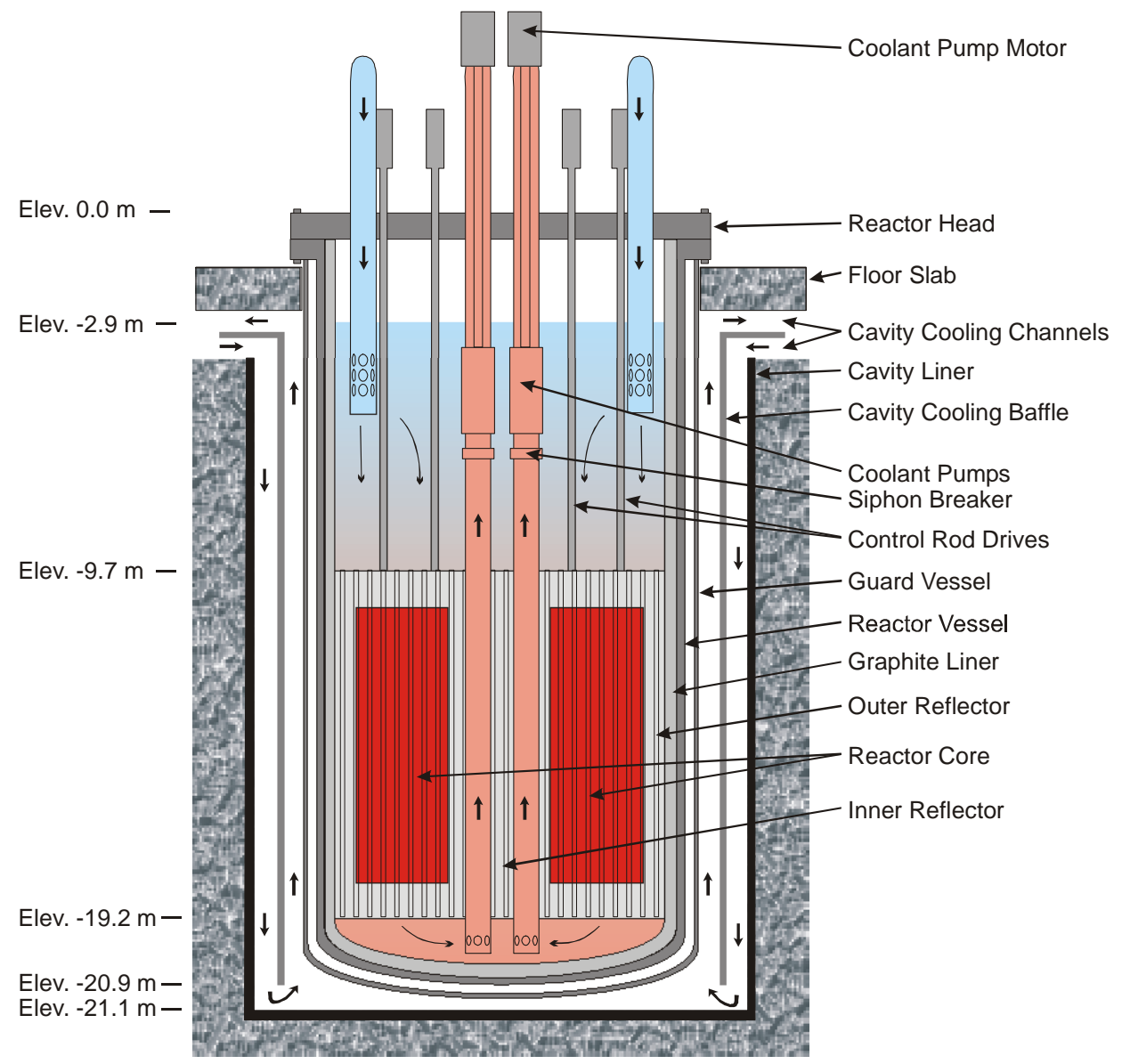

Fig. 2.6. Elevation view of AHTR core, vessels, and internals. 
Molten salt coolant flows down through the reactor core and up through a pair of central return pipes with siphon breaks and centrifugal pumps. The details of the primary coolant pumps and siphon breaks have not been decided yet, but the design will build on experience gained from the earlier molten salt reactor experiments. The siphon breaks will introduce a small amount of bypass coolant flow, but there is sufficient margin to accommodate the slight loss of efficiency. The coolant is pumped to one of two intermediate heat exchangers located external to the reactor vessel but within the containment building, and then returned to the reactor vessel. The downflow core provides operational and safety advantages: the coolant temperature is lowest near the vessel head, the cooler temperature of the large pool above the reactor core provides additional thermal inertia during accident situations, and the coolant flow near the vessel wall does not change if loss of forced cooling occurs.

The design of the reactor internals has not been addressed yet, but they likely will be made of graphite or carbon composites to accommodate the high-core outlet temperature required by the NGNP $\left(1000^{\circ} \mathrm{C}\right)$. It is possible that carboninsulated metallic alloy will be used for the core support structure, although this has not been evaluated yet. Control rods will be required to provide for reactor startup, normal operation, and shutdown. The number and placement of control rods has not been evaluated yet, but the rods will be constructed from carbon composites for the drive shafts and absorber casing and boron carbide or other high-temperature absorber for the neutron absorber. The control rod drive mechanisms will be located above the reactor enclosure head. While the GT-MHR relies on control rods located in the inner and outer reflectors for reactivity compensation during normal operation, it is likely that control rods will be needed within the AHTR-fueled core because of its larger size. Control rod designs developed for the MSBR should be applicable for use in the AHTR.

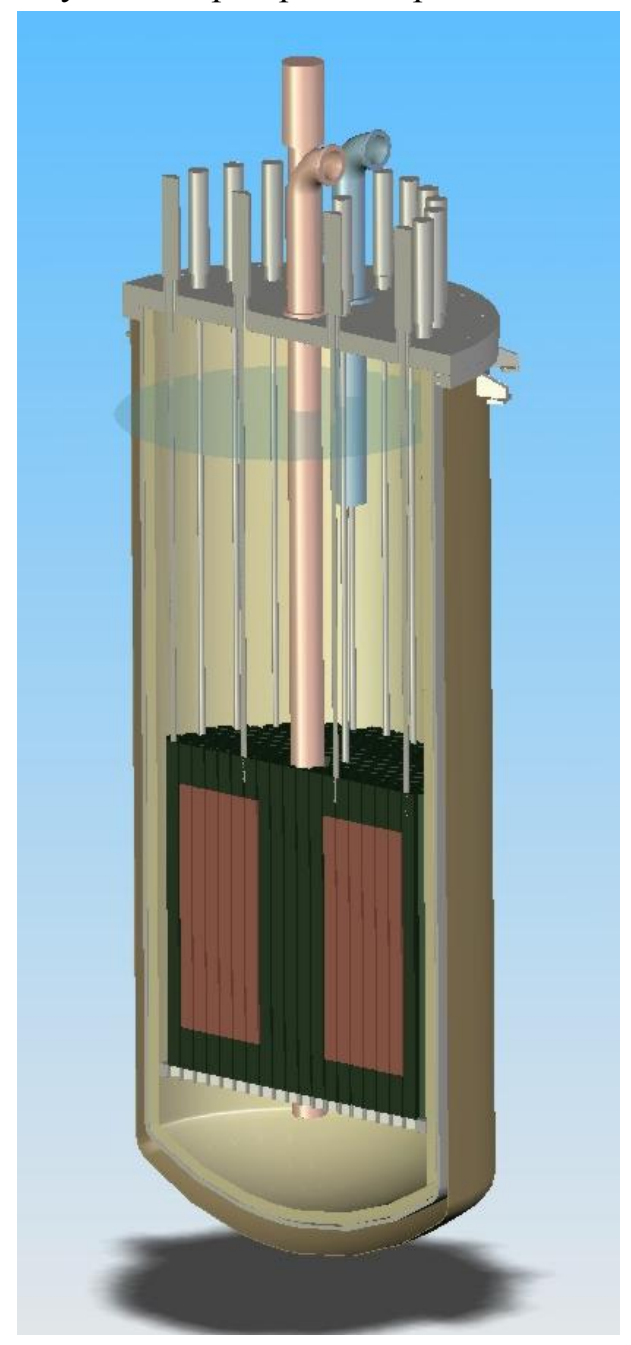

Fig. 2.7. AHTR reactor vessel.

\subsection{THERMAL BLANKET SYSTEM}

The thermal blanket system (TBS) is the key design feature that distinguishes the AHTR from pooltype, sodium-cooled reactors like S-PRISM. The TBS allows the AHTR to take advantage of the very high boiling temperatures of molten salts by allowing the primary salt coolant and core to be heated to high temperatures while keeping the reactor vessel at substantially lower temperatures.

The TBS requirements create some of the most important technical and design questions for the AHTR. The TBS must be constructed using materials that maintain adequate strength when heated to the peak primary coolant temperature following loss of forced cooling. For the intermediate temperature AHTR-IT, the initial temperature of the primary pool is below $700^{\circ} \mathrm{C}$. With an S-PRISM-size vessel at $2400 \mathrm{MW}(\mathrm{t})$, peak salt temperatures following loss of flow can be kept inside the limits where metallic materials can be used for the thermal blanket. Metallic insulations systems, like that used in the Swedish PIUS reactor design, take advantage of the relatively low thermal conductivity of the liquid coolant to 
create an insulating layer by suppressing convection inside the blanket. This type of metallic insulation system was thoroughly studied for the PIUS reactor, and hence is considered to have low technical risk.

For the very high-temperature AHTR-VT, which has a primary pool temperature of approximately $900^{\circ} \mathrm{C}$, high-temperature, carbon-based materials must be used for the high-temperature side of the TBS To maintain peak vessel temperatures in the range of 600 to $750^{\circ} \mathrm{C}$, this TBS must sustain temperature differences of several hundred degrees while keeping the heat transfer rate across the blanket within the capacity of the passive cooling systems, typically below $20 \mathrm{MW}(\mathrm{t})$.

For gas-cooled reactors, graphite blocks are used to create a TBS that allows the core to reach much higher temperatures (up to $1600^{\circ} \mathrm{C}$ ) compared with the reactor vessel, which is typically limited to a maximum temperature below $500^{\circ} \mathrm{C}$ because of its relatively large thickness $(22 \mathrm{~cm})$. Heat transfer from the core to the vessel occurs by a combination of conduction through the graphite blocks of the TBS, and by natural convection of helium through the joints between the graphite blocks driven by buoyancy forces. Gas reactor cores are designed with down-flow, so that natural circulation is suppressed if forced circulation of the coolant is stopped. Still, the potential for hot gas to reach the reactor vessel and cause localized overheating is considered an important design issue for gas-cooled reactors.

The much higher thermal capacity of molten salts, compared with high-pressure helium, makes the control of natural convection across the TBS a key design issue for the ATHR-VT. Because of the mismatch of thermal expansion coefficients of graphite and steel, some gap must be provided between the graphite blocks of the TBS and the reactor vessel. Relatively large differences in salt density will exist between the hot and cold sides of the blanket, and the different hydrostatic pressure gradients on each side create a pressure differential across the TBS that can drive leakage flows.

If the AHTR-VT reactor vessel is built with the same dimensions as the 9.2-m-diam, 19.5-m-high S-PRISM reactor vessel, then the TBS will have an outside diameter of $\sim 8 \mathrm{~m}$ and a total surface area (including the bottom) of $500 \mathrm{~m}^{2}$. For a typical graphite thermal conductivity of $32 \mathrm{~W} / \mathrm{m}^{\circ} \mathrm{C}, 0.64-\mathrm{m}$-thick graphite blocks would transfer $15 \mathrm{MW}(\mathrm{t})$ at a TBS temperature difference of $600^{\circ} \mathrm{C}$. At this temperature difference, a $6 \mathrm{l} / \mathrm{s}$ leakage flow through the blanket would also transfer $15 \mathrm{MW}(\mathrm{t})$ across the blanket.

Figure 2.8 shows a schematic diagram of an AHTR blanket configuration that might potentially meet the difficult thermal protection requirements. This TBS conceptual design draws significantly on the ORNL MSBR graphite blanket design. ${ }^{6}$

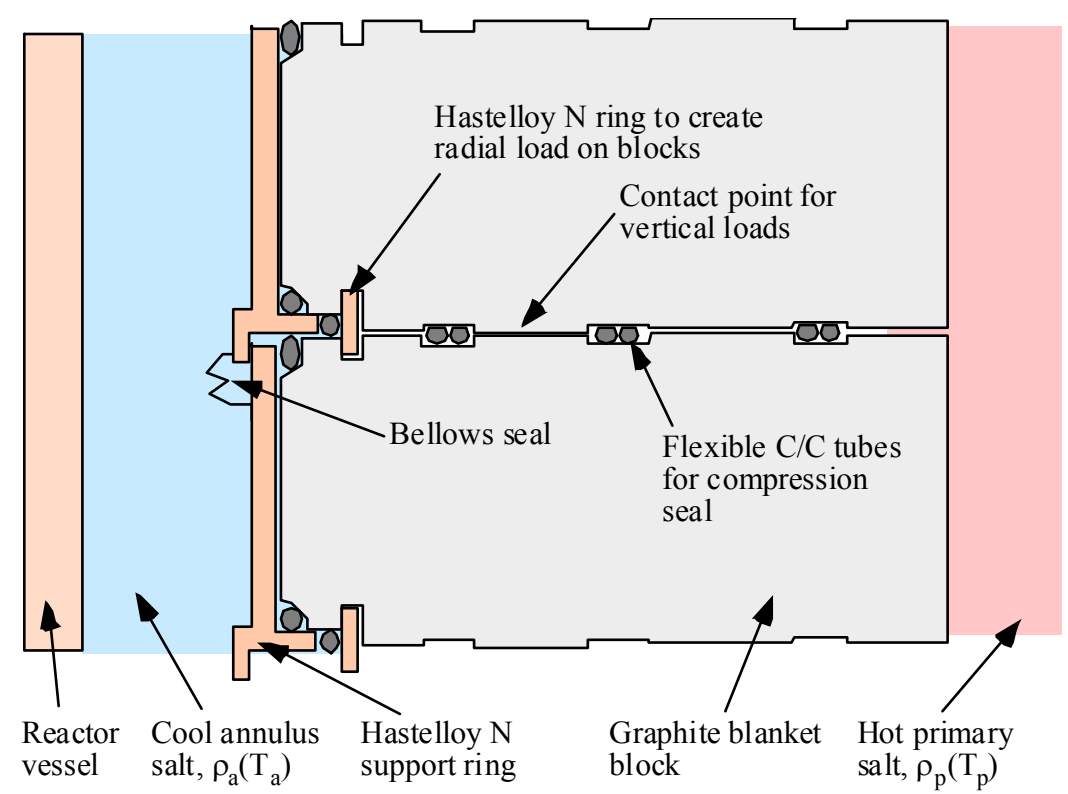

Fig. 2.8. Schematic showing a vertical cross-section for an AHTR thermal blanket system. 
This conceptual TBS introduces several features.

- The hot primary salt, with density $\rho_{\mathrm{p}}\left(\mathrm{T}_{\mathrm{p}}\right)$, is hermetically isolated from the salt in the annulus between the reactor vessel and the TBS. The hermetic seal prevents leakage flow across the TBS because of the different hydrostatic pressure gradients on the cool and hot sides. With appropriate control of the inventory of salt in the annulus and primary pool, this results in a further reduction of the pressure differential across the TBS at all elevations.

- The graphite blocks have lower density than the molten salts and, thus, float. This effect is counteracted by the mass of Hastelloy N support rings, and an additional Hastelloy ring placed on top of the column of graphite blanket blocks, similar to the MSBR blanket design. The option also exists to add high-density materials to the graphite to increase the block density. Each support ring is keyed to ribs in the vessel wall to control the support ring's radial position while permitting vertical motion. The keying system also transfers the limited horizontal accelerations that would occur during seismic events, from the seismically base-isolated reactor vessel to the TBS.

- To control the radial position of each block, a Hastelloy $\mathrm{N}$ expansion ring is provided, located in a slot machined in the top and bottom of each blanket block, as was used in the MSBR design. Because the expansion ring expands radially the same amount as the support ring as a result of temperature changes, the expansion ring keeps the blocks in contact with the support ring and maintains the seals between the blocks and the support rings.

- Flow between the primary pool and the annulus is prevented by a metallic bellows between each support ring. A carbon/carbon $(\mathrm{C} / \mathrm{C})$ composite O-ring provides backup sealing between each support ring. The bellows is sufficiently strong to support hydrostatic pressure upon filling, because the low-pressure gas caught in the bellows is isolated from the primary pool by the $\mathrm{C} / \mathrm{C}$ O-ring.

- To control the vertical position of each block, each support ring can move vertically, with the differential expansion being accommodated by the bellows. Because the blocks will distort as a result of thermal expansion from the temperature gradient through the blocks, and because of radiation-induced swelling, the contact point between the blocks is located at the effective center of mass of the submerged blocks. Conveniently, the radial block temperature at the contact point is higher than the temperature of the support ring, increasing the vertical thermal expansion of the block and compensating, to some degree, for the different thermal expansion coefficient of the metallic support ring and the graphite TBS blocks.

- Various types of flexible seals could potentially be used to provide sealing between each layer of graphite blocks. Here hollow carbon-carbon tubes are shown wrapped in a slot twice around the ring of blocks, at three radial locations. Flow through the tube provides a path for equalizing pressure and venting gas during filling of the blanket system, while limiting leakage rates, as shown schematically in Fig. 2.9.

- Additional azimuthal joints exist between blocks around each ring. These joints are staggered vertically so that they do not align. Flexible $\mathrm{C} / \mathrm{C}$ seals are provided to control flow through these azimuthal joints.

- Inspection requirements and methods must be defined for the TBS. Inspection is assisted by the transparency of the molten salts, but still must be performed at elevated temperature. Visual inspection is assumed to be possible using actively cooled, submersible camera systems with sapphire viewing windows. Other inspection methods may also be adaptable to the TBS but have not as yet been evaluated. Here it is assumed that corrosion of carbon-based materials (particularly $\mathrm{C} / \mathrm{C}$ O-rings) will be sufficiently slow that inspection of flexible $\mathrm{C} / \mathrm{C}$ seals between blocks will not be required over the life of the TBS. 


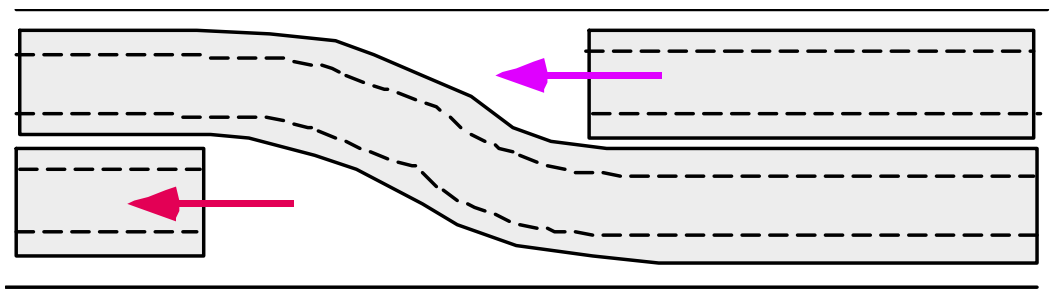

Fig. 2.9. Schematic showing how controlled leakage occurs through a hollow double-wrapped hollow $\mathrm{C} / \mathrm{C}$ O-ring seal.

The design of the AHTR-VT TBS to control leakage flow and heat transfer will be a key part of AHTR design efforts. For AHTR designs that have lower peak salt temperatures, such as the AHTR-IT, greater flexibility exists for the design of the TBS using metallic materials. While the TBS presents important challenges for the design of the AHTR, potential design approaches exist that can limit convective bypass across the blanket and ensure acceptable vessel temperatures.

\subsection{REACTOR AND GUARD VESSELS}

The primary reactor vessel has a diameter of $9.2 \mathrm{~m}$ and a height of $19.5 \mathrm{~m}$. The vessel thickness is $10 \mathrm{~cm}$, which is significantly less than the 22-cm thickness of the GT-MHR vessel because of the low ressure of the molten salt coolant of the AHTR compared with the high-pressure helium of the GT-MHR. Although S-PRISM also uses a low-pressure coolant, the AHTR vessel is thicker than the S-PRISM 5$\mathrm{cm}$-thick vessel because the higher density of the salt compared with sodium results in a hydrostatic load that is 2-4 times higher than for S-PRISM. The guard vessel separates the reactor vessel from the reactor cavity cooling system. It is $2.5-\mathrm{cm}$ thick and is separated from the reactor vessel by a 20 -cm-thick argon gap. The optimum materials to be used for the primary and guard vessels have not been selected yet. Nickel-based superalloys are the leading candidates for the primary vessel, but there are a number of options that can be considered. This is discussed in a Sect. 5.

\subsection{PRIMARY COOLANT}

The reference primary coolant is a molten fluoride salt containing lithium and beryllium $\left(\mathrm{Li}_{2} \mathrm{BeF}_{4}-\right.$ referred to as "Flibe"). It has a melting point of $459^{\circ} \mathrm{C}$, a boiling point of $1430^{\circ} \mathrm{C}$, and a density of $1.94 \mathrm{~g} / \mathrm{cm}^{3}$. There are a number of positive and negative aspects to this salt, which are discussed thoroughly in later sections. The heat capacity of Flibe is $4540 \mathrm{~kJ} / \mathrm{m}^{3}$, which is similar to that of water, more than four times that of sodium, and more than 200 times that of helium (at typical reactor conditions). This enables several design performance improvements relative to gas-cooled systems. There is considerable experience with Flibe in nuclear systems. It was used in both the primary and secondary loops of the Molten Salt Reactor Experiment (MSRE) and related test loops.

\subsection{DECAY HEAT REMOVAL SYSTEMS}

The ultimate power output of the AHTR is limited by the capacity of the passive decay system, which, in turn, is driven by the reactor vessel temperature. The reference AHTR design uses an air-cooled passive decay-heat-removal system similar to the reactor vessel auxiliary cooling system (RVACS) developed for the S-PRISM reactor. ${ }^{5}$ The reactor and decay heat cooling system are located in an underground silo. Decay heat is (1) transferred to the reactor core and graphite reflectors by natural circulation of the molten salts, (2) conducted through the graphite thermal blanket and reactor vessel wall, (3) transferred across an argon gap by radiation to a guard vessel, (4) conducted through the guard vessel, and then (5) removed from outside of the guard vessel by natural circulation of ambient air. The rate of 
heat removal is controlled primarily by the radiative heat transfer through the argon gas from the reactor vessel. Radiative heat transfer increases by the temperature to the fourth power $\left(\mathrm{T}^{4}\right)$; thus, a small rise in the reactor vessel temperature (as would occur upon the loss of normal decay-heat-removal systems) greatly increases heat transfer out of the system.

It is also possible to supplement the RVACS heat removal capacity using a direct reactor auxiliary cooling system (DRACS) based on natural circulation of an intermediate coolant from bayonet heat exchangers in the reactor vessel to air-cooled heat exchangers. This type of DRACS system was used in the Experimental Breeder Reactor II (EBR-II) with sodium-potasium as the intermediate coolant. There are a variety of potential intermediate coolants, several of which have been used extensively in industry for similar heat transfer applications.

Figure 2.10 shows a schematic diagram of a combined RVACS/DRACS system for the AHTR, where the DRACS natural-circulation flow loop transfers heat from a cool-salt annulus between the reactor vessel and thermal blanket to a heat exchanger located in the RVACS exhaust chimney. Prewarming of the air going to the DRACS air-cooled heat exchanger controls the potential for freezing, and the additional heat added to the air increases buoyancy forces and augments the total flow rate of air through the system. For this configuration, compact tube-type bayonet heat exchangers can be designed with surface areas between one and two times larger than the vessel surface area, providing substantial potential for augmentation of heat removal. The addition of a DRACS system would also permit the reactor vessel to operate at lower peak temperatures (under $600^{\circ} \mathrm{C}$ ), increasing the range of materials that could be used for vessel fabrication. 


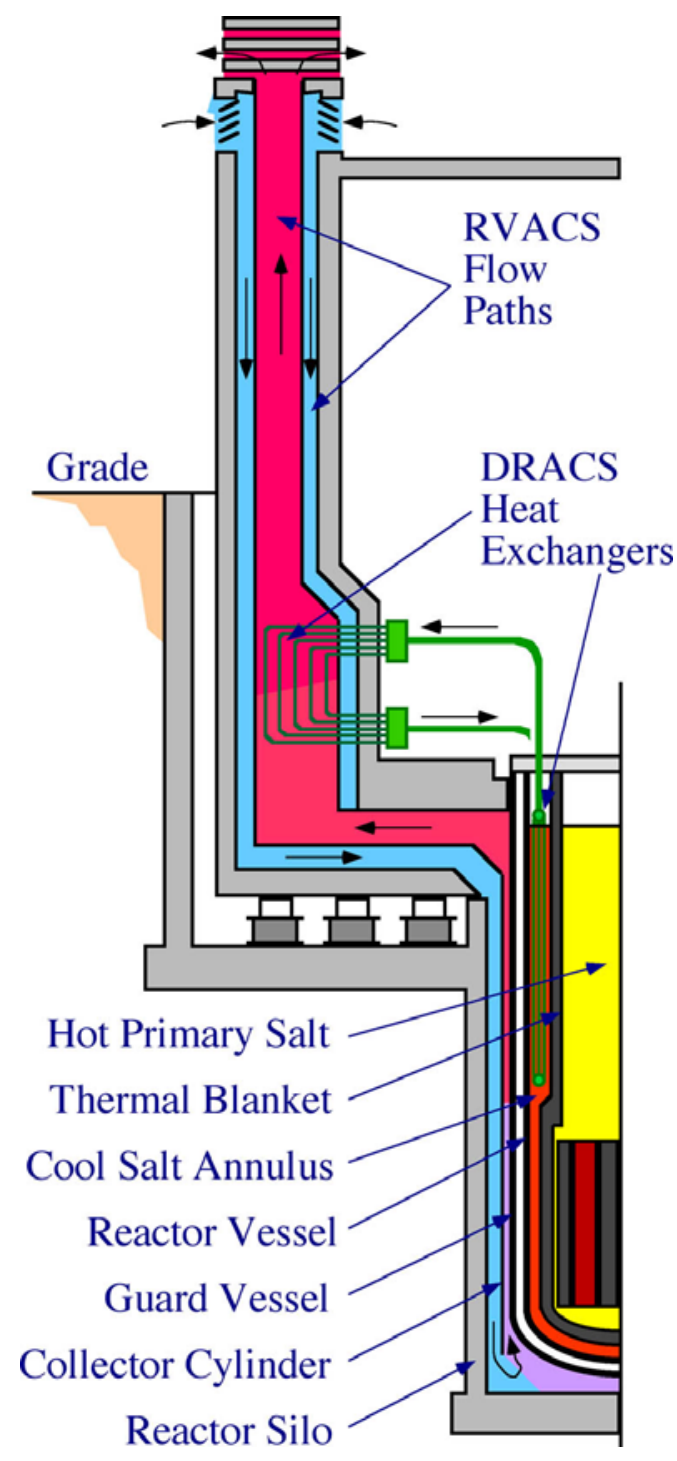

Fig. 2.10. Illustration of a combined RVACS/DRACS system for the AHTR.

\subsection{POWER CONVERSION SYSTEM}

The power conversion system to produce electricity from the AHTR uses a multistage molten coolant gas cycle (MCGC), ${ }^{7,8}$ which is based on the GT-MHR power conversion unit (PCU). With similar power output, the MCGC system is expected to be more compact and, thus, provide the potential for major reductions in the turbine building volume and power conversion system capital cost for the AHTR relative to conventional systems that use a steam Rankine cycle.

Figure 2.11 provides a schematic diagram of the MCGC flow configuration. The $2400 \mathrm{MW}(\mathrm{t})$ helium-based very high-temperature MCGC design uses three PCUs and a turbine inlet temperature of $900^{\circ} \mathrm{C}$ to achieve a thermal efficiency of $54 \%$ [1300 MW(e)]. To achieve the same thermodynamic efficiency as the very high-temperature design, the nitrogen-based design has a total volume $40 \%$ greater than that of the helium-based design. All of the Brayton power systems are significantly smaller than equivalent steam cycle systems that must include large subatmospheric turbines and moisture separators. 


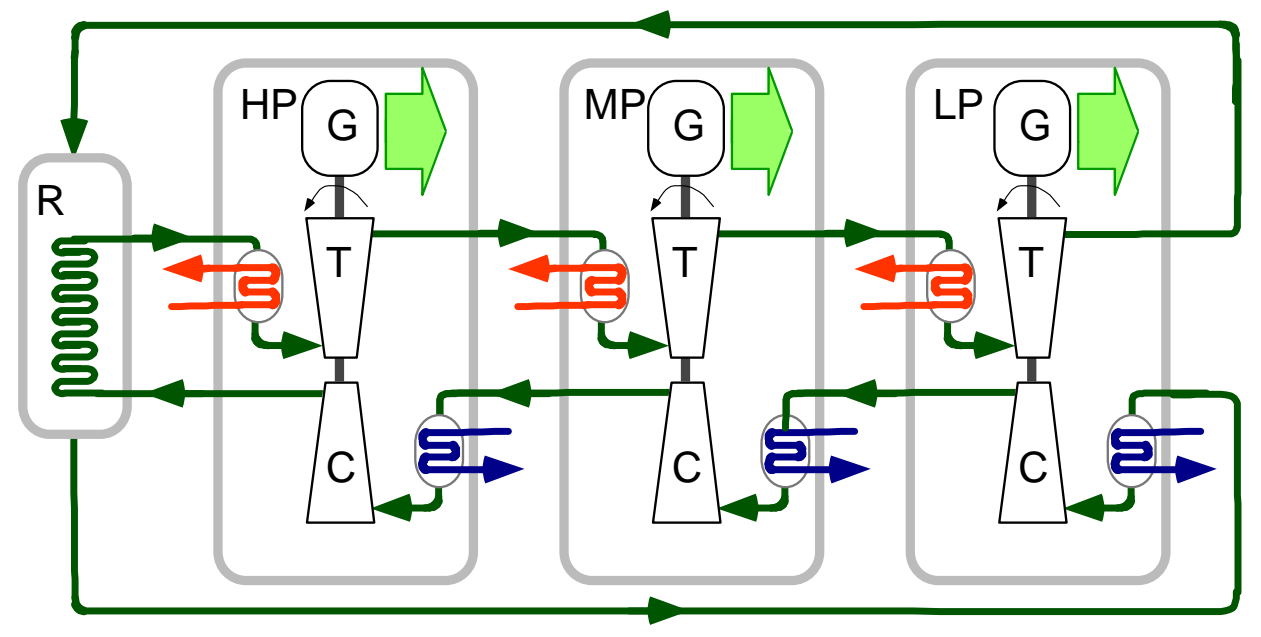

Fig. 2.11. Schematic flow diagram for the reference three-expansion-stage MCGC, using three PCU modules [high pressure (HP), medium pressure (MP), and low pressure (LP)] each containing a generator $(G)$, turbine (T), compressor (C), and heater and cooler heat exchangers, with a recuperator $(R)$ located in a fourth vessel.

The PCU developed by GA for the GT-MHR, shown in Fig. 2.12, is currently the only closed helium cycle system that has undergone detailed engineering design analysis, and that has turbomachinery sufficiently large to extrapolate to a $>1000 \mathrm{MW}$ (e) MCGC power conversion system. Analysis presented below shows that, with relatively small engineering modifications, multiple GT-MHR PCUs can be ganged together to create a MCGC power conversion system in the $>1000 \mathrm{MW}(\mathrm{e})$ class. To do this, compact salt-to-helium heat exchangers (power densities from 80 to $120 \mathrm{MW} / \mathrm{m}^{3}$ ) are inserted into the annular space around the turbines, currently occupied by the upper set of recuperator heat exchangers in the GT-MHR design (Fig. 2.12), and the MCGC recuperator is moved to a separate pressure vessel. The resulting configuration is quite compact and results in what is likely the minimum helium duct volume possible for a multiple-reheat system.

The GT-MHR PCU produces $285 \mathrm{MW}(\mathrm{e})$ with $850^{\circ} \mathrm{C}$ turbine inlet temperature, a PCU power density of $230 \mathrm{kWh}(\mathrm{e}) / \mathrm{m}^{3}$. Based on the same turbomachinery parameters, and using three PCUs with size similar to the GT-MHR PCU, the very high-temperature MCGC is predicted to achieve a power density of $360 \mathrm{kWh}(\mathrm{e}) / \mathrm{m}^{3}$. The MCGC power conversion system can be located in conventional structures rather than within the nuclear safety envelope. Also, the GT-MHR PCU pressure vessel is constructed from the same $9 \mathrm{Cr}-1 \mathrm{Mo}-\mathrm{V}$ high-temperature alloy as the GT-MHR reactor vessel, while the MCGC vessels all operate at low temperature (under $160^{\circ} \mathrm{C}$ ), allowing the use of less expensive and stronger low-temperature steel. These considerations suggest that the MCGC PCU capital cost per kW(e) will be around half that of the GT-MHR PCU. 


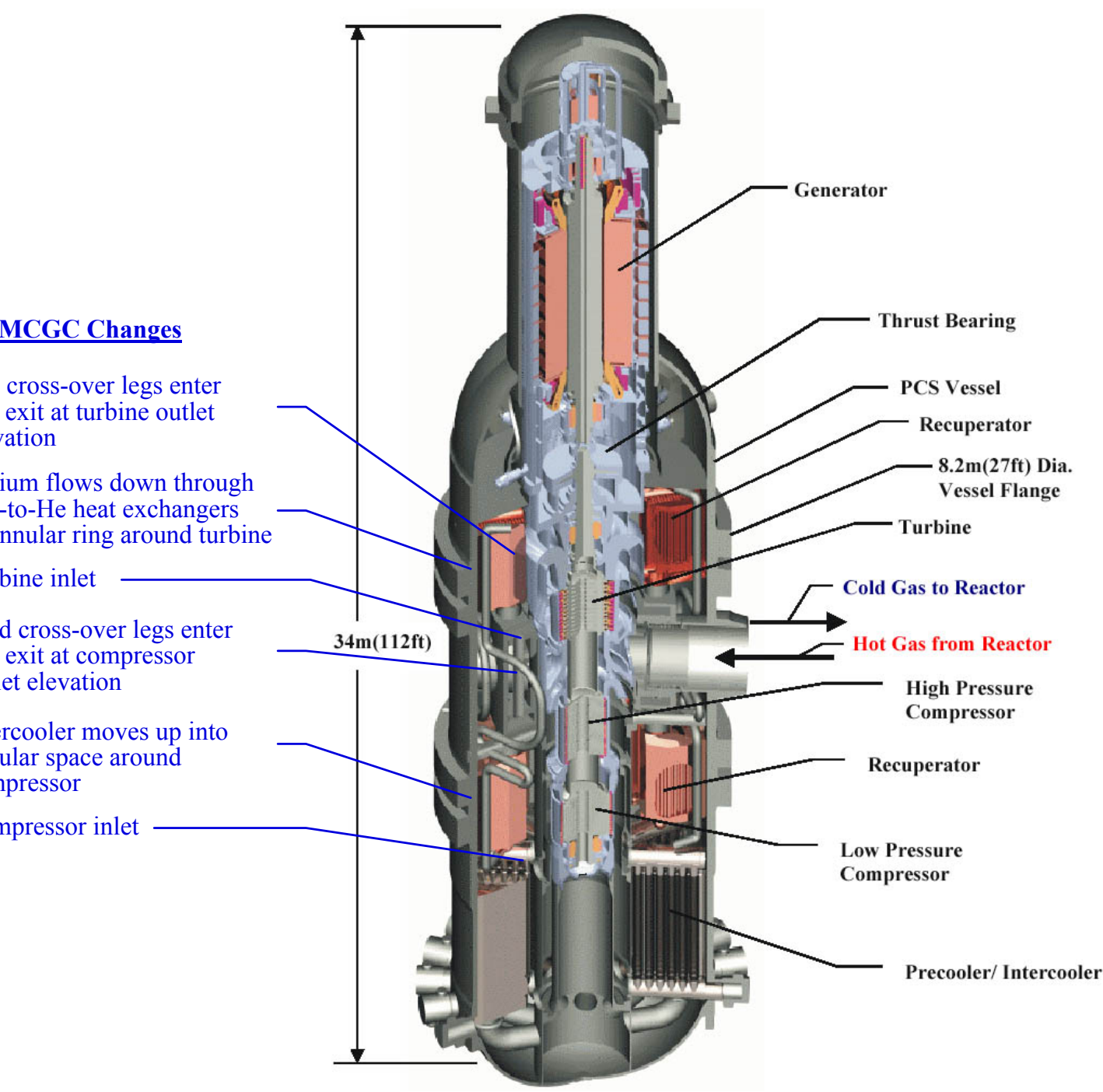

Fig. 2.12. Cross section of the current GT-MHR PCU, with changes required for MCGC indicated on left.

The reference very high-temperature MCGC configuration uses three PCUs, each connected by an upper hot leg and a lower cold leg, as shown in Fig. 2.13. A separate recuperator vessel is also connected to the low-pressure and high-pressure PCUs with similar hot and cold legs. As shown in Fig. 2.13, the hot legs connect the PCU vessels at the elevation of the turbine outlets. Flow is collected from the turbine outlet diffuser and crosses at $\sim 650^{\circ} \mathrm{C}$ in the hot leg to the next PCU vessel. This hot-leg flow enters the top of an annular ring of liquid-silicon infiltrated (LSI) $\mathrm{C} / \mathrm{C}$ composite heat exchangers and flows downward to be heated to $900^{\circ} \mathrm{C}$, and then is ducted directly into the next turbine inlet, resulting in a very short hot-gas flow path. Current calculations for the frontal area, flow path length, and volume of these heaters, based on the LSI composite plate-design shown in Fig. $2.14,{ }^{9}$ indicates that they should fit in the annular volume around the turbine, currently occupied by the upper recuperator bank of the current GTMHR PCU design. 


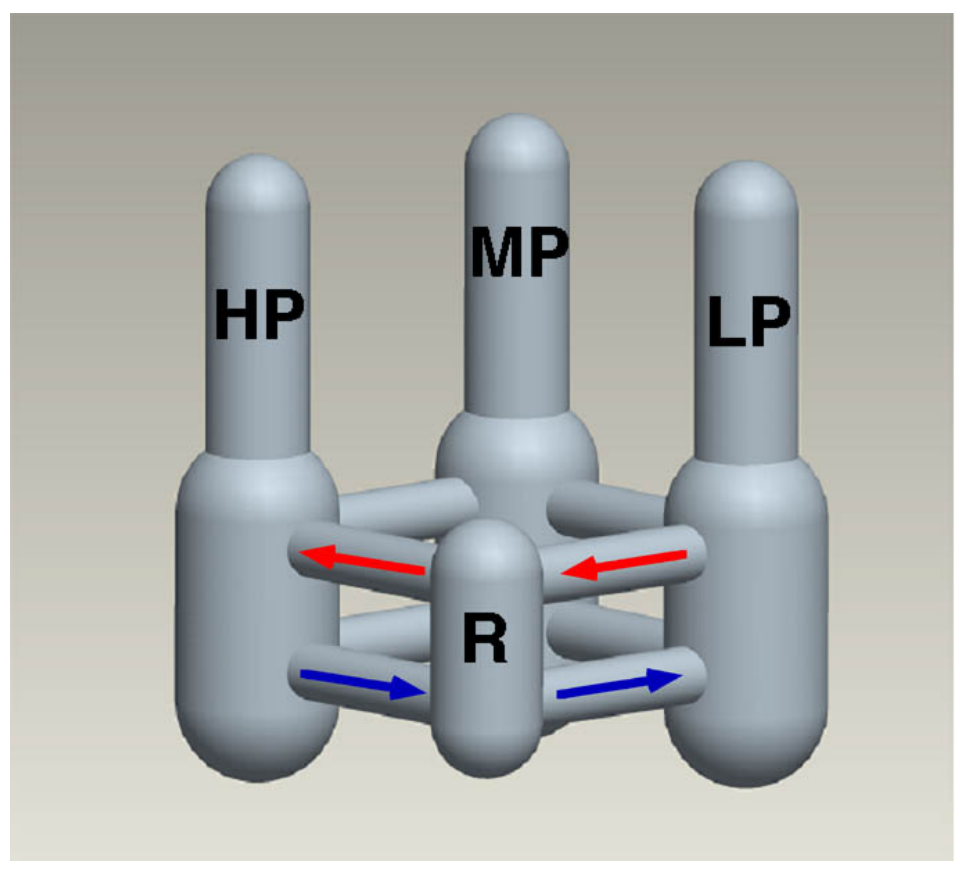

Fig. 2.13. Hot- and cold-leg configurations for the MCGC based on three (HP, MP, and LP) PCUs and a separate recuperator vessel $(R)$.
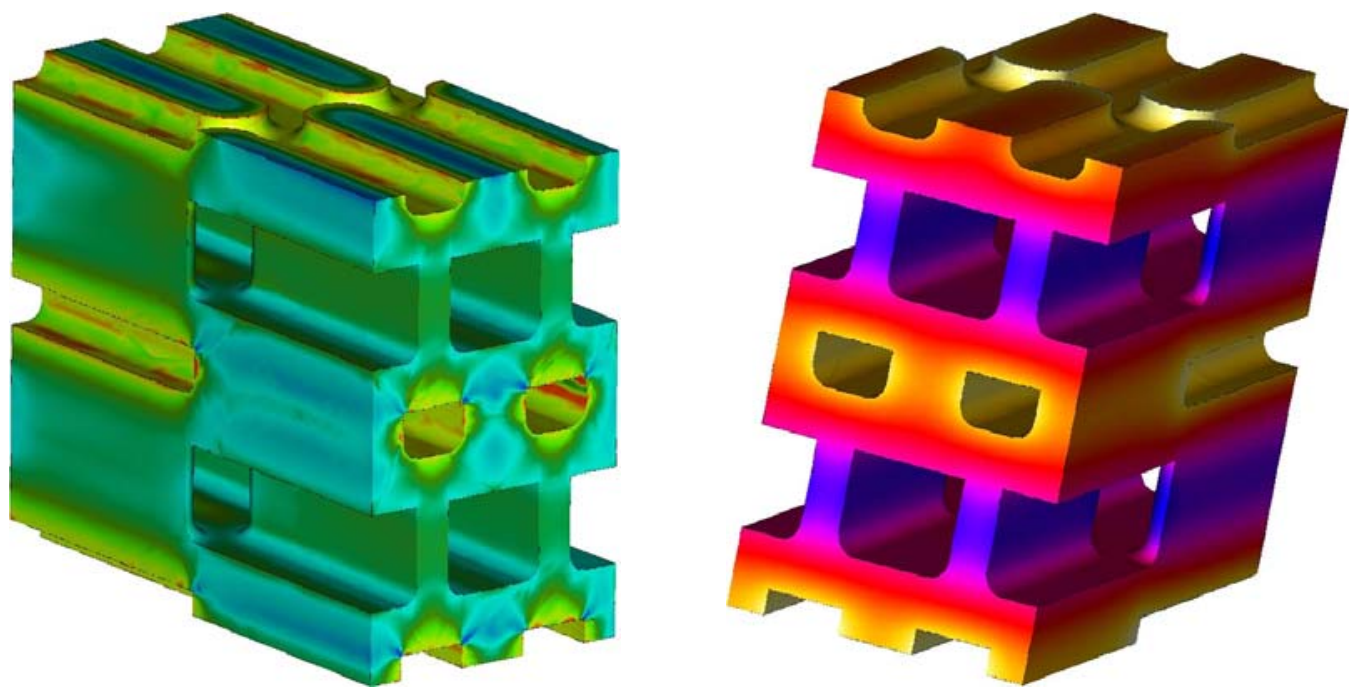

Fig. 2.14. Stress and temperature distributions in a plate-type LSI composite heat exchanger currently under development at UCB.

Likewise, the cold legs connect the PCUs at the elevation of the compressor outlets. Flow is collected from the compressor diffuser, and approximately $90 \%$ of the flow at $\sim 140^{\circ} \mathrm{C}$ crosses in the cold leg and enters the top of an annular ring of coolers to flow downward, to be cooled, and then to go directly into the next compressor inlet. Approximately $10 \%$ of the cold flow is bypassed upward to flow through an annulus around the hot-leg duct, so the hot-leg pressure boundary is maintained at the same temperature as the cold-leg boundary to minimize thermal stresses due to the PCU vessels being connected at two elevations by cross-over legs. The cold cross-over leg eliminates the vessel volume and pressure drop that 
would be required to bring $100 \%$ of the cold flow to the hot-leg elevation to flow across in an annular duct, as is done with direct-cycle gas-cooled reactors.

With this configuration, for the recuperator, the low-pressure turbine discharges its gas into a hot leg going over to the top of the recuperator vessel, and the low-pressure gas flows down through the recuperator and then returns to the low-pressure compressor in the low-pressure cold leg. Likewise, the discharge from the high-pressure compressor flows across in the high-pressure cold leg to the recuperator vessel, flows upward through the recuperator to be heated, and then flows across in the high-pressure hot leg to the high-pressure PCU. Table 2.2 lists the primary design parameters for two candidate MCGC designs - one using helium only and one using a nitrogen-helium mix.

In designing closed helium cycles, a major cost driver is the volume of ducting required to transfer helium between equipment, because it affects the cost of the pressure boundary. It is doubtful that one will be able to identify a more compact configuration for the MCGC than this multiple-shaft design with annular rings of heaters around each turbine, because all flows enter at the optimal elevation in the vessels, and the hot gas flow path is extremely short.

Table 2.2. MCGC design parameters

\begin{tabular}{|lccc||}
\hline & $\begin{array}{c}\text { High-temperature } \\
\text { helium MCGC }\end{array}$ & $\begin{array}{c}\text { High-temperature } \\
\text { nitrogen-helium } \\
\text { MCGC }\end{array}$ & $\begin{array}{c}\text { Reference } \\
\text { GT-MHR PCU }\end{array}$ \\
\hline Number of PCUs & 3 & 3 & 1 \\
Working fluid & Helium & $\begin{array}{c}\text { Nitrogen-helium } \\
\text { mixture }(10 \mathrm{wt} \%\end{array}$ & Helium \\
Gas mass flow rate $(\mathrm{kg} / \mathrm{s})$ & & $\mathrm{He})$ & \\
Turbine inlet temperature & 596 & 1934 & 317 \\
Turbine outlet temperature & $900^{\circ} \mathrm{C}$ & $900^{\circ} \mathrm{C}$ & $848^{\circ} \mathrm{C}$ \\
MS inlet temperature & $650^{\circ} \mathrm{C}$ & $650^{\circ} \mathrm{C}$ & $508^{\circ} \mathrm{C}$ \\
MS outlet temperature & $920^{\circ} \mathrm{C}$ & $920^{\circ} \mathrm{C}$ & $\mathrm{N} / \mathrm{A}$ \\
Compressor inlet temperature & $860^{\circ} \mathrm{C}$ & $860^{\circ} \mathrm{C}$ & $\mathrm{N} / \mathrm{A}$ \\
System pressure & $35^{\circ} \mathrm{C}$ & $35^{\circ} \mathrm{C}$ & $26.4{ }^{\circ} \mathrm{C}$ \\
Cycle pressure ratio & $10 \mathrm{MPa}$ & $10 \mathrm{MPa}$ & $7.24 \mathrm{MPa}$ \\
Turbine efficiency & 7.04 & 14.3 & 2.69 \\
Compressor efficiency & 0.93 & 0.93 & 0.93 \\
Recuperator effectiveness & 0.88 & 0.88 & 0.88 \\
Generator efficiency & 0.95 & 0.95 & 0.95 \\
Pressure loss fraction & 0.98 & 0.98 & 0.98 \\
Overall cycle efficiency & 0.04 & 0.06 & 0.013 \\
Power density $\left[\mathrm{kWh}(\mathrm{e}) / \mathrm{m}^{3}\right]$ & 0.54 & 0.54 & 0.46 \\
\hline
\end{tabular}




\subsection{INTERMEDIATE HEAT TRANSPORT SYSTEM}

The AHTR will use an intermediate heat transport loop containing molten salt to transfer heat generated in the reactor system to the hydrogen production plant. The salt composition has not been selected yet and may be different from the salt used as the primary coolant. A comparison was performed of the performance of low-pressure molten salt vs high-pressure helium for the intermediate loop.

The much higher volumetric thermal capacity $\left(\rho C_{p}\right)$ of molten salts, compared with high-pressure helium, has a large effect upon the relative heat transfer capability. In general, a molten salt loop will use piping of $1 / 5$ the diameter and pumps $1 / 20$ the power of those required for high-pressure helium. These large differences in pumping power and pipe size reduce the capital cost of high-temperature piping systems and allow the arrangement of process equipment to be optimized more easily, since process heat can be delivered over larger distances easily.

A second, less obvious difference between helium and molten salts relates to the log-mean temperature difference (LMTD). Smaller values of LMTD are desirable to increase the temperature at which heat is delivered to the hydrogen production process, and/or to decrease the peak temperature of the reactor while maintaining the same hydrogen production efficiency. Heat transfer coefficients for molten salts are typically an order of magnitude greater than those for helium. In compact helium heat exchangers, a strong competition exists between adding surface area to decrease the LMTD, and reducing surface area to reduce the helium pressure drop. Pressure drop and pumping power considerations usually drive helium heat exchangers to higher LMTD values than would be selected for molten salt heat exchangers.

The effect on LMTD can be seen in Fig. 2.15, which presents the total pumping power (both sides) and the total volume of a $600 \mathrm{MW}(\mathrm{t})$ heat exchanger as a function of LMTD for three combinations of fluids. In the figure, the comparison between point $\mathrm{A}$ and point $\mathrm{B}$ shows that the He-to-molten salt heat exchanger has an LMTD less than half that of the LMTD for the He-to-He heat exchanger, for the same pumping power and a similar heat exchanger volume (and capital cost).

Table 2.3 compares typical compact heat exchanger parameters for several possible primary and intermediate fluid options for the case where the pumping power for the helium is kept constant. Note in particular the difference between the pumping power for salt vs helium. The largest surface area occurs with the case of the 1.0 MPa intermediate helium loop, designed to be in pressure balance with hydrogen process equipment. 


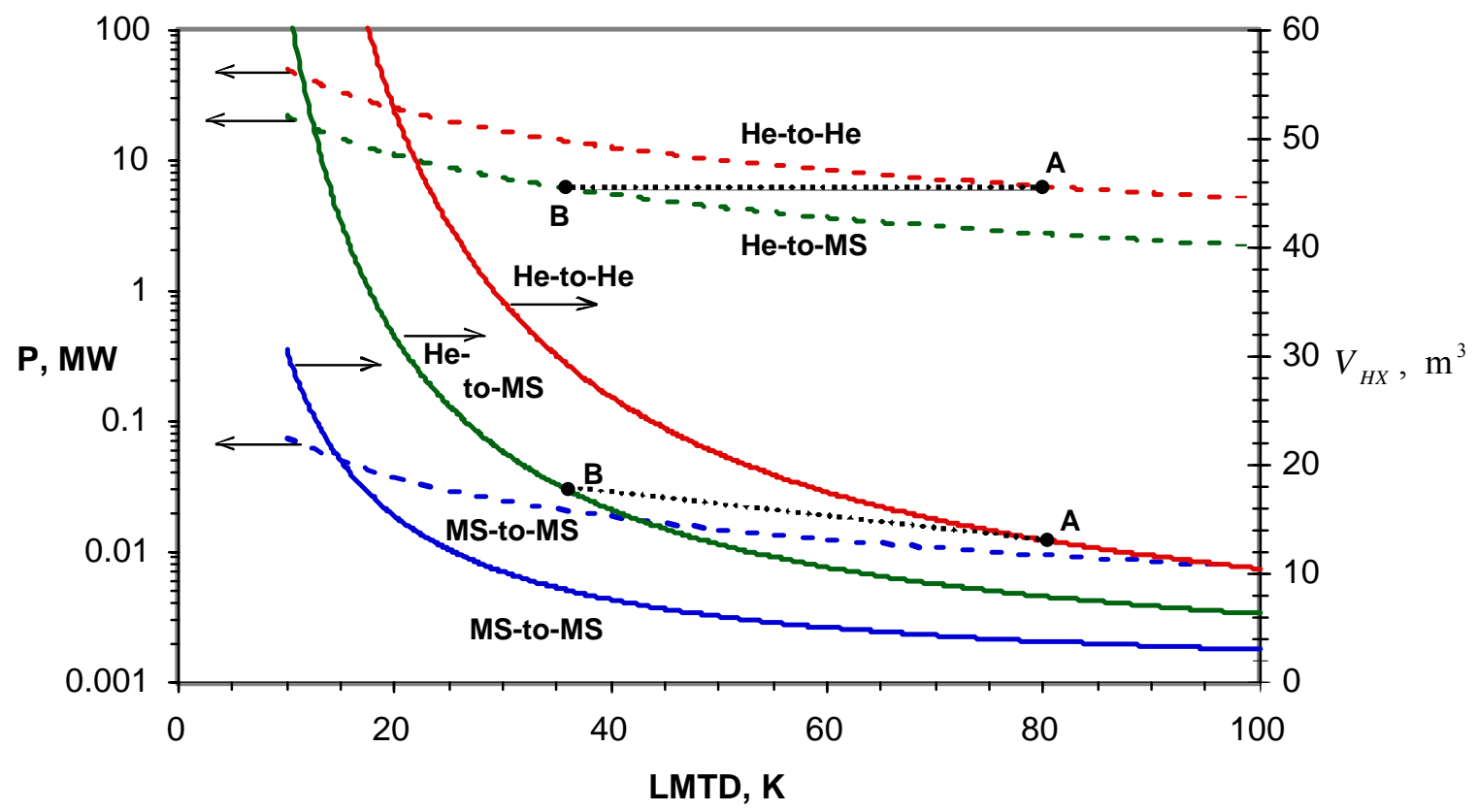

Fig. 2.15. Total pumping power $P$ (dashed) and the total volume $V_{H X}$ (solid) for a $600 \mathrm{MW}(t)$ compact intermediate heat exchanger as a function of LMTD for three combinations of helium (7.0 MPa) and/or molten salt.

Table 2.3. Comparison of $600 \mathrm{MW}(\mathrm{t})$ compact intermediate heat exchanger designs (the molten salt is $0.42 \mathrm{LiF}-0.29 \mathrm{NaF}-0.29 \mathrm{ZrF}_{4}$ )

\begin{tabular}{|lcccc|}
\hline \multicolumn{1}{|c}{ Primary/intermediate fluids } & $\mathbf{H e} / \mathrm{He}$ & $\mathbf{H e} / \mathbf{H e}$ & $\mathbf{H e} / \mathbf{M S}$ & MS/MS \\
\hline Primary/intermediate pressures $(\mathrm{MPa})$ & $7.0 / 7.0$ & $7.0 / 1.0$ & $7.0 / *$ & $* / *$ \\
Primary inlet/outlet temperatures $\left({ }^{\circ} \mathrm{C}\right)$ & $1000 / 634$ & $1000 / 634$ & $1000 / 634$ & $1000 / 634$ \\
Intermediate outlet/inlet temperatures $\left({ }^{\circ} \mathrm{C}\right)$ & $975 / 450$ & $975 / 450$ & $975 / 560$ & $975 / 595$ \\
LMTD $\left({ }^{\circ} \mathrm{C}\right)$ & 80 & 80 & 45 & 31 \\
Primary/intermediate pressure loss $(\mathrm{kPa})$ & $40 / 19$ & $2.7 / 9.0$ & $40 / 13$ & $24 / 25$ \\
Primary/intermediate pump power $(\mathrm{MW})^{\dagger}$ & $4.8 / 1.5$ & $0.3 / 4.8$ & $4.8 / 0.005$ & $0.012 / 0.012$ \\
Primary/intermediate fin heights $(\mathrm{mm})$ & $2.0 / 2.0$ & $2.0 / 2.0$ & $2.0 / 1.0$ & $1.0 / 1.0$ \\
HX flow length $(\mathrm{m})$ & 0.76 & 0.40 & 0.89 & 1.1 \\
HX plate area $\left(\mathrm{m}^{2}\right)$ & 3200 & 5600 & 4100 & 3500 \\
HX volume $\left(\mathrm{m}^{3}\right)$ & 13 & 23 & 14 & 9.7 \\
\hline
\end{tabular}

${ }^{\dagger}$ Power required to pump primary and intermediate fluids through the intermediate heat exchanger.

*Molten salt is incompressible, so pressure and pumping power are independent, and pressure can be set to any desired value. 


\section{DESIGN ANALYSIS}

To date, the AHTR concept has evolved largely through the thoughtful and creative merging of design features from several other reactor designs. Earlier analyses made frequent use of scaling laws from similar reactor systems and have not kept pace with the evolving AHTR concept. For the current study, several analyses were performed with a higher level of sophistication to reduce uncertainties in the predicted AHTR performance and to assist in the selection of several design parameters. In particular, core physics, thermal hydraulics, decay heat removal, and power conversion analyses were performed. Since multiple organizations were involved in the analyses, and since the AHTR design continued to be refined, the analyses presented below used a variety of models and approaches to analyzing the various phenomena. In general, different approaches tended to yield similar results and different models yielded small or well-understood differences. The conclusion of this initial analysis effort is that there are no phenomenological "show stoppers" but that there are a number of design alternatives and trade-offs that will need to be explored. Also, more sophisticated analyses will be needed to reduce performance uncertainties.

\subsection{CORE PHYSICS ANALYSIS}

The AHTR reactor core physics is similar to that of a GT-MHR because they share the same fuel and moderator. A few key differences are expected, though, primarily due to differences in the neutron cross sections of molten salt vs helium coolant, and different coolant volume fractions due to the improved thermal properties of molten salts. A number of physics analyses were performed to evaluate these effects. Since the analysis was done in a short period of only a few months with both SNL and ORNL working in parallel, and since the core design was evolving quickly based on input from other analyses such as thermal-hydraulics, the results reported here were generated using a number of model variations. In most cases, model variations are not expected to change the results or conclusions significantly. Supporting this claim is the observation that the neutron lifetime determined from the analyses ranged from 600 to $1200 \mu \mathrm{s}$. This compares with approximately $100 \mu \mathrm{s}$ for light-water reactors (LWRs). This means that the neutron diffusion length is very large and that results should be relatively insensitive to geometrical changes in the fuel assemblies.

A key characteristic of this type of thermal reactor system is a strong temperature feedback effect due to the Doppler broadening of the uranium resonances that occurs at elevated temperatures. Because of this feature, as the temperature of the fuel increases, the parasitic absorption of neutrons by the fertile component of the fuel increases, which reduces the total reactivity of the system and reduces the power level. The AHTR temperature coefficient was estimated as $-\$ 0.01 /{ }^{\circ} \mathrm{C}$ ( or $6 \times 10^{-5} \mathrm{k} /{ }^{\circ} \mathrm{C}$ ), which is in good agreement with the point design analysis reported for the gas-cooled prismatic NGNP design. ${ }^{1}$

\subsubsection{Coolant Void Coefficient}

An anticipated difference between the ATHR and helium-cooled reactors is the coolant void coefficient of reactivity, since the relevant nuclear cross sections for molten salts are larger than those for helium. The void coefficient corresponds to the amount of reactivity that is added or subtracted by complete removal of the coolant. Since initial AHTR calculations indicated that the void coefficient could be positive or negative depending on the precise design of the core, the focus of the physics analysis effort was to characterize this effect more carefully.

A series of neutronics calculations were conducted to evaluate the coolant void coefficient and to understand its sensitivity to various core parameters. Both ORNL and SNL participated in the physics analysis using slightly different models and assumptions. The results are in good agreement, however. The Monte Carlo N-Particle (MCNP) (version 4C2) code was used for most of the neutronics analyses by both organizations. 
The initial SNL analysis used the core model depicted in Fig. $3.1{ }^{10}$ A 2.54-cm-diam fuel compact was surrounded by six $0.8-\mathrm{cm}$-diam coolant channels in a hexagonal array with a $3.41-\mathrm{cm}$ pitch. The fuel and coolant channels were contained in an annular core region (i.e., the individual hexagonal fuel assemblies were not modeled explicitly). This yielded a 10\% coolant volume fraction and a 50\% fuelcompact volume fraction. The computed void coefficients for total core voiding are given in Table 3.1 for several candidate salts. For salts containing $\mathrm{Li}$, it was assumed that the lithium contained no ${ }^{6} \mathrm{Li}$ isotope.

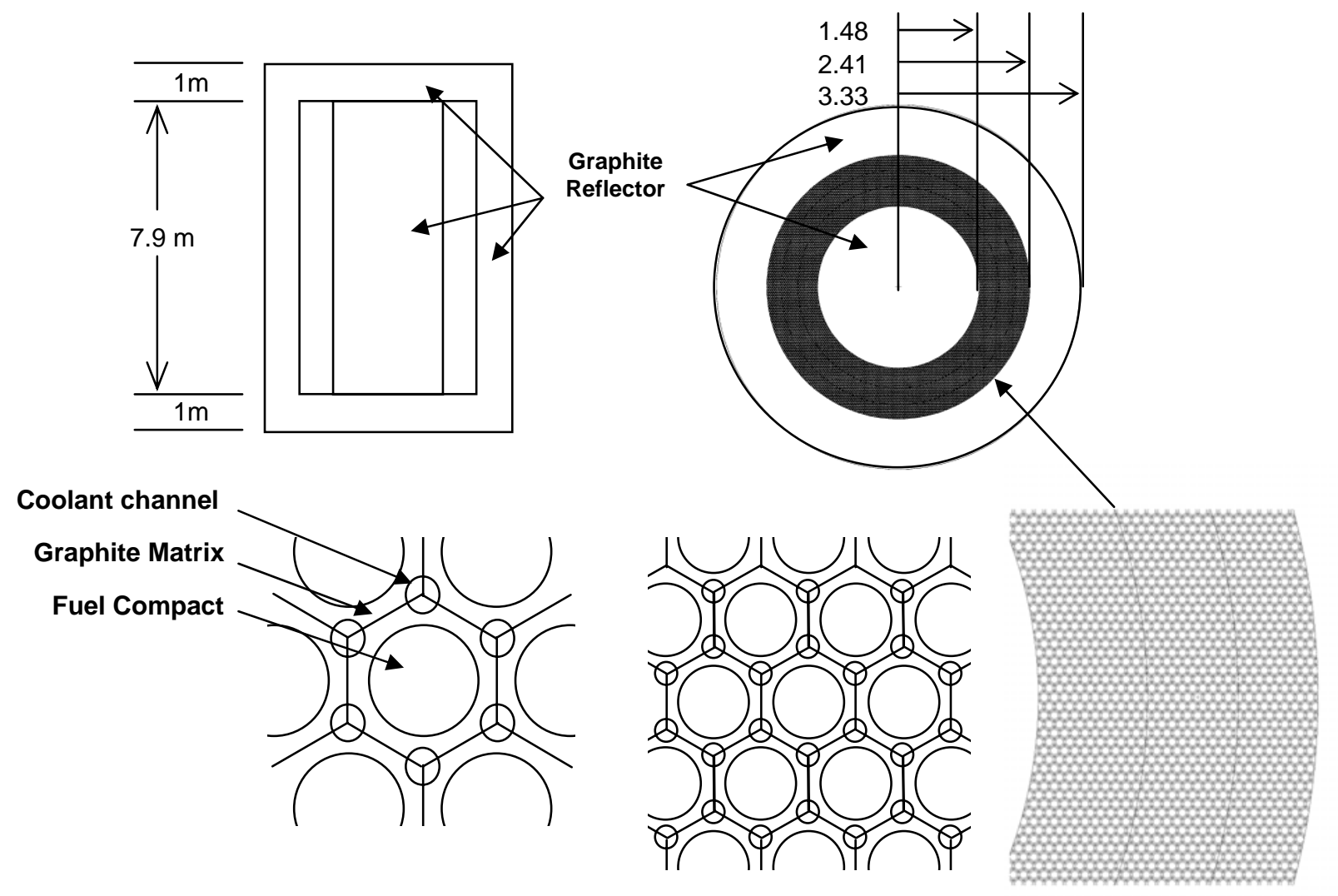

Fig. 3.1. Core model used in initial SNL analysis.

The coolant void reactivity coefficient was first analyzed for a core with a $10 \%$ coolant fraction, a $10 \%{ }^{235} \mathrm{U}$ enrichment, and fuel fractions ranging from $10 \%$ to $50 \%$. The results (Fig. 3.2) show that for fuel fractions less than $\sim 30 \%$, complete voiding of the Flibe coolant from the core could result in a positive reactivity addition. As the fuel concentration is increased to provide more realistic excess reactivity values and longer core burnup times, the relative importance of the absorption and moderation in the Flibe is reversed, and the overall void coefficient is then negative as the uranium-to-carbon atom ratio exceeds approximately 0.05 . For an $\mathrm{NaZrF}_{5}$ salt, the void coefficient is positive for fuel fractions less than $60 \%$.

The void coefficient is inversely correlated with the neutron absorption cross section of the coolant (i.e., reducing the amount of coolant increases reactivity). Since the AHTR operates in a regime where the core is undermoderated, the void coefficient is directly correlated to the coolant's moderating cross section (i.e., reducing the amount of coolant reduces the reactivity). After comparing the capture cross sections for candidate salt constituents in Fig. 3.3 and their scattering cross sections in Fig. 3.4, it is clear 
why salts containing beryllium are preferred (i.e., beryllium has the smallest capture cross section and the largest scattering cross section of all the choices).

Table 3.1. Void coefficient of reactivity for different salt compositions (initial SNL model)

\begin{tabular}{|l|c|}
\hline \multicolumn{1}{|c|}{ Salt } & $\begin{array}{c}\text { Total void reactivity effect } \\
\text { (\$) }\end{array}$ \\
\hline $\mathrm{BeF}_{2}$ & -1.46 \\
$\mathrm{LiF}_{\mathrm{BeF}}(66 / 34)$ & -0.47 \\
$\mathrm{MgF}_{2} / \mathrm{BeF}_{2}(50 / 50)$ & -0.49 \\
$\mathrm{LiF}\left(\mathrm{Li}^{-7}\right)$ & +0.16 \\
$\mathrm{ZrF} / \mathrm{BeF}_{2}(50 / 50)$ & +0.43 \\
$\mathrm{ZrF} / \mathrm{LiF}_{(52 / 48)}$ & +1.25 \\
$\mathrm{NaF} / \mathrm{BeF}_{2}(57 / 43)$ & +1.82 \\
$\mathrm{ZrF}$ & +1.41 \\
$\mathrm{NaF} / \mathrm{ZrF}_{4}(25 / 75)$ & +1.88 \\
$\mathrm{NaF} / \mathrm{ZrF}_{4}(50 / 50)$ & +2.64 \\
$\mathrm{NaF} / \mathrm{ZrF}_{4}(75 / 25)$ & +3.83 \\
$\mathrm{NaF}$ & +7.05 \\
\hline
\end{tabular}




\section{$10 \%$ enriched $U$}

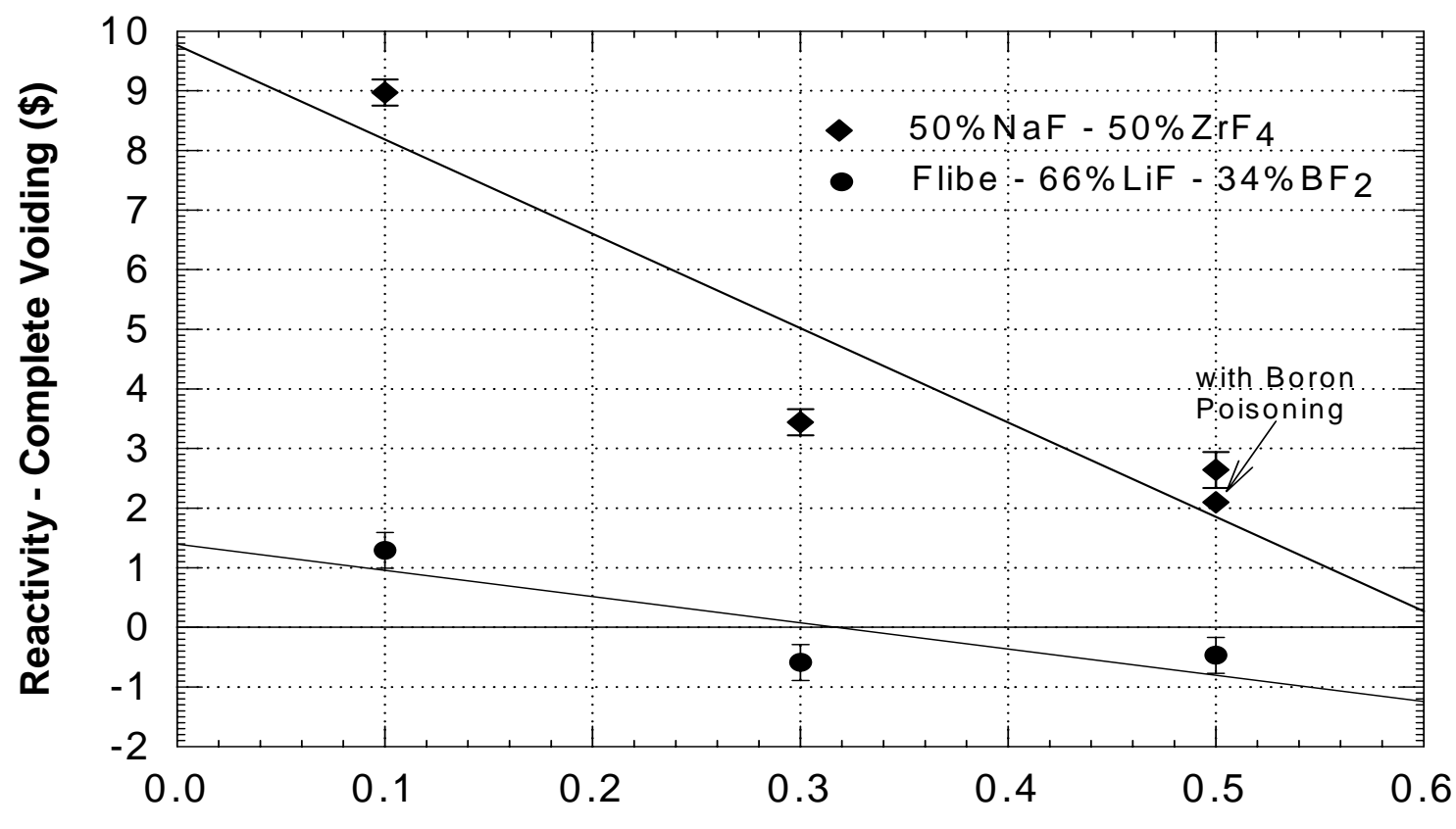

Fuel Volume Fraction

Fig. 3.2. Variation of coolant void coefficient with fuel volume fraction.

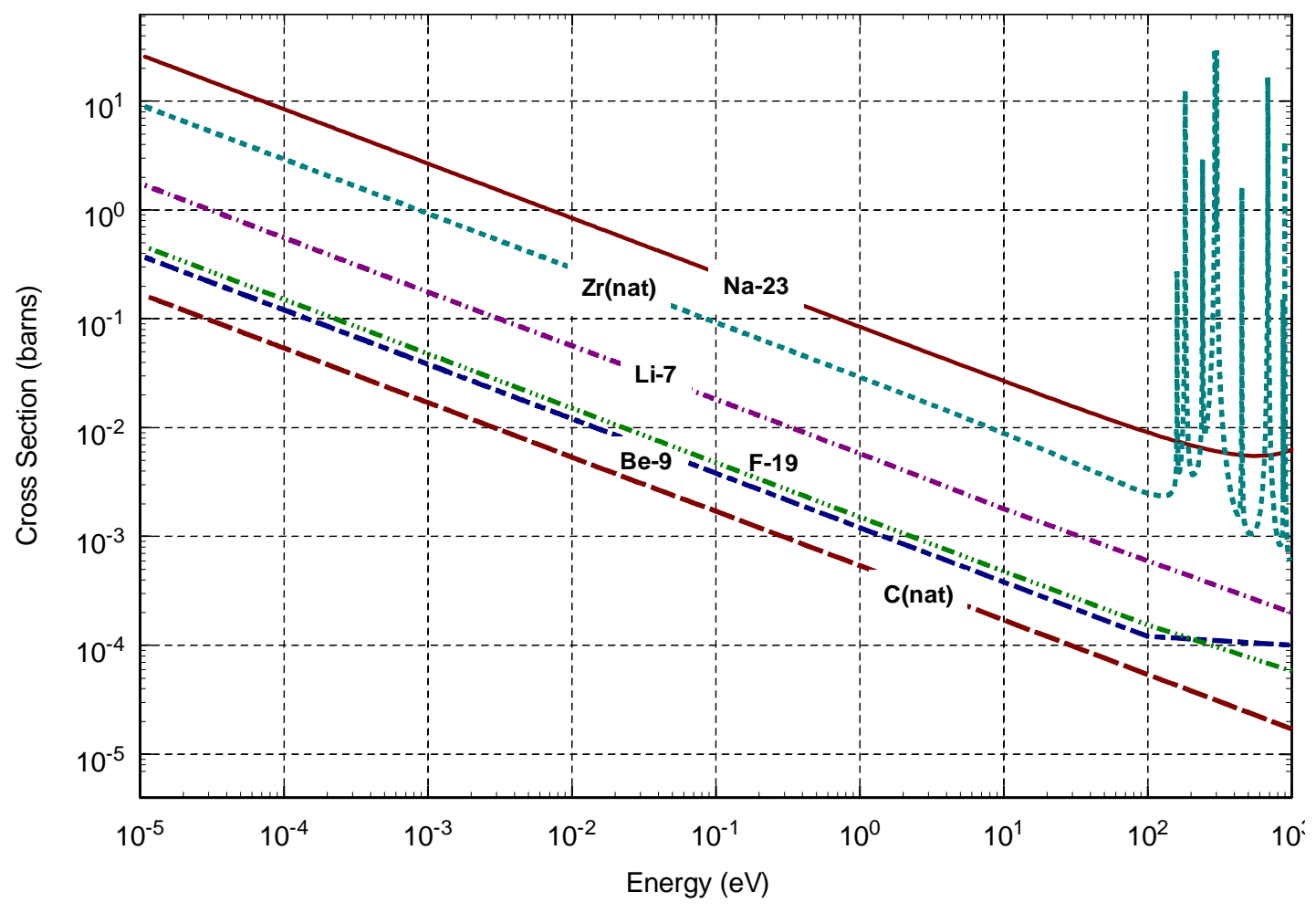

Fig. 3.3. Capture cross section for candidate salt constituents (and carbon). 


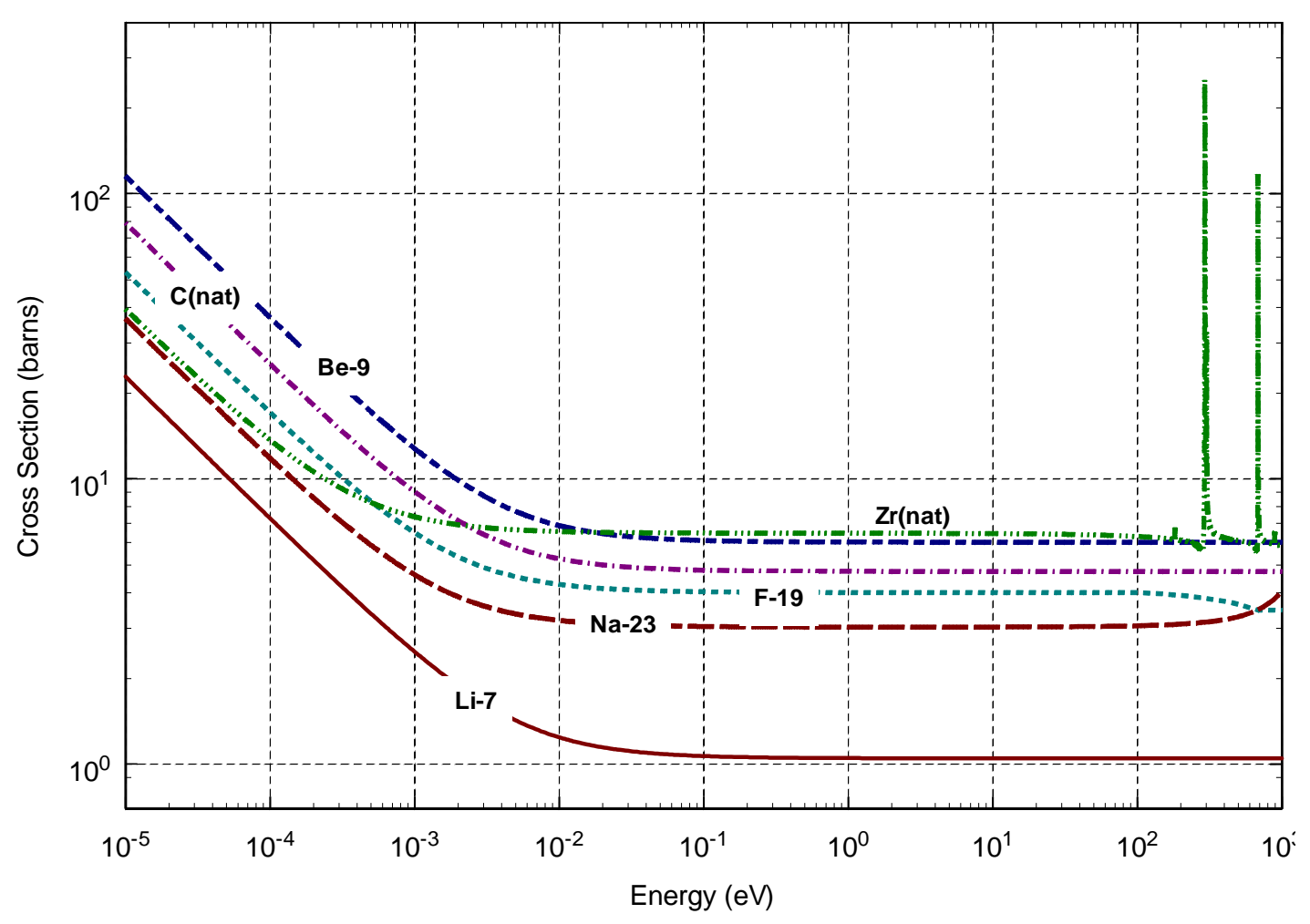

Fig. 3.4. Scattering cross section for candidate salt constituents (and carbon).

The ORNL analysis of the void coefficient used a core geometry that modeled individual prismatic fuel elements as depicted in Fig. 2.4. Table 3.2 lists the key parameters for the detailed ORNL fuel assembly model. The fuel assemblies were formed into a 102-column annular core corresponding to the GT-MHR core model, but with molten salt (Flibe) coolant. The core contained 78 fuel columns and 24 control columns. The focus of the analysis was to explore options for reducing the void coefficient through the use of burnable poisons (BPs) placed either in discrete rods within the fuel assembly or distributed in the graphite blocks. Because the presence of the BP lowers the overall reactivity of the core, the fuel enrichment was increased to $14 \mathrm{wt} \%{ }^{235} \mathrm{U}$ for all cases.

Figure 3.5 shows the result of replacing 14 fuel rods per assembly with europium oxide rods with varying amounts of erbium loading. Increasing the amount of thermal absorber tends to harden the neutron energy spectrum, which reduces the impact of removing the ${ }^{2} \mathrm{LiF}_{-} \mathrm{BeF}_{2}$ coolant. In these calculations, the lithium in the coolant contained $0.01 \%{ }^{6} \mathrm{Li}$. The impact of the $0.01 \%{ }^{6} \mathrm{Li}$ was investigated by removing all ${ }^{6} \mathrm{Li}$ from one of the cases shown in Fig. 3.5, specifically the case with $15 \mathrm{~g}$ erbium per BP rod. For this case, the whole core void coefficient dropped from $\$ 0.98$ to $\$ 0.04$. However, it is difficult to produce lithium with higher than $99.99 \%{ }^{7} \mathrm{Li}$. Reducing the ${ }^{6} \mathrm{Li}$ content by an additional factor of 10 would be highly desirable, but further reduction would not be helpful because of transmutation effects in the reactor that produce ${ }^{6} \mathrm{Li}$ from beryllium during normal operation (discussed in Sect. 4.5).

ORNL also studied the impact on the void coefficient of distributing a BP uniformly within the prismatic graphite that forms the fuel assemblies and reflector blocks. Again using the case of 14 erbium rods per fuel assembly with $15 \mathrm{~g}$ erbium per rod, adding 5.0 weight-ppm natural boron to the graphite was observed to drop the void coefficient from $\$ 0.98$ to $\$ 0.80$. Adding 40.0 weight-ppm erbium to the graphite, instead of the boron, yielded a void coefficient of $\$ 0.85$. The analysis demonstrates that the positive void coefficient can be reduced by increasing the BP loading in the core. Disadvantages of doing this are increased fuel cycle costs and an increasing void coefficient with burnup due to burnout of the poison. 


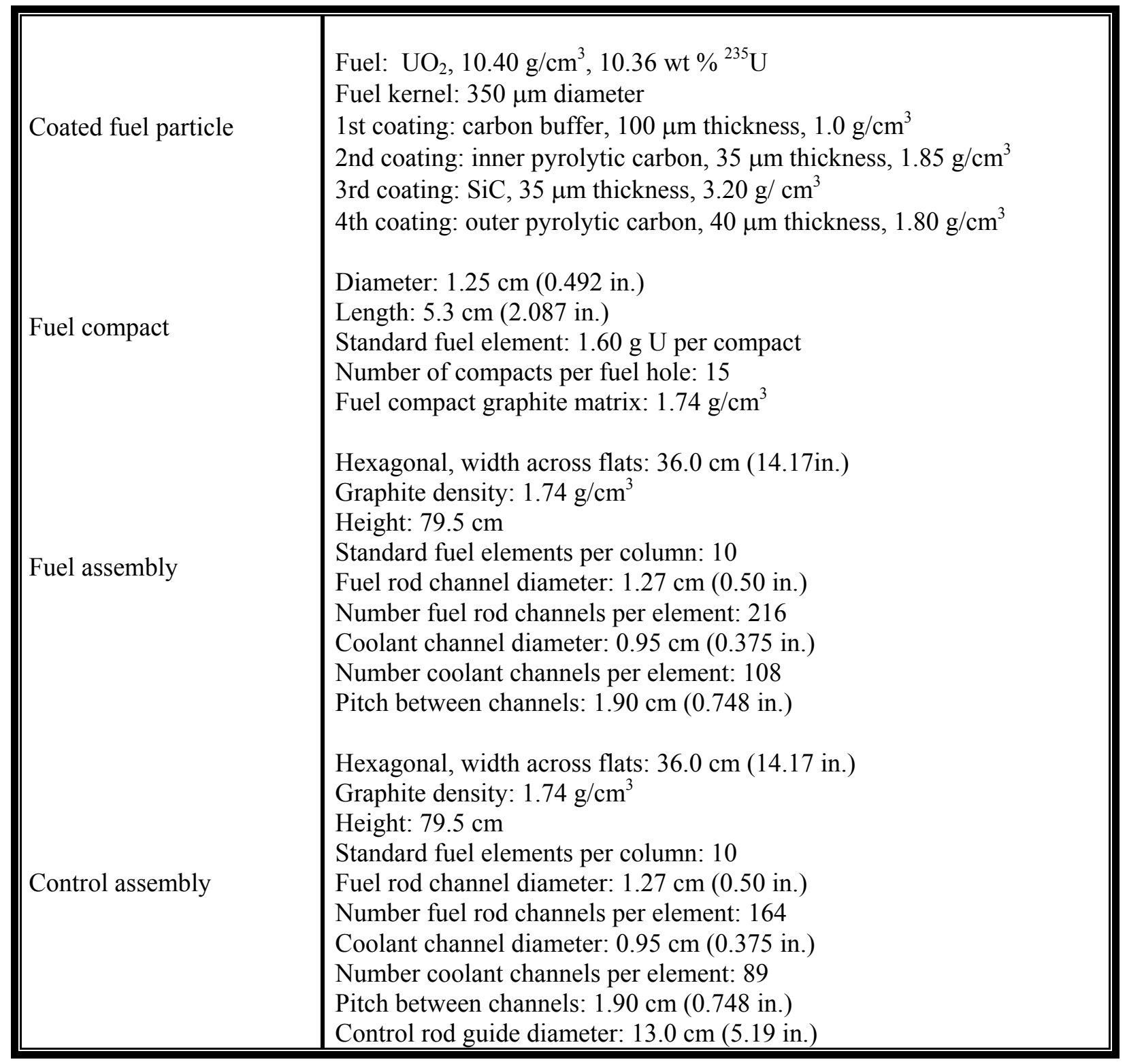




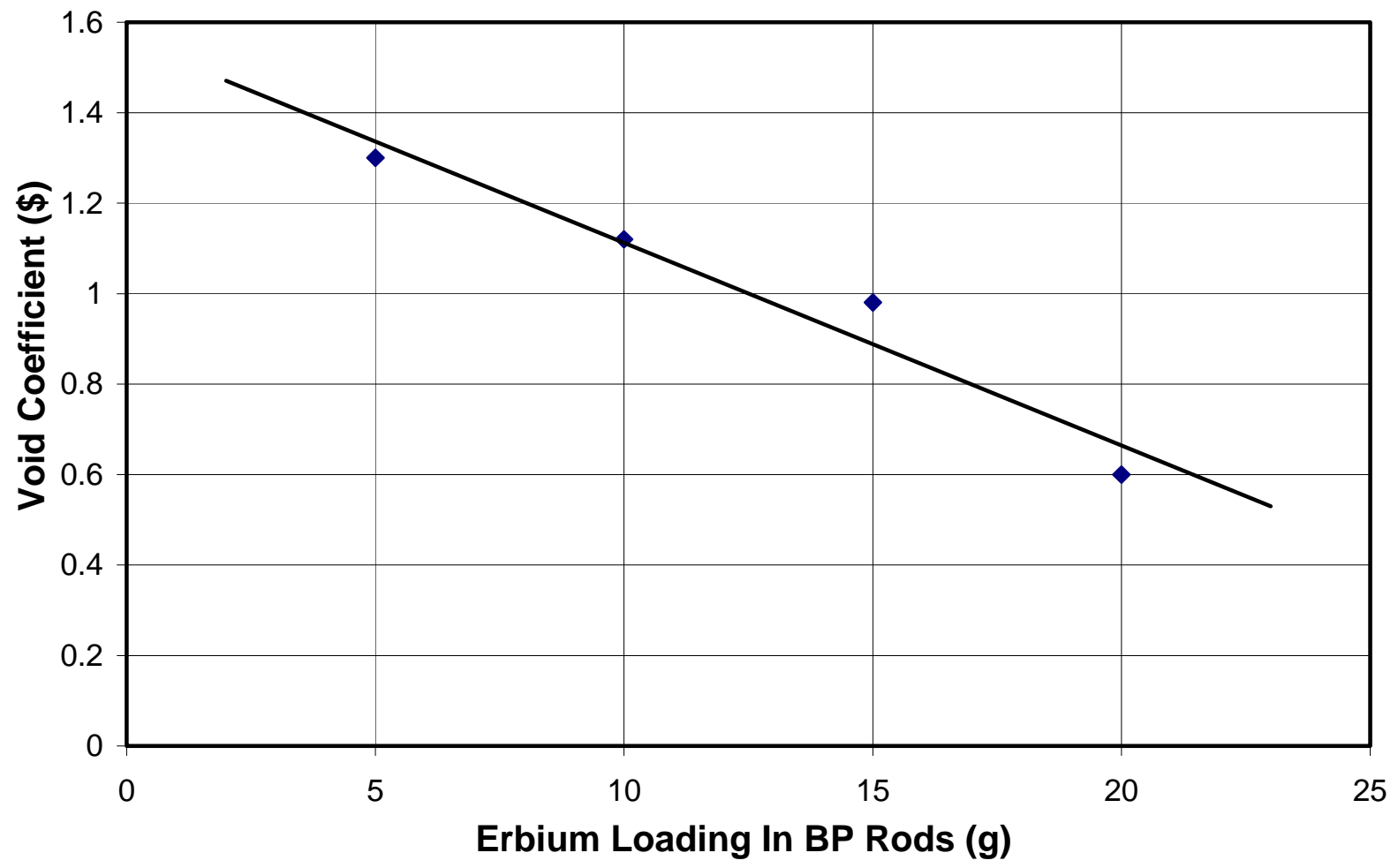

Fig. 3.5. Sensitivity of void coefficient (whole core voiding) on erbium loading in BP rods (14 per assembly).

Updated neutronics analyses were performed at SNL to better match the reference AHTR geometry and fuel/coolant fractions. As before, the fuel type was TRISO-coated particle fuel with a particle packing fraction of $30 \%$ in the fuel compacts. All of the calculations were performed with $1200 \mathrm{~K}$ neutron crosssections, and the thermal scattering function, $\mathrm{S}(\alpha, \beta)$, was also used at $1200 \mathrm{~K}$ for the carbon in the fuel compacts and prismatic matrix.

Two geometric configurations were used: (1) the reference AHTR configuration with a separate coolant channel surrounded by six fuel element channels on a 1.9-mm triangular pitch and (2) a configuration in which each coolant channel is surrounded by an annular fuel compact. The coolant channel diameter was $0.953 \mathrm{~cm}$ and the coolant fraction was $7.6 \%$ for all of the calculations. The fuel fraction varied in the calculations, with the standard configuration having a fuel fraction of $26.9 \%$. The standard AHTR configuration and revised annular fuel model are shown in Fig. 3.6.

Two salts were used in the analysis: Flibe- $66 \% \mathrm{LiF}$ and $34 \% \mathrm{BeF}_{2}$ with a density of $1.82 \mathrm{~g} / \mathrm{cm}^{3}$, and $50 \% \mathrm{NaF}$ and $50 \% \mathrm{ZrF}_{4}$ with a density of $2.906 \mathrm{~g} / \mathrm{cm}^{3}$. The Flibe analyses were performed for two cases - either $0.01 \%{ }^{6} \mathrm{Li}$ or pure ${ }^{7} \mathrm{Li}$. Uranium enrichments were varied from 5 to $20 \%$, with $10 \%$ enrichment set as the standard. The core was modeled as an annular cylinder $7.93 \mathrm{~m}$ in height, $3.72 \mathrm{~m}$ outer radius, and $1.48 \mathrm{~m}$ inner radius. The inner region of the core is graphite. An external $0.78-\mathrm{m}$-thick reflector of graphite yielded a total diameter of the reactor of $9.0 \mathrm{~m}$. A 1.0-m-thick axial graphite reflector was at the top and bottom of the core. 

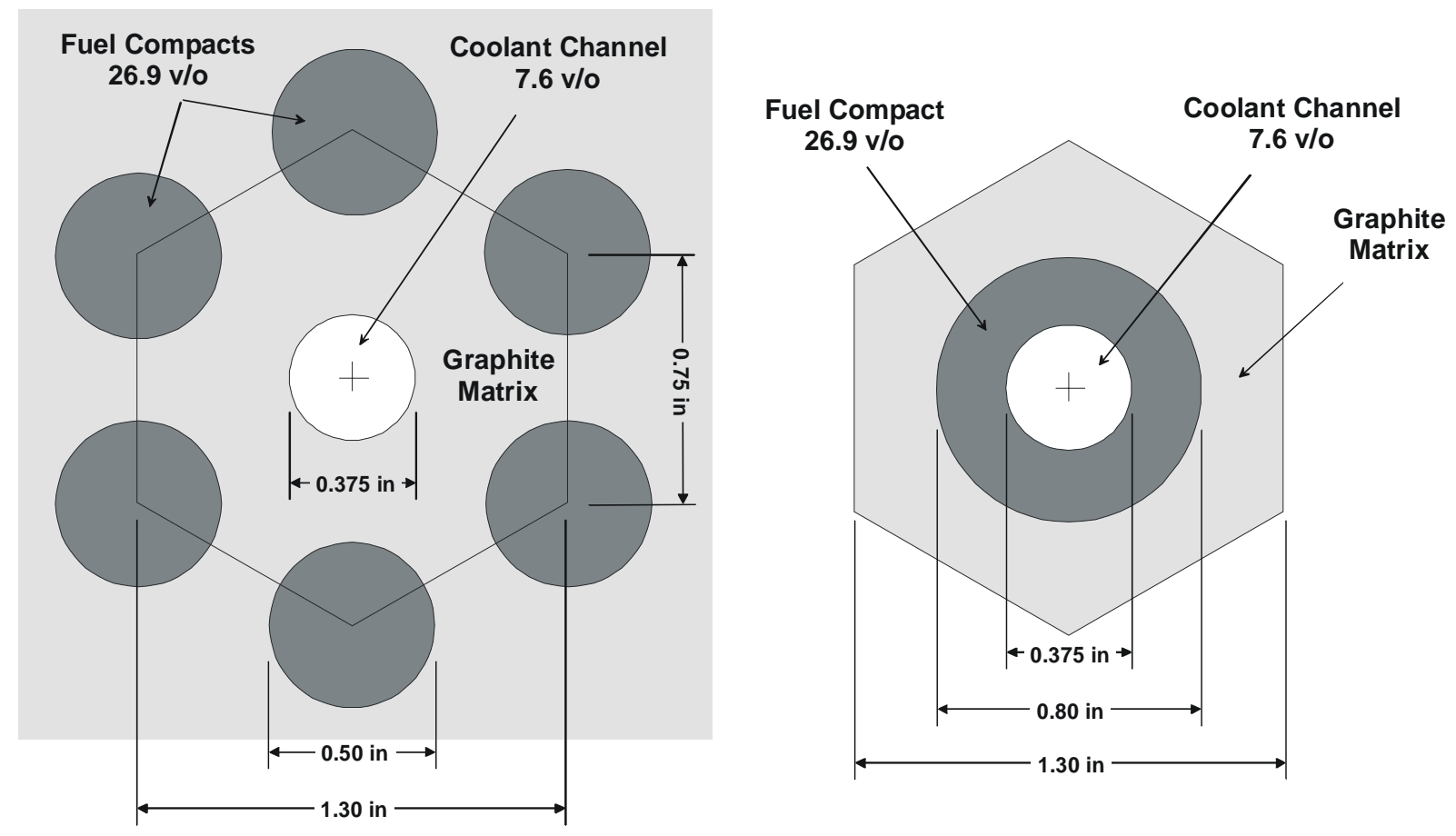

Fig. 3.6. SNL model of the reference AHTR fuel/coolant geometry (left) and a revised annular fuel geometry (right).

As shown in Fig. 3.7, $\mathrm{k}_{\text {eff }}$ is shown to increase significantly with lower fuel fractions. This is because the core is undermoderated, and increasing the carbon-to-uranium $(\mathrm{C} / \mathrm{U})$ ratio increases the moderation. For a pure carbon moderator with no poison, an overmoderated condition will never be attained. An increasing $\mathrm{k}_{\text {eff }}$ with lower fuel fraction does not mean that the burnup core lifetime is larger. In fact, there is typically a value for fuel fraction (for a given enrichment) where the burnup time is maximized. This level of optimization has not been studied yet, but it is expected that the optimum will occur near the value used for the standard configuration (i.e., around 0.3).

The void coefficient results for the updated reference AHTR model are shown in Fig. 3.8 and are similar to the initial SNL results. For the coolant fraction of $7.6 \%$ and an enrichment of $10 \%$, a negative void reactivity effect can be attained for a fuel fraction greater than $\sim 0.25$ for pure ${ }^{7} \mathrm{Li}$ Flibe and greater than $\sim 0.5$ for Flibe with $0.01 \%{ }^{6} \mathrm{Li}$ content. Increasing the fuel enrichment allows for slightly lower void reactivity effects, as also shown in Fig. 3.8.

Calculations for the standard configuration at $10 \%{ }^{235} \mathrm{U}$ enrichment with natural boron in the fuel were made to determine BP effects on reactivity. At a fuel fraction of 0.268 , no change in the reactivity effects were found for the Flibe $\left(0.01 \%{ }^{6} \mathrm{Li}\right)$ or the $\mathrm{NaF} / \mathrm{ZrF}_{4}$ salts. A concentration of $0.00007 \mathrm{~g} / \mathrm{cm}^{3}$ of ${ }^{10} \mathrm{~B}$ in the fuel compact was enough to make $\mathrm{k}_{\text {eff }}$ near 1.0. This value is about 14 times more than the quantity of ${ }^{6} \mathrm{Li}$ in the core.

Arranging the configuration in an annular geometry with the same coolant fraction and fuel fraction was not found to be helpful in decreasing the void reactivity effect. In fact, slightly more positive effects are found, although the results were within two standard deviations of each other. It is unclear as to why the effects could be slightly more positive. 


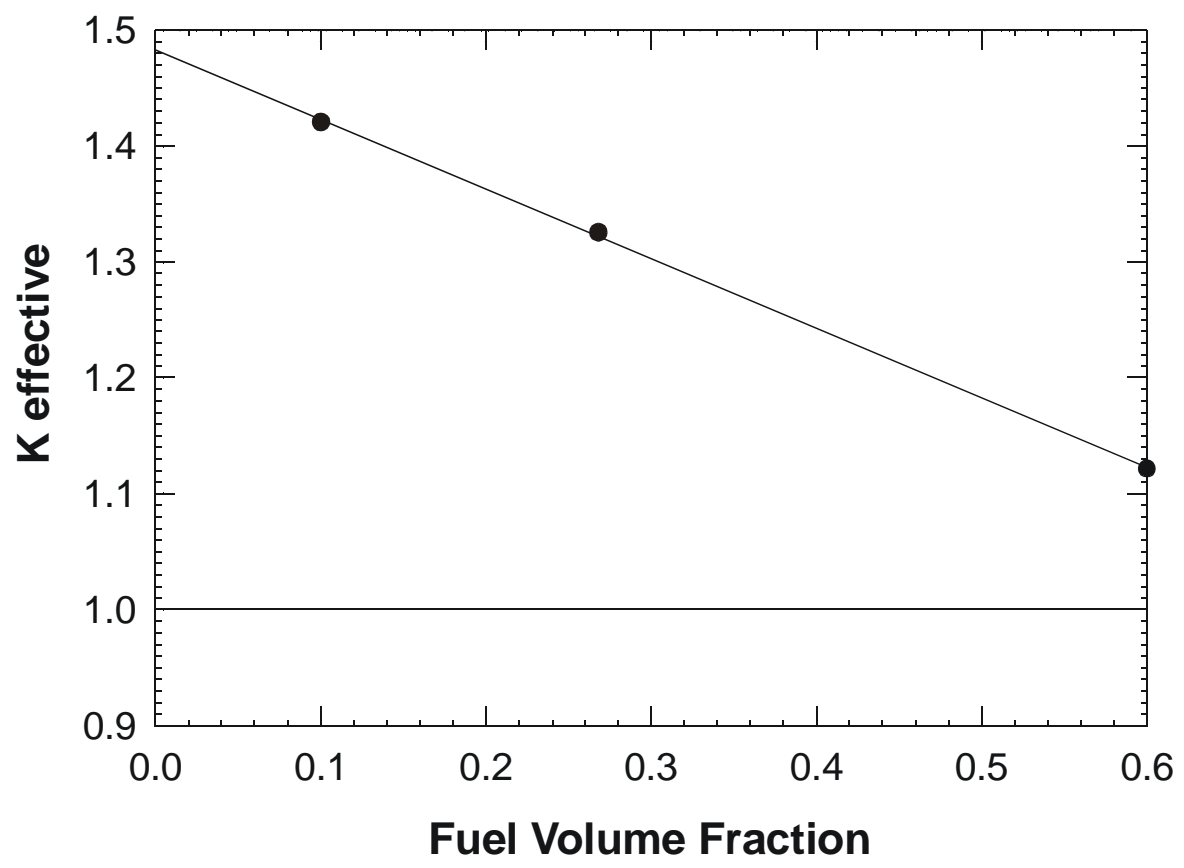

Fig. 3.7. Variation of $k_{\text {eff }}$ with fuel fraction for reference AHTR core model.

Several design options exist that can help to lower the coolant void coefficient, and these will need to be explored further. Fortunately, the intrinsic characteristics of the prismatic core design allow the volume fraction of the fuel, coolant, and moderator to be independently varied. The use of discrete or distributed BPs is expected to reduce the void coefficient, as well as geometry changes. Earlier versions of the Canadian power reactors (heavy water moderated) and U.S. production reactors (graphite moderated) had positive coolant void coefficients. With more advanced fuel designs, the Hanford-N reactor was able to achieve a negative void coefficient, and the advanced CANDU design is projected to also have a negative void coefficient. Similar design approaches will be evaluated for the AHTR.
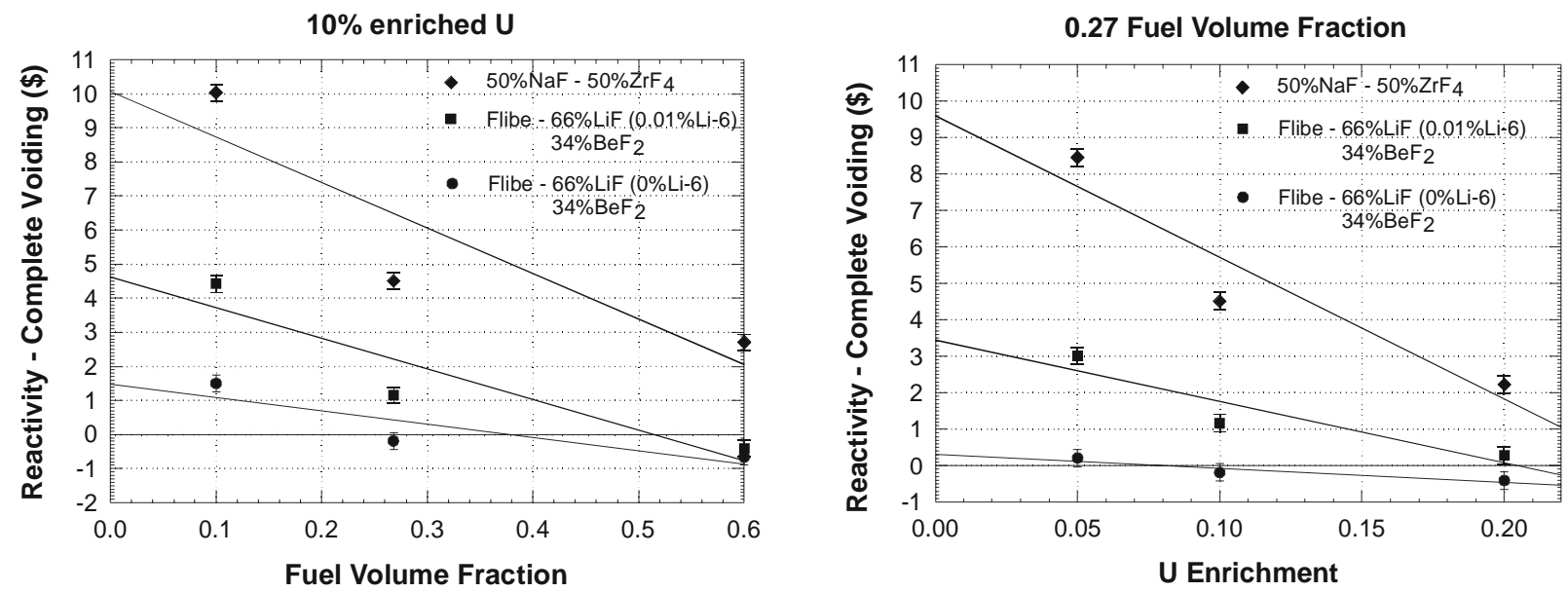

Fig. 3.8. Sensitivity of void coefficient to fuel fraction (left) and uranium enrichment (right). 


\subsubsection{Core Transient Behavior}

Even though a positive void coefficient was predicted for whole-core voiding in some of the designs studied, it was expected that the large negative temperature coefficient would act to mitigate transients in the reactor core and would limit power excursions. Figure 3.9 shows a result for the transient behavior of the core for the case of an instantaneous reactivity addition of $+\$ 0.4$. This would be similar to the effect of voiding $\sim 20 \%$ of a core cooled with $\mathrm{NaF} / \mathrm{ZrF}_{4}$ salt, which has the largest void coefficient. The core temperature feedback balances the reactivity addition, and a new steady-state core temperature is achieved. The assumption here is that the core continues to be cooled at a rate that removes $2400 \mathrm{MW}$ of thermal power. The large negative Doppler coefficient $\left(\$-0.01 /{ }^{\circ} \mathrm{C}\right)$ combined with large margins to fuel failure allows the reactor core to survive such transients without the need for an active core protection system, and the large heat capacity of the core and the coolant inventory result in a relatively slow transient.

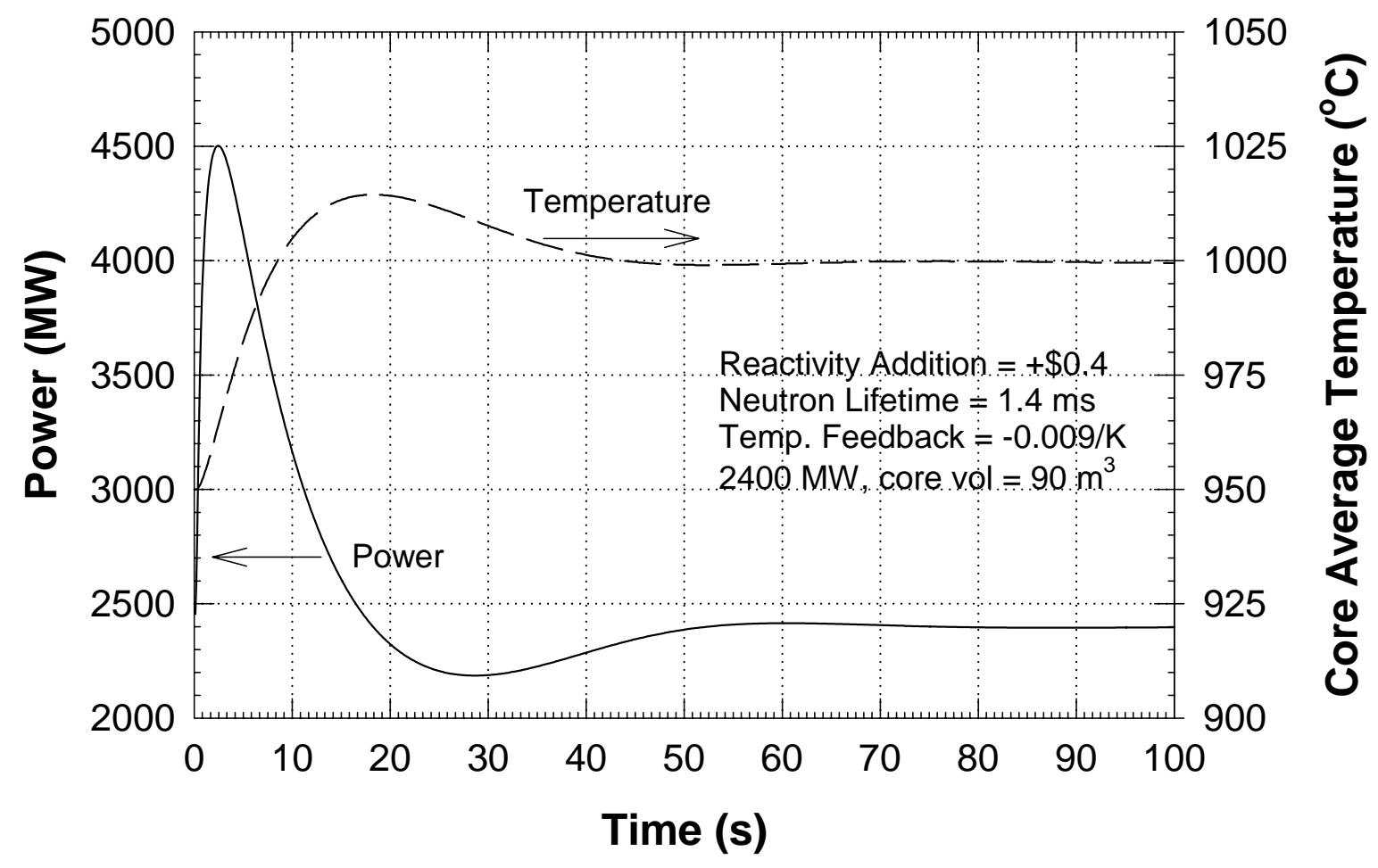

Fig. 3.9. Thermal power and average core temperature following a $\$ 0.4$ reactivity insertion.

\subsubsection{Fuel Burnup}

Burnup calculations were performed for the reactor for the standard $2400 \mathrm{MW}(\mathrm{t})$ configuration with $10 \%$ enriched and $20 \%$ enriched fuel. The calculations were made by having an inner, middle, and outer core with equal volumes. The first curve, starting at $\mathrm{t}=0$, represents the initial core loading with fresh $10 \%$ or $20 \%$ enriched fuel. When $\mathrm{k}_{\text {eff }}$ approached 1.0, the fuel was shuffled, with fresh fuel placed in the outer core region, the outer region moved to the middle region, and the middle region moved to the inner region. This was repeated several times so that an "equilibrium" state resulted. Anomalies in the shapes of the curves are due to the rather coarse statistics used in the MCNP calculations. 
The results, shown in Figs. 3.10 and 3.11, indicate that the $290-\mathrm{m}^{3}$ core at $2400 \mathrm{MW}(\mathrm{t})$ would have a burnup cycle of $\sim 330$ days ( 990 days total core lifetime) for 10\% enriched fuel and $\sim 510$ days (1530 days total core lifetime) for $20 \%$ enriched fuel. These fuel reloading times are similar to those of an LWR.

Void reactivity effect calculations were performed for the cores near the end of the burnup cycle to determine the effect of the lower ${ }^{235} \mathrm{U}$ content and larger fission product inventory. The results showed that the void reactivity was about the same value as for the fresh core configurations.

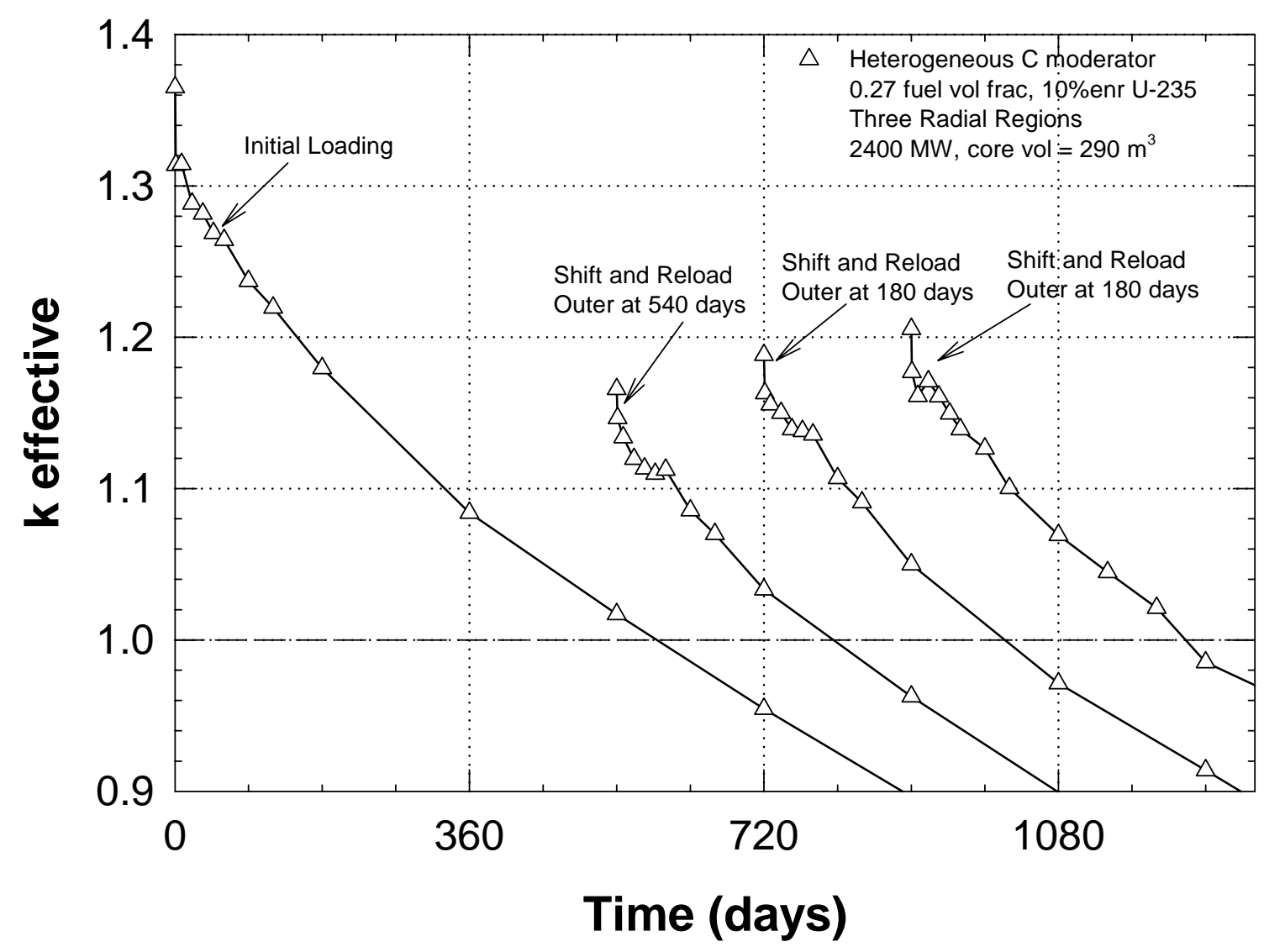

Fig. 3.10. Fuel burnup predictions for $10 \%{ }^{235} \mathrm{U}$ enriched core. 


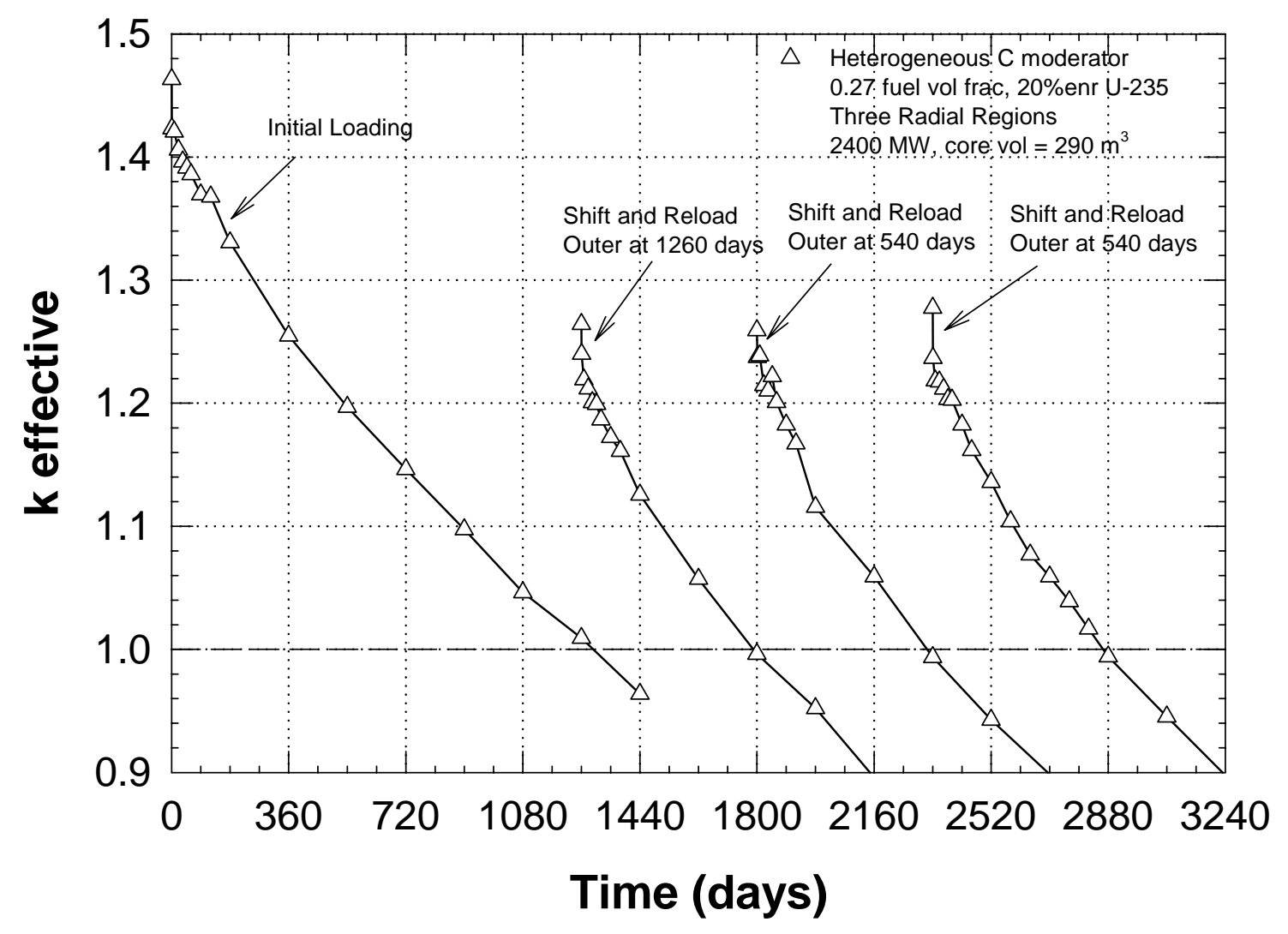

Fig. 3.11. Fuel burnup predictions for $20 \%{ }^{235} \mathrm{U}$ enriched core.

\subsection{THERMAL-HYDRAULICS ANALYSIS}

It is anticipated that the superior heat capacity and transport properties of molten salts relative to helium should yield significantly better plant performance, including increased total power output, reduced temperature gradients, lower pumping powers, and cooler fuel temperatures. Initial thermalhydraulics analyses of the AHTR support these expectations.

An initial thermal-hydraulics analysis was performed using simplified mass/energy balance equations. The method was first used to analyze both the GT-MHR and the prismatic NGNP designs and compared with more rigorous results reported by Idaho National Energy and Engineering Laboratory (INEEL). ${ }^{1}$ The simplified method showed excellent agreement with the INEEL results. Figure 3.12 compares curves generated with our method compared with data points corresponding to the INEEL analysis. The method was then used to analyze both a $600 \mathrm{MW}(\mathrm{t})$ and a $2400 \mathrm{MW}(\mathrm{t})$ AHTR design for a range of coolant channel diameters and core inlet temperatures. In all cases, the core outlet temperature was fixed at $1000^{\circ} \mathrm{C}$, corresponding to the NGNP functional requirement.

Figure 3.13 shows the variation of pumping power as a function of the coolant channel diameter and the core inlet temperature. Based on power conversion considerations, a core inlet temperature of $900^{\circ} \mathrm{C}$ appeared desirable, and based on the curves in Fig. 3.13, a coolant channel diameter of $0.95 \mathrm{~cm}$ was selected. This channel diameter yields a coolant volume fraction of $6.7 \%$ and a pumping power of $716 \mathrm{~kW}$. Figure 3.14 shows a comparison of the axial temperature distribution in the hot channel for the $2400 \mathrm{MW}(\mathrm{t})$ AHTR and the $600 \mathrm{MW}(\mathrm{t})$ prismatic gas-cooled NGNP. The figure shows distributions for both the coolant channel centerline and the fuel compact centerline. Note that in the AHTR, the peak fuel temperature is more than $100^{\circ} \mathrm{C}$ cooler than for the NGNP. 


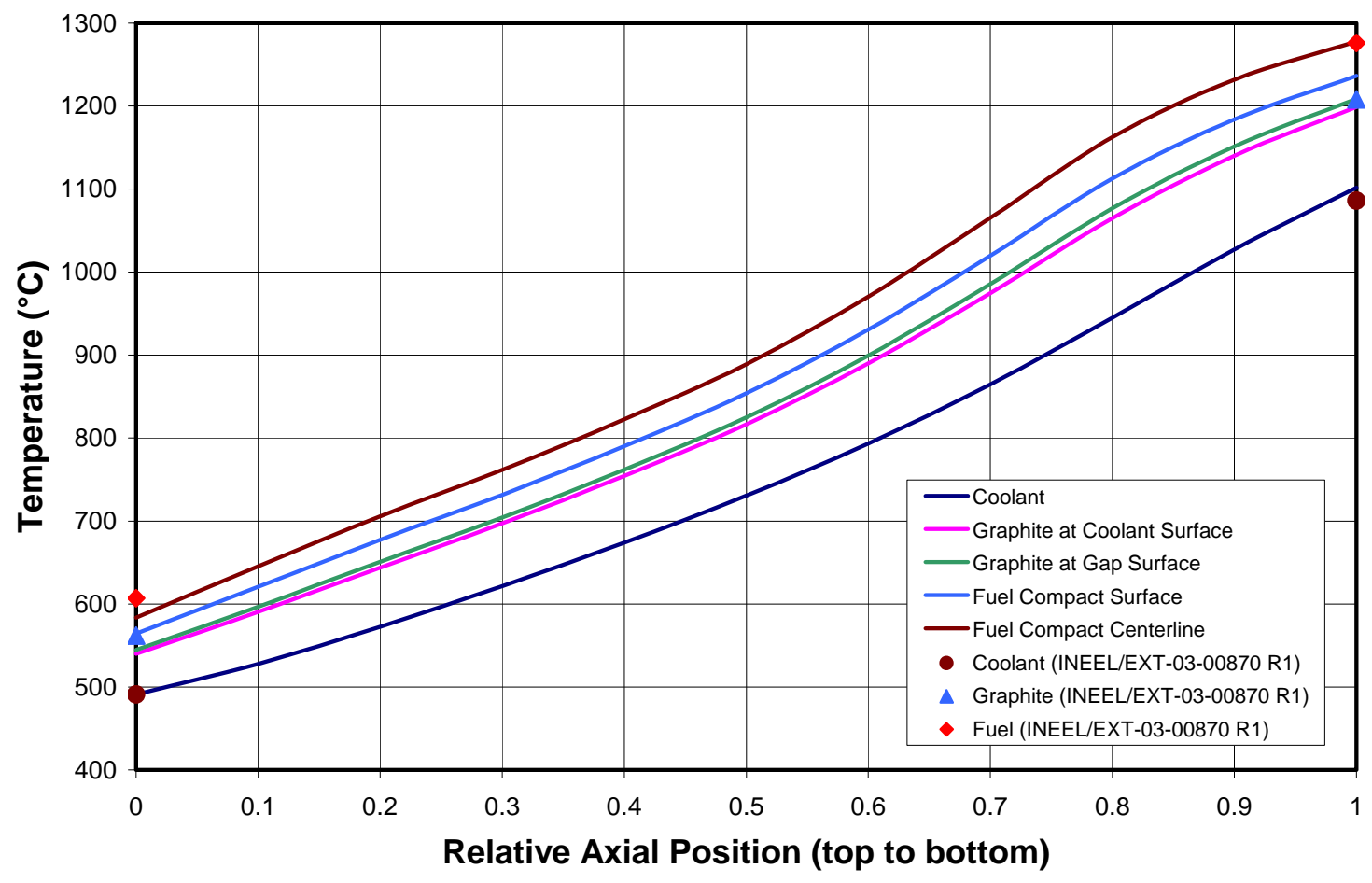

Fig. 3.12. Comparison of ORNL (lines) and INEEL (points) calculations of hot channel temperatures for 600 MW helium-cooled NGNP design.

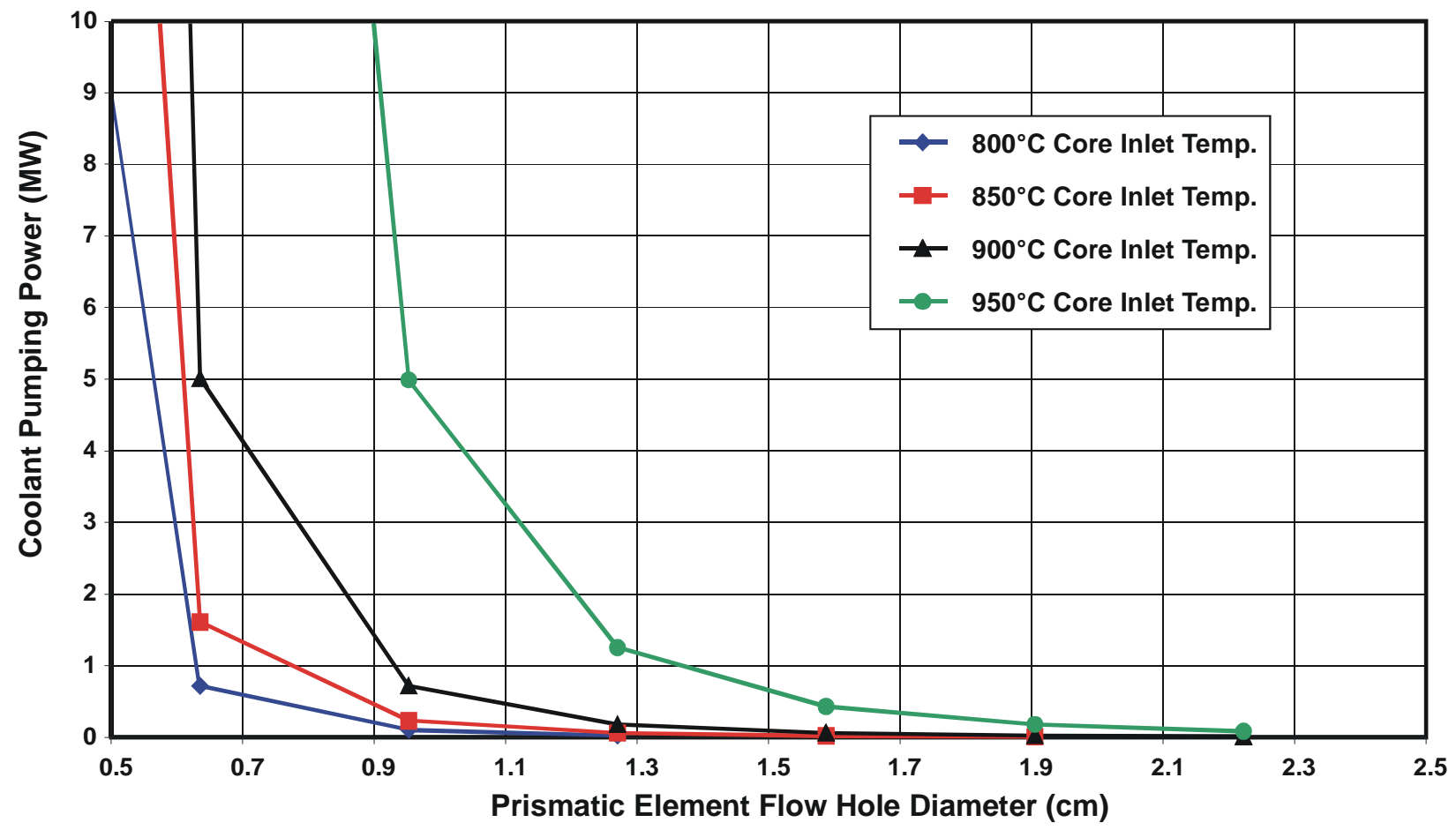

Fig. 3.13. Pumping power as function of coolant channel size and core inlet temperature. 


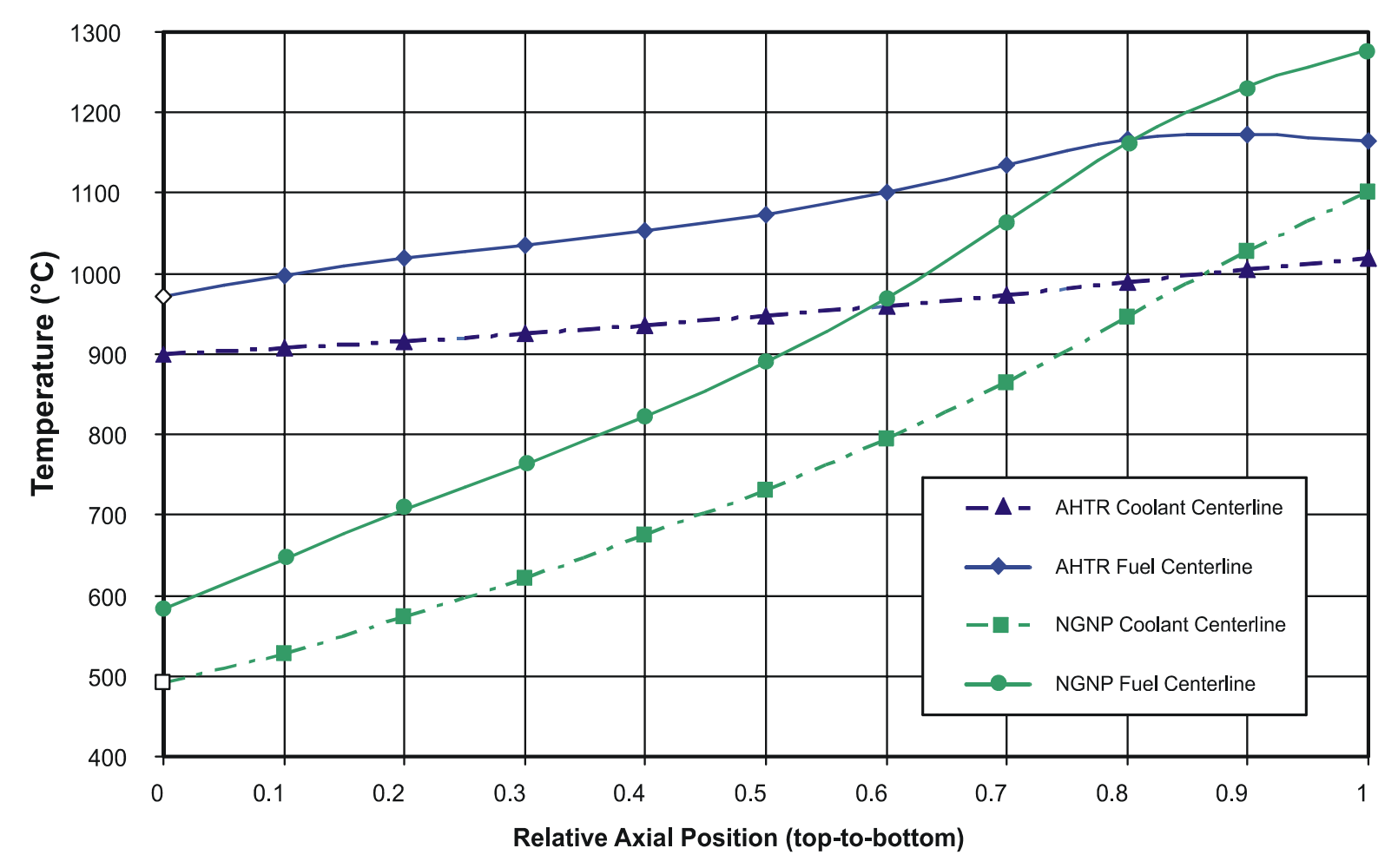

Fig. 3.14. Axial temperature profiles in hot channel of 600 MW(t) NGNP and 2400 MW(t) AHTR.

A one-dimensional heat transfer calculation was also performed from the centerline of the coolant channel to the centerline of the fuel compact for the average channel at the outlet of the core. For this configuration, the coolant temperature was fixed at $1000^{\circ} \mathrm{C}$. The NGNP result is given in Fig. 3.15, compared with the same distribution for a $600 \mathrm{MW}(\mathrm{t})$ and a $2400 \mathrm{MW}(\mathrm{t})$ AHTR. In all cases, the narrow gap between the fuel compact and the graphite matrix is assumed to be filled with helium. These curves show that for the average channel, the $2400 \mathrm{MW}(\mathrm{t})$ AHTR fuel temperature will be at least $30^{\circ} \mathrm{C}$ cooler than that of the helium-cooled NGNP. 


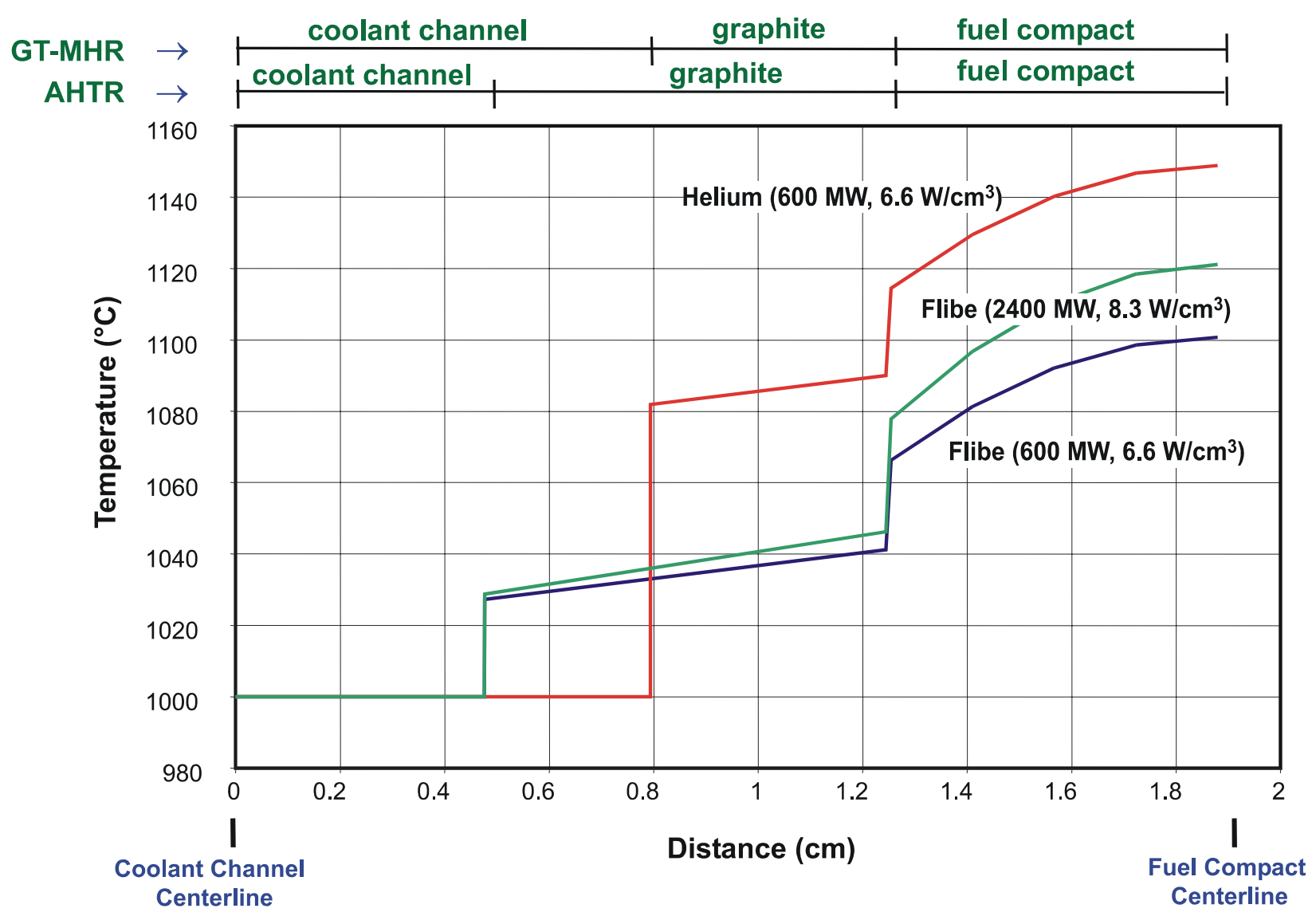

Fig. 3.15. Radial temperature profiles from coolant channel centerline to fuel compact centerline for average temperature channel.

\subsection{DECAY HEAT REMOVAL ANALYSIS}

Passive safety is a key functional requirement for the NGNP plant, which requires adequate decay heat removal via passive systems (i.e., systems that do not require operator action). The reference AHTR design uses an air-cooled RVACS similar to that in the S-PRISM design (see Fig. 2.10). The AHTR reactor and RVACS were modeled using the Graphite Reactor Severe Accident Code (GRSAC), ${ }^{11}$ which contains a 3000-node 3-D thermal-hydraulics approximation for the core. GRSAC was developed for gascooled reactor simulations, and it required some modifications and approximations in order to account for the different thermodynamic properties of the molten salt coolant relative to helium. Although the AHTR may include a DRACS to augment the RVACS heat removal and reduce peak vessel temperatures, it was not included in this decay heat analysis.

A loss-of-forced-cooling (LOFC) with scram accident was simulated to determine the peak core and vessel temperatures and the amount of decay heat that could be removed using the passively safe RVACS. Figure 3.16 compares the total heat removal capacity of the RVACS and the amount of decay heat generated as a function of time after the start of the accident and shows that the RVACS capacity exceeds the decay heat at $40 \mathrm{~h}$ into the transient. For this transient, the peak core temperature is $\sim 1160^{\circ} \mathrm{C}$ and occurs at approximately $30 \mathrm{~h}$ (Fig. 3.17). As shown in Fig. 3.18, the maximum vessel temperature occurs at $45 \mathrm{~h}$ at a value of $\sim 750^{\circ} \mathrm{C}$. Large coolant recirculation flows develop in the core, with most of the downflow occurring in the inner and outer reflector regions and most of the upflow occurring in the fueled annulus. A typical temperature differential between the inlet and outlet regions of the core was 
observed to be $\sim 50^{\circ} \mathrm{C}$, and with the significant natural circulation flow, the molten salt pool would achieve a relatively uniform temperature distribution.

These preliminary results indicate that with passive RVACS cooling and a coolant boiling temperature of $1430^{\circ} \mathrm{C}$, there will be a considerable safety margin for an LOFC accident. An additional calculation performed by UCB for a $4000 \mathrm{MW}(\mathrm{t})$ core yielded a peak core temperature of $1325^{\circ} \mathrm{C}$, still more than $100^{\circ} \mathrm{C}$ below the salt boiling limit. These transient response calculations confirm early scaling analyses that predicted passive safety characteristics because of the very large thermal inertia of the AHTR. ${ }^{12}$

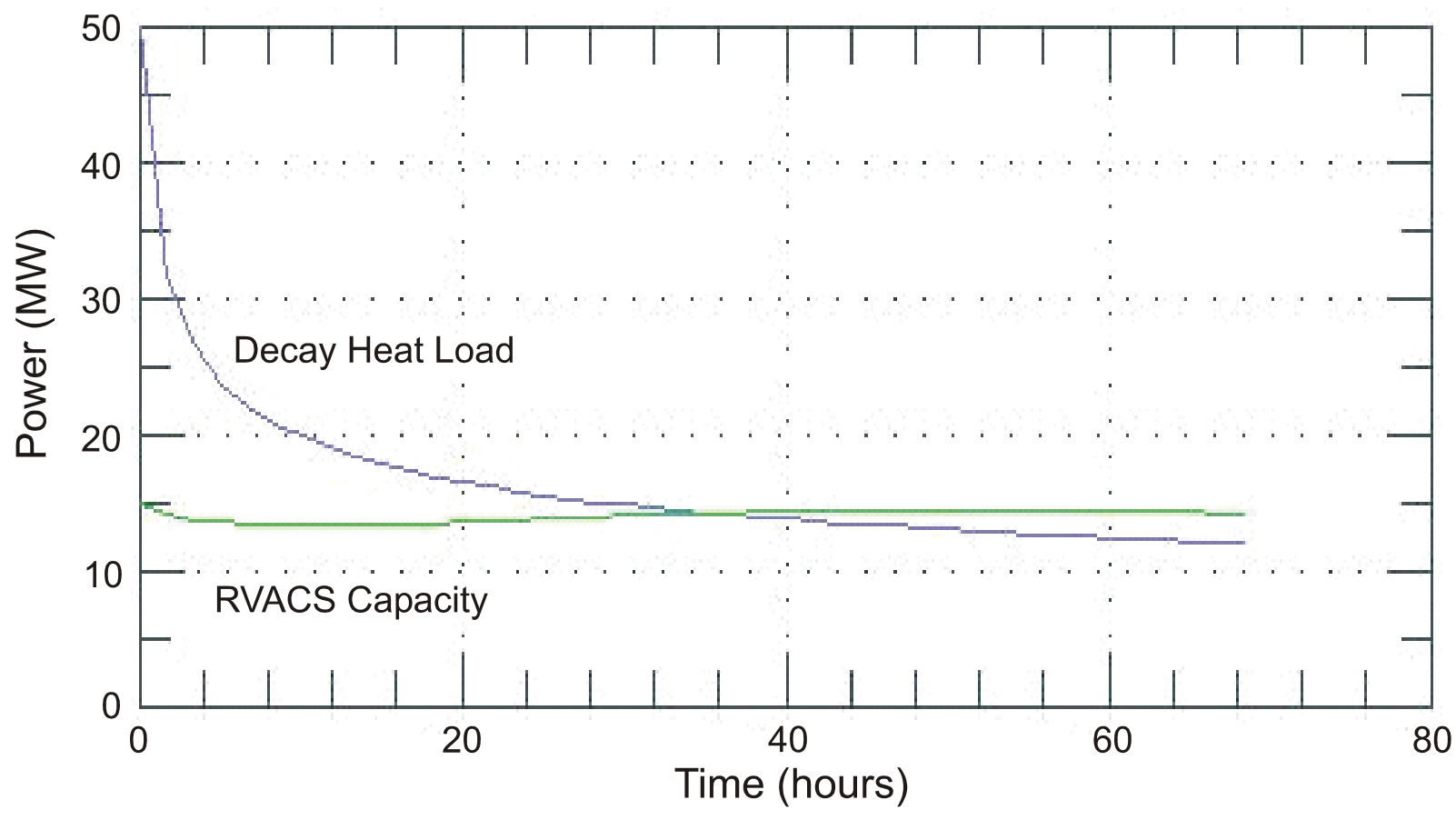

Fig. 3.16. Comparison of RVACS heat removal capacity and heat load generated after an LOFC accident (with scram). 


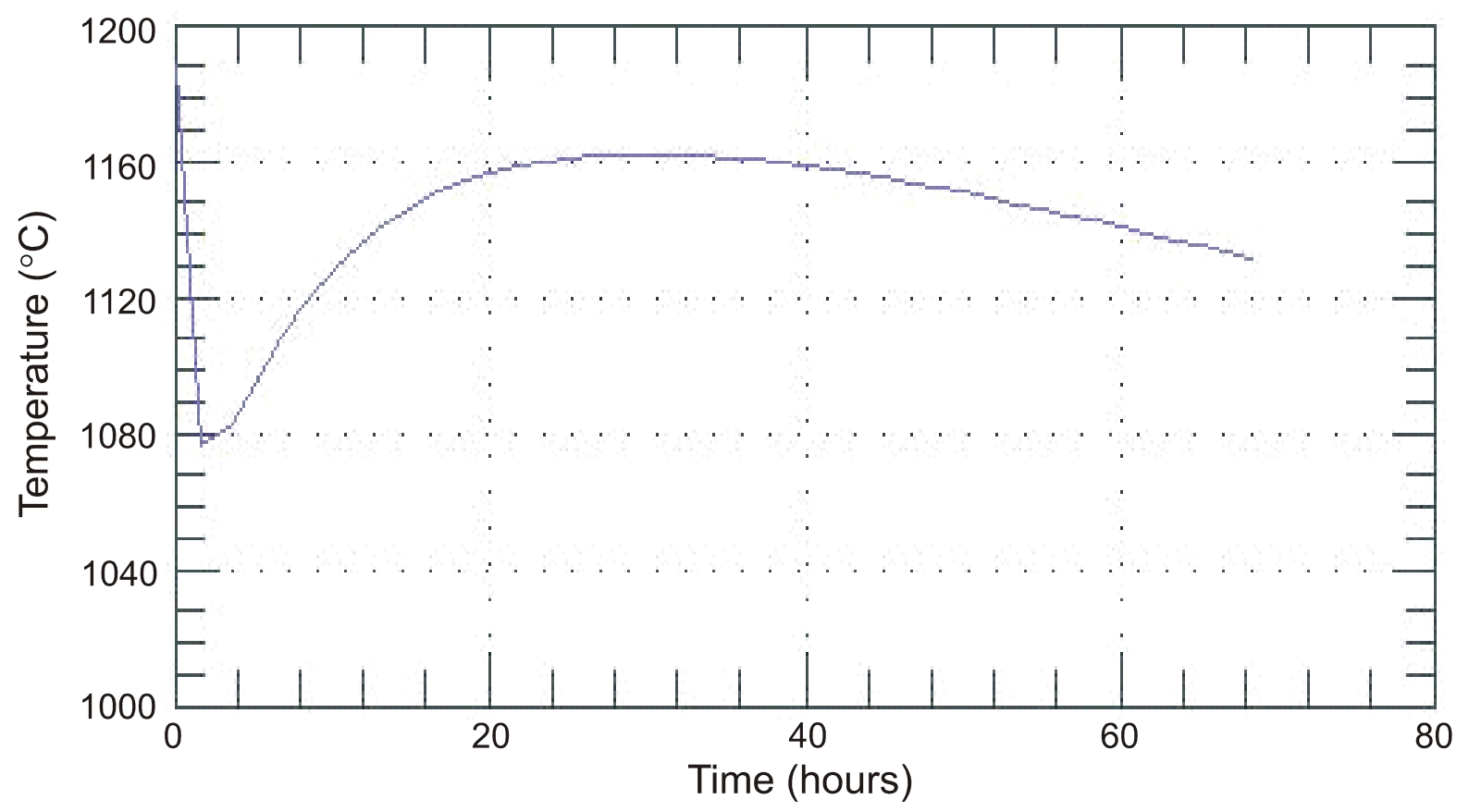

Fig. 3.17. Maximum core temperature as a function of time after an LOFC accident (with scram).

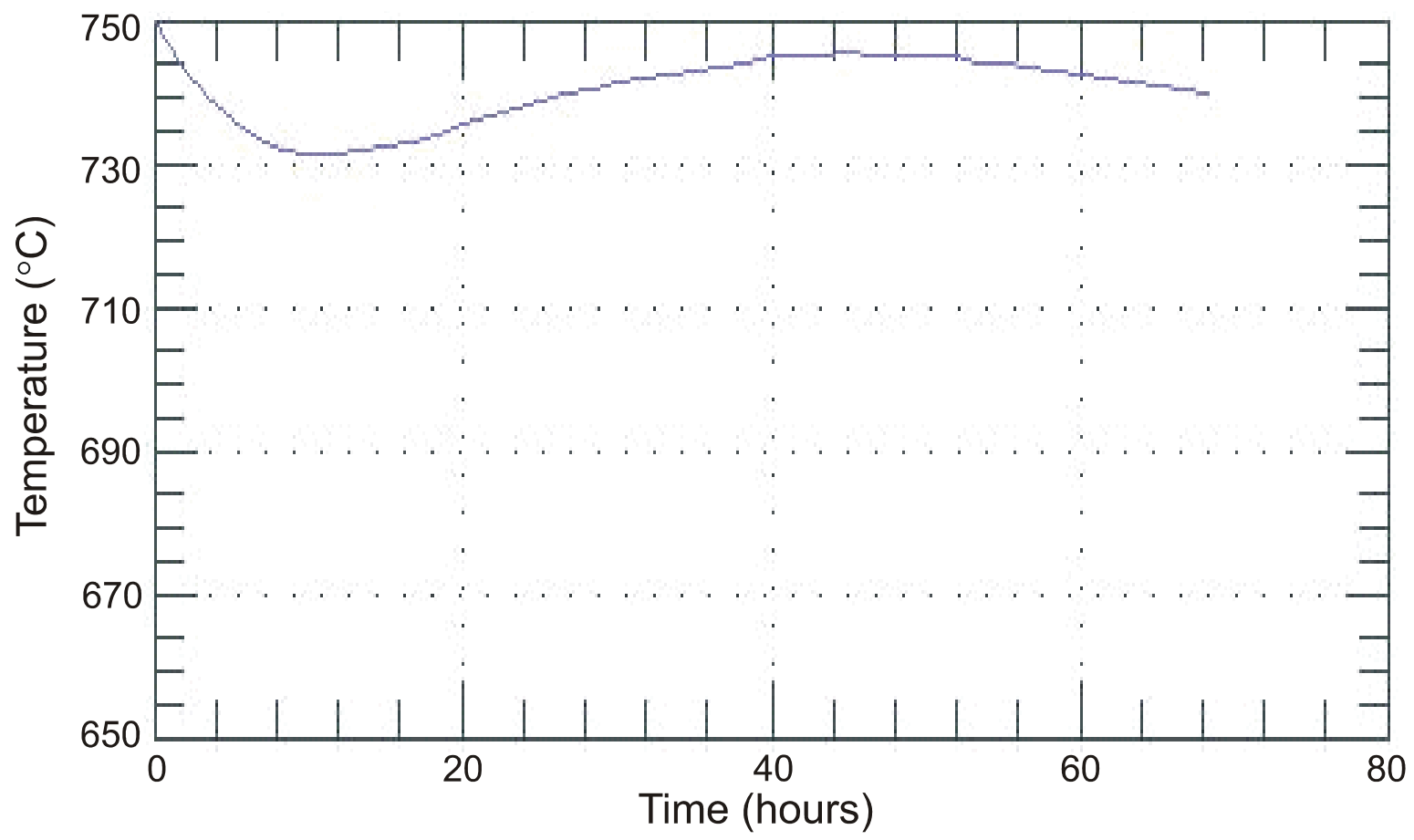

Fig. 3.18. Maximum reactor vessel temperature as a function of time after an LOFC accident (with scram). 


\subsection{POWER CONVERSION THERMODYNAMIC ANALYSIS}

The equations for analyzing the thermal efficiency of the MCGC are presented elsewhere. ${ }^{7}$ Using these equations, a parametric search was used to identify promising design parameters for the very hightemperature MCGC system. ${ }^{8}$ It was found that a relatively high total pressure ratio was desirable, because a high pressure ratio does not have a strong effect on the cycle efficiency; and it results in a relatively low turbine outlet temperature and a significantly smaller recuperator volume. As shown in the temperatureentropy diagram in Fig. 3.19, the turbine outlet temperature is sufficiently low $\left(650^{\circ} \mathrm{C}\right)$ for conventional materials to be used for the recuperator and the hot cross-over leg ducts.

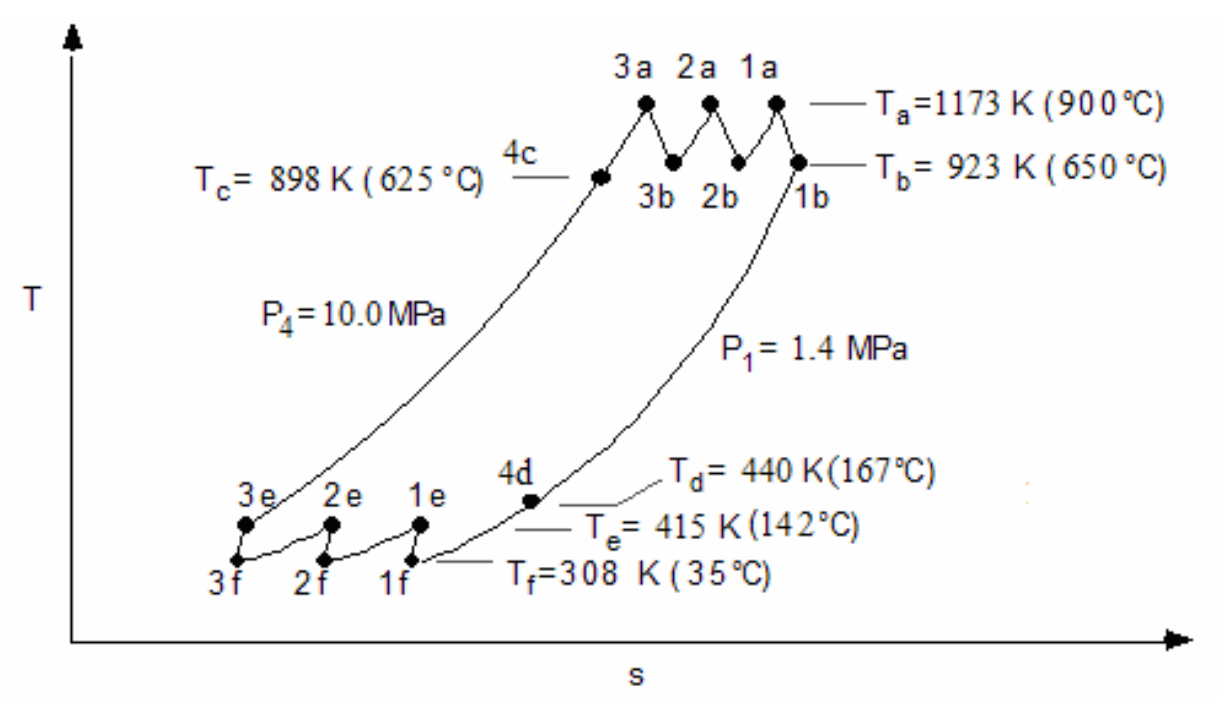

Fig. 3.19. Temperature (T)—entropy (S) diagram for the MCGC very high-temperature reference case.

\subsubsection{Multiple-Reheat Helium Gas Cycle}

Table 3.3 shows the heat exchanger parameters for the very high-temperature helium MCGC. ${ }^{7,9}$ These heat exchangers use a compact offset-fin plate configuration with 1-mm-thick plates, 1-mm-high moltensalt fins, and 2-mm-high helium fins. Here the small volume of the compact heaters is notable, showing that they can be fit with relative ease into the annular volume around the turbines in each PCU.

Table 3.4 shows the turbomachinery parameters for the very high-temperature helium MCGC. The diameter of the turbomachinery is quite similar to that of the GT-MHR PCU (1.7-m tip diameter for compressor, $2.0 \mathrm{~m}$ for turbine), and the length of the turbomachine rotor is somewhat shorter. The generators for the MCGC PCUs will be somewhat taller than those of the GT-MHR generator because of their larger power output. But the main MCGC PCU vessels will be shorter than those of the GT-MHR, because the coolers move upward; and the volume of each MCGC PCU will be similar or smaller than that of the GT-MHR PCU. 
Table 3.3. High-temperature helium MCGC heat exchanger design parameters

\begin{tabular}{|c|c|c|c|c|}
\hline & \multirow[b]{2}{*}{ Recuperator } & \multicolumn{3}{|c|}{ MS to helium heaters } \\
\hline & & $\begin{array}{l}\text { High-pressure } \\
\text { (HP) heater }\end{array}$ & $\begin{array}{c}\text { Medium- } \\
\text { pressure (MP) } \\
\text { heater }\end{array}$ & $\begin{array}{l}\text { Low-pressure } \\
\text { (LP) heater }\end{array}$ \\
\hline Power (MW) & 1495 & 852 & 774 & 774 \\
\hline $\mathrm{T}_{\max }\left({ }^{\circ} \mathrm{C}\right)$ & 650 & 920 & 920 & 920 \\
\hline $\mathrm{T}_{\min }\left({ }^{\circ} \mathrm{C}\right)$ & 142 & 625 & 650 & 650 \\
\hline Core volume $\left(\mathrm{m}^{3}\right)$ & 35 & 7.0 & 7.9 & 9.1 \\
\hline Flow length $(\mathrm{m})$ & 0.51 & 0.45 & 0.37 & 0.31 \\
\hline Total frontal area $\left(\mathrm{m}^{2}\right)$ & 70 & 15 & 21 & 30 \\
\hline $\begin{array}{l}\text { Thermal density } \\
\left(\mathrm{MW} / \mathrm{m}^{3}\right)\end{array}$ & 43 & 122 & 98 & 85 \\
\hline $\begin{array}{l}\text { Fractional pressure } \\
\text { losses for the counter } \\
\text { flow parts }\end{array}$ & 0.0072 & 0.0028 & 0.0025 & 0.0023 \\
\hline
\end{tabular}

Table 3.4. Very high-temperature helium MCGC preliminary turbomachinery design parameters

\begin{tabular}{||lcccccc||}
\hline & \multicolumn{3}{c}{ Compressors } & \multicolumn{3}{c|}{ Turbines } \\
\cline { 2 - 7 } & HP & MP & LP & HP & MP & LP \\
\hline Power (MW) & 330 & 330 & 330 & 774 & 774 & 774 \\
Inlet temperature $\left({ }^{\circ} \mathrm{C}\right)$ & 35 & 35 & 35 & 900 & 900 & 900 \\
Pressure ratio & 1.94 & 1.94 & 1.94 & 1.92 & 1.92 & 1.92 \\
Number of stages & 19 & 19 & 17 & 13 & 13 & 13 \\
Adiabatic efficiency & 0.88 & 0.88 & 0.88 & 0.93 & 0.93 & 0.93 \\
Exit dynamic pressure & $0.57 \%$ & $0.54 \%$ & $0.56 \%$ & $0.55 \%$ & $0.55 \%$ & $0.53 \%$ \\
over system pressure & & & & & & \\
Maximum tip diam (m) & 1.86 & 1.86 & 1.86 & 1.93 & 1.96 & 2.00 \\
Tip speed (m/s) & 350 & 350 & 350 & 363 & 369 & 378 \\
Minimum hub/tip ratio & 0.85 & 0.77 & 0.67 & 0.79 & 0.70 & 0.57 \\
Overall length (m) & 4.9 & 4.9 & 4.7 & 4.8 & 4.9 & 5.0 \\
\hline
\end{tabular}

\subsubsection{Multiple-Reheat Nitrogen Gas Cycle}

A brief summary for the thermal design of a $2400 \mathrm{MW}(\mathrm{t})$ multiple-reheat nitrogen Brayton cycle is given in this section. To increase the gas thermal conductivity, $10 \mathrm{wt} \%$ helium, or $44 \mathrm{~mol} \%$ helium, is added to the nitrogen. Compared with the pure helium very high-temperature MCGC, the optimum nitrogen cycle pressure ratio is two times larger. The nitrogen system volume and mass are about $40 \%$ larger than for helium, so there is a clear economic attraction to using helium as the working fluid because of its better thermophysical properties. 
Table 3.5 shows the heat exchanger parameters for the very high-temperature nitrogen MCGC. Comparing Table 3.5 with Table 3.3, the nitrogen MCGC thermal densities are much smaller than the helium thermal densities because of the less attractive thermophysical properties of nitrogen.

Table 3.6 shows the turbomachinery parameters for the very high-temperature nitrogen MCGC. Because of the large mass flow rate, only a supersonic blade design is possible, like those used in modern combustion turbines. The tip diameters for turbomachines are much larger than for helium turbines.

Table 3.5. Very high-temperature nitrogen MCGC heat exchanger design parameters

\begin{tabular}{|lcccc|}
\hline & & \multicolumn{3}{c|}{ MS to nitrogen heaters } \\
\cline { 3 - 5 } & Recuperator & $\begin{array}{c}\text { High-pressure } \\
\text { heater }\end{array}$ & $\begin{array}{c}\text { Medium- } \\
\text { pressure } \\
\text { heater }\end{array}$ & $\begin{array}{c}\text { Low-pressure } \\
\text { heater }\end{array}$ \\
\hline Power $(\mathrm{MW})$ & 1489 & 852 & 774 & 774 \\
$\mathrm{~T}_{\max }\left({ }^{\circ} \mathrm{C}\right)$ & 650 & 920 & 920 & 920 \\
$\mathrm{~T}_{\min }\left({ }^{\circ} \mathrm{C}\right)$ & 142 & 624 & 650 & 650 \\
Core volume $\left(\mathrm{m}^{3}\right)$ & 93 & 11 & 14 & 17 \\
Flow length $(\mathrm{m})$ & 0.74 & 0.67 & 0.53 & 0.42 \\
Total frontal area $\left(\mathrm{m}^{2}\right)$ & 125 & 17 & 26 & 41 \\
Thermal density & 16 & 77 & 56 & 45 \\
$\left(\mathrm{MW} / \mathrm{m}^{3}\right)$ & & & & 0.0034 \\
Fractional pressure & 0.012 & 0.004 & 0.0036 & \\
losses for the counter & & & & \\
flow parts & & & & \\
\hline
\end{tabular}

Current large combustion turbines are designed to operate in horizontal orientation. The required nitrogen MCGC mass flow is approximately three times that of existing large combustion turbines. However, the nitrogen MCGC operates with a compressor inlet pressure of $0.7 \mathrm{MPa}$, while combustion turbines are forced to operate with an inlet pressure of $0.1 \mathrm{MPa}$. Because power density scales with the gas density, the nitrogen MCGC turbomachinery achieves much higher power density than current combustion turbines, and the physical dimensions of the $1300 \mathrm{MW}(\mathrm{e})$ nitrogen MCGC turbomachinery are similar to those for a $400 \mathrm{MW}(\mathrm{e})$ combustion turbine.

The higher gas density of the MCGC, relative to current combustion turbines, also reduces pressure losses in recuperators, so the MCGC adapts well to a recuperated Brayton cycle. Combustion turbines, however, must commonly use complex and expensive steam bottoming cycles to achieve thermodynamic efficiencies above $50 \%$.

In summary, to obtain similar thermodynamic efficiency, it appears that nitrogen-based systems will have somewhere around $40 \%$ larger volume than helium-based systems. Their capital cost will be higher because of the less optimal thermodynamic properties of nitrogen compared with helium. However, the nitrogen-based Brayton cycle is expected to be less expensive than the equivalent Rankine steam cycle because of the low-pressure steam components and the moisture separator components required for the Rankine cycle. 
Table 3.6. Very high-temperature nitrogen MCGC preliminary turbomachinery design parameters

\begin{tabular}{||lcccccc||}
\hline & \multicolumn{3}{c}{ Compressors } & \multicolumn{3}{c||}{ Turbines } \\
\cline { 2 - 7 } & HP & MP & LP & HP & MP & LP \\
\hline Power (MW) & 331 & 331 & 331 & 774 & 774 & 774 \\
Inlet temperature $\left({ }^{\circ} \mathrm{C}\right)$ & 35 & 35 & 35 & 900 & 900 & 900 \\
Pressure ratio & 2.48 & 2.48 & 2.48 & 2.43 & 2.43 & 2.43 \\
Number of stages & 7 & 7 & 6 & 4 & 4 & 4 \\
Adiabatic efficiency & 0.88 & 0.88 & 0.88 & 0.93 & 0.93 & 0.93 \\
Exit dynamic pressure & $0.11 \%$ & $0.27 \%$ & $0.74 \%$ & $0.09 \%$ & $0.23 \%$ & $0.55 \%$ \\
over system pressure & & & & & & \\
Maximum tip diam (m) & 2.5 & 2.5 & 2.5 & 3 & 3 & 3 \\
Tip speed (m/s) & 470 & 470 & 470 & 559 & 556 & 560 \\
Minimum hub/tip ratio & 0.56 & 0.56 & 0.57 & 0.56 & 0.57 & 0.56 \\
Overall length (m) & 5 & 5 & 5 & 5 & 5 & 5 \\
\hline
\end{tabular}

\subsubsection{Vertical vs Horizontal Turbomachinery}

The GT-MHR PCUs use vertical turbomachinery, and the NGNP may end up demonstrating the design and reliability of large, vertical turbomachines, including the control of vertical turbine rotor dynamics and the performance of axial catcher bearings. The other option for the MCGC involves a horizontal configuration, but there would be several negative impacts from a horizontal orientation that would balance the potential simplification of the turbomachinery bearing systems.

For horizontal turbomachinery, it would be much more difficult to configure the MCGC heaters and coolers into compact annular volumes around horizontal turbomachinery to provide a uniform flow into the turbine and compressor inlets and to minimize the hot-gas flow length. It would also be more difficult to configure the salt-to-helium heat exchangers to drain their molten salt by gravity.

The vertical orientation permits a very short vessel flange perimeter length compared with the horizontal orientation. Because high-pressure flanges tend to be massive structures, the smaller flanges of the vertical vessels reduce the pressure boundary mass and cost for the same vessel volume, as well as the helium leakage rate. For molten salt reactors and fusion power applications, the reduced flange perimeter should also simplify tritium management and control. For horizontal turbomachinery, it would likely be difficult to minimize the helium duct volume to the small value possible with the cross-over-leg configuration of the vertical PCUs; so the total pressure-vessel volume of a horizontal turbomachine design would also likely be larger, further increasing the mass of the pressure boundary materials.

Vertical closed-cycle helium turbomachinery may be developed and deployed before horizontal helium turbomachinery, because the first application of a closed helium cycle will most likely be to direct-cycle power conversion for gas-cooled reactors (potentially the NGNP). Thus, at the time of deployment of the MCGC, engineering design and manufacturing capabilities are likely to be further advanced for vertical machinery than for horizontal. As with aeroturbines, there exist strong drivers to reduce the mass of vertical helium turbomachinery that have the potential to ultimately make vertical machinery less expensive and resource-intensive than horizontal machinery. 
The MCGC PCU turbomachinery will be only slightly larger in diameter, and shorter, than the GTMHR PCU turbomachinery. Substantial optimization of the GT-MHR PCU design has occurred during GA's collaboration with Russian scientists to design a plutonium-burning version of the GT-MHR, which has greatly reduced the mass and improved the rotational dynamics of the turbomachinery. Because the MCGC turbomachinery will be located away from the plant's nuclear island, structureal costs will be lower. 


\section{MOLTEN-SALT COOLANT}

\subsection{MOLTEN SALT COMPOSITIONS}

There are several molten-fluoride salts that have been used in test reactors or other applications that are applicable to the AHTR. The 2.5 MW(t) Aircraft Reactor Experiment (ARE) operated in the 1950s with an $\mathrm{NaF} / \mathrm{ZrF}_{4}$ molten salt, while the $8 \mathrm{MW}(\mathrm{t}) \mathrm{MSRE}^{3}$ operated in the 1960 s with $\mathrm{Li}_{2} \mathrm{BeF}_{4}$ (Flibe) molten salt in both the primary and secondary loops. Although it was never used in a reactor, extensive investigations were performed for a ternary alkali-fluoride (LiF-NaF-KF- "FLiNaK") for hightemperature nuclear service. In both the ARE and the MSRE reactors, the fuel was dissolved in the salt, whereas the AHTR uses solid fuel and fuel-free salt. The term molten salt reactors discussed in the literature typically refers to reactors in which the fuel and fission products are dissolved in the coolant and, unfortunately, leads to frequent confusion regarding the nature of the AHTR. Despite the confusion, the AHTR benefits from a large technological base of experience gained from both of the earlier programs. These programs operated major test facilities for studying corrosion, pumps, valves, heat exchangers, and other components in molten salt environments up to $\sim 850^{\circ} \mathrm{C}$. This experience is captured in a repository of more than 1000 technical reports.

The use in the AHTR of a solid fuel and molten-salt coolant, rather than fissile materials and fission products dissolved in the salt, has major advantages in terms of operations. The radioactivity in the coolant will be many orders of magnitude lower than that in a fluid-fueled reactor and will largely result from activation of the salt constituents. For some salts, such as $\mathrm{Li}_{2} \mathrm{BeF}_{4}$, the level of activation is expected to be very low and short-lived. At operating temperatures up to $\sim 750^{\circ} \mathrm{C}$, Hastelloy- $\mathrm{N}$ received code approval for nuclear service and showed excellent corrosion resistance. Since the time of the development of Hastelloy-N, nickel superalloys (e.g., Hastelloy-X) have been developed that can be used at even higher temperatures. It is likely that the use of these alloys, without cladding or coating, will require that the chemistry of the salt be maintained in a chemically reducing condition to minimize system corrosion. ${ }^{13,14}$ The use of a corrosion-resistant base alloy is the most robust type of protection-no passive layers, films, coatings, or cladding protection is required for very high-temperature service. There are no potential weak spots at joints or welds. For long-term operation above $800^{\circ} \mathrm{C}$, new materials of construction must be qualified. These requirements are similar to those of the very high-temperature reactor (VHTR) and the fusion materials research programs.

Table 4.1 lists key thermophysical parameters for Flibe and $\mathrm{NaF} / \mathrm{ZrF}_{4}$ salts compared with several other common coolant materials. The MSBR program in the 1960 s chose a ${ }^{7} \mathrm{Li}_{2} \mathrm{BeF}_{4}$ salt because the primary goal was to maximize the breeding ratio in the reactor. Significant reactor experience and engineering test data exist for this salt. The ${ }^{6} \mathrm{Li}$ version of this salt is being developed as a coolant and tritium breeder for fusion reactors. The physical properties and characteristics of many other candidate molten salts have been investigated. The current reference salt for the AHTR is ${ }^{7} \mathrm{Li}_{2} \mathrm{BeF}_{4}$; however, the ultimate choice of molten-salt coolant for the AHTR will depend upon goals and trade-offs involving coolant costs, salt melting points, activation products, reactor dynamics, reactor design goals (electricity, hydrogen production, etc.), occupational hazards, and other factors.

All primary-system salt components must have low neutron-absorption cross sections, reasonable melting points, and suitable coolant properties. Candidate fluoride salts include ${ }^{7} \mathrm{Li}, \mathrm{Na}, \mathrm{Be}, \mathrm{Zr}, \mathrm{Rb}$, and others. Chloride molten salts are not viable candidates because of their corrosive characteristics, high thermal-neutron-absorption cross sections, and generation of ${ }^{36} \mathrm{Cl}-\mathrm{a}$ long-lived radionuclide ${ }^{15}$ that would create significant waste management challenges. The toxicity of the molten fluoride coolant depends upon the specific salt and varies from the fluoride salts used in toothpaste for prevention of tooth decay to toxic materials. All of the candidate fluoride coolants have high boiling temperatures. The reference salt, ${ }^{7} \mathrm{Li}_{2} \mathrm{BeF}_{4}$, has a boiling point of $\sim 1400^{\circ} \mathrm{C}$. In all cases, binary or more complex fluoride salt mixtures are preferred because their melting points are lower than those for single-component salts. For example, the 
molten salt $\mathrm{Li}_{2} \mathrm{BeF}_{4}$ has a melting point of $459^{\circ} \mathrm{C}$, whereas pure $\mathrm{LiF}$ has a melting point of $847^{\circ} \mathrm{C}$ and pure $\mathrm{BeF}_{2}$ has a melting point of $544^{\circ} \mathrm{C}$. Other candidate salts include $\mathrm{NaF}-\mathrm{ZrF}_{4}(50 \mathrm{~mol} \% \mathrm{NaF}, 50 \mathrm{~mol}$ $\left.\% \mathrm{ZrF}_{4}\right)$, with a melting point of $510^{\circ} \mathrm{C}$, and $\mathrm{NaF}-\mathrm{RbF}-\mathrm{ZrF}_{4}(8 \mathrm{~mol} \% \mathrm{NaF}, 50 \mathrm{~mol} \% \mathrm{RbF}$, and $42 \mathrm{~mol}$ $\% \mathrm{ZrF}_{4}$ ), with a melting point of $400^{\circ} \mathrm{C}$. With some three-component mixtures such as ${ }^{7} \mathrm{LiF}-\mathrm{BeF}_{2}-\mathrm{NaF}$, and potentially four-component mixtures, it is possible to reduce melting points to $\sim 350^{\circ} \mathrm{C}$. At operating conditions, molten fluoride salt thermophysical properties are similar to those of water except for the very low vapor pressure.

Table 4.1. Thermophysical properties* common reactor coolants

\begin{tabular}{||lccccccc||}
\hline \multicolumn{1}{|c}{ Coolant } & $\begin{array}{c}\mathbf{T}_{\text {melt }} \\
\left({ }^{\circ} \mathbf{C}\right)\end{array}$ & $\begin{array}{c}\mathbf{T}_{\text {boil }} \\
\left({ }^{\circ} \mathbf{C}\right)\end{array}$ & $\begin{array}{c}\rho \\
\left(\mathbf{k g} / \mathbf{m}^{3}\right)\end{array}$ & $\begin{array}{c}\mathbf{C}_{\mathbf{p}} \\
\left(\mathbf{k J} / \mathbf{k g}{ }^{\circ} \mathbf{C}\right)\end{array}$ & $\begin{array}{c}\mathbf{\rho C}_{\mathbf{p}} \\
\left(\mathbf{k J} / \mathbf{m}^{\circ} \mathbf{C}\right)\end{array}$ & $\begin{array}{c}\mathbf{K} \\
\left(\mathbf{W} / \mathbf{m}^{\circ} \mathbf{C}\right)\end{array}$ & $\begin{array}{c}\mathbf{v} \cdot \mathbf{1 0}^{\mathbf{6}} \\
\left(\mathbf{m}^{2} / \mathbf{s}\right)\end{array}$ \\
\hline $\mathrm{Li}_{2} \mathrm{BeF}_{4}$ (Flibe) & 459 & 1,430 & 1,940 & 2.34 & 4,540 & 1.0 & 2.9 \\
$0.58 \mathrm{NaF}^{\circ} 0.42 \mathrm{ZrF}_{4}$ & 500 & 1,290 & 3,140 & 1.17 & 3,670 & $\sim 1$ & 0.53 \\
Sodium & 97.8 & 883 & 790 & 1.27 & 1,000 & 62 & 0.25 \\
Lead & 328 & 1,750 & 10,540 & 0.16 & 1,700 & 16 & 0.13 \\
Helium (7.5 MPa) & & & 3.8 & 5.2 & 20 & 0.29 & 11.0 \\
Water (7.5 MPa) & 0 & 100 & 732 & 5.5 & 4,040 & 0.56 & 0.13 \\
\hline
\end{tabular}

${ }^{*} \rho$ is density; $\mathrm{C}_{\mathrm{p}}$ is specific heat; $\mathrm{k}$ is thermal conductivity; $\mathrm{v}$ is viscosity.

\subsection{MATERIALS COMPATIBILITY}

Molten fluoride salts have a relatively benign and noncorrosive interaction with dry air or $\mathrm{CO}_{2}$, but they will slowly react with water to promote corrosion of metals. Fluoride salts are compatible with graphite fuels. ${ }^{16}$ In the MSRE, the reactor core contained bare graphite as the neutron moderator, which was in direct contact with the fueled salt. The postexamination study showed absolutely no erosion or corrosion of the graphite - the original machining marks were still clearly visible, and insignificant weight and dimension changes were recorded. ${ }^{17}$ This reactor experience (and many test-reactor irradiations) showed that the molten fluoride salt does not react with the graphite under operating reactor conditions or decompose in radiation fields. In addition to the MSRE experience at $650^{\circ} \mathrm{C}$ and capsule irradiation experience up to $900^{\circ} \mathrm{C}$, a special experiment was conducted to test very high-temperature compatibility at $1400^{\circ} \mathrm{C} .{ }^{18}$ Graphite did not react with the salt even at this extremely high temperature.

There is a century of industrial experience with graphite and fluoride salt compatibility; almost all aluminum metal is electrolytically produced using molten cryolite $\left(3 \mathrm{NaF}-\mathrm{AlF}_{3}\right)$ in very large graphite baths at $\sim 1000^{\circ} \mathrm{C}$. In this application, the graphite crucible is very stable. The observed degradation of graphite electrodes is the result of an extremely aggressive reducing environment needed to make the aluminum, which will not be the case in the AHTR. Also, molten salts are candidates for cooling the first wall of fusion reactors ${ }^{19}$ and are currently under active experimental study by DOE's Office of Fusion Energy Science.

There is a vast literature on the compatibility of nickel alloys with molten fluorides. Because there are important trade-offs between strength, salt corrosion resistance, and air oxidation resistance, this subject is treated in Sect. 5, which discusses structural materials.

The lithium-beryllium salt also possesses the rather unique property of exhibiting extremely shortlived and weak radiation due to neutron activation (7-s N-15, 11-s F-20). This coolant would require the minimum in shielding to accommodate hands-on maintenance. 


\subsection{HEAT TRANSFER CHARACTERISTICS}

The excellent heat transfer properties of molten salts, compared with those of helium gas (see Table 4.1), reduce the temperature drops between (1) the solid fuel and molten salt and (2) the molten salt and any secondary system. Comparable calculations were made of the temperature drop between the centerline of a fuel compact similar to that in an HTGR and the centerline of a coolant channel for helium and molten-salt coolants. The temperature drops for helium and molten-salt coolants were, respectively, 150 and $100^{\circ} \mathrm{C}$. The better heat transfer capabilities of molten salts (liquids) compared with those of helium (a gas) provide for several potential benefits:

- Design margins. The thermal design margins can be increased compared with those for gascooled reactors.

- Higher output temperatures. The maximum exit coolant temperature for a molten-salt-cooled reactor can be higher than that for a gas-cooled reactor-assuming the same maximum fuel temperature.

- Cooler fuel temperatures. Conversely, the maximum fuel temperature for a molten-salt-cooled reactor will be lower than that for a gas-cooled reactor-assuming the same maximum core outlet temperature.

- Higher core power densities. The power densities can be increased to decrease the reactor core size or increase power output. Gas-cooled reactors traditionally have very low power densities because of poor heat transfer. With a liquid molten-salt coolant, the power density can be increased significantly.

- Improved decay heat removal. Improved heat transfer by natural circulation of the molten salt allows the design of larger reactors with passive safety (see Sect. 3.3).

The heat transfer analyses reported in the previous section were performed using conventional correlations. This type of approach produces conservative results at higher temperatures. Molten salts, like molten glasses, are optically transparent in the visible light band and have significant transparency in the infrared band. The heat capacities are also large. These characteristics imply that above $\sim 700^{\circ} \mathrm{C}$, radiative transfer begins to become an important mechanism to enhance heat transfer since it increases as the fourth power of the temperature $\left(\mathrm{T}^{4}\right)$. The optical properties vary between salts and can be altered by addition of certain cations. Hence, optical properties, and thus, high-temperature heat-transfer properties, are partly controlled by the designer. Although this factor is a consideration in the design of industrial facilities that produce molten glass, it has not historically been a consideration for reactor coolants.

\subsection{SALT FREEZING}

The relatively high melting point $\left(350-500^{\circ} \mathrm{C}\right)$ of the molten salt will require special design features. There is significant experience from the operation of sodium-cooled fast reactors, Russian lead-cooled submarine reactors, and the MSRE. The AHTR uses a pool-type reactor vessel that reduces some of these challenges. As with other high-temperature, liquid-cooled reactors, the reactor will be refueled with liquid covering the reactor core. In this context, the AHTR has two advantages over sodium- and lead-cooled reactors: (1) molten salts are transparent, and (2) the fuel has a lower power density and thus a lower rate of volumetric decay heat generation.

\subsection{TRITIUM PRODUCTION}

The production of tritium will depend upon the final choice of salts. If the AHTR uses nonlithium molten salts, the total tritium production will be less than for gas-cooled reactors and there will be a much lower tritium level in the coolant. If molten-salts with ${ }^{7} \mathrm{LiF}$ are used, the tritium production will be significantly higher than for helium-cooled reactors but similar tothat for the Canadian Deuterium 
Uranium Reactor (CANDU) (heavy water) reactors. In the AHTR, tritium can be trapped (if requireddependent upon the salt) using systems very similar to those used in the Fort St. Vain gas-cooled reactor.

All graphite coated-particle fuels produce tritium via tertiary fission, and all nuclear-grade graphite produces tritium via neutron reactions with impurities in the graphite. Gas-cooled reactors also produce tritium by the ${ }^{3} \mathrm{He}(\mathrm{n}, \mathrm{p})^{3} \mathrm{H}$ reaction. In the Fort St. Vrain reactor, almost all of the tritium that was released is believed to have come from this reaction, since previous testing in Dragon and Peach Bottom reactors showed that tritium produced in the fuel and graphite tend to stay there. Tritium production in gas-cooled reactors is sensitive to the rate of helium loss from the system, since ${ }^{3} \mathrm{He}$ is added as an inherent constituent in the fresh helium makeup. It is also sensitive to the original source of helium, which can vary in its ${ }^{3} \mathrm{He}$ content (the natural abundance of ${ }^{3} \mathrm{He}$ is $0.000137 \%$ ).

Tritium and ${ }^{6} \mathrm{Li}$ production were calculated for the reference AHTR configuration. The overwhelmingly dominant reactions are the ${ }^{6} \mathrm{Li}(\mathrm{n}, \alpha)^{3} \mathrm{H}$ reaction and the ${ }^{9} \mathrm{Be}(\mathrm{n}, \alpha)^{6} \mathrm{He}$ reaction with subsequent beta decay to ${ }^{6} \mathrm{Li}$. At $2400 \mathrm{MW}(\mathrm{t})$, the equilibrium ${ }^{6} \mathrm{Li}$ concentration in the coolant is $0.001 \mathrm{wt} \%$, or about $10 \%$ of its initial concentration. This is due to the burnout of the initial ${ }^{6} \mathrm{Li}$ loading balanced by the generation of new ${ }^{6} \mathrm{Li}$ from the Be reaction. At this equilibrium concentration, tritium production is $\sim 500 \mathrm{Ci} /$ day. However, the exponential decay constant for the ${ }^{6} \mathrm{Li}$ concentration is $\sim 460$ days, which means that it will take several years for the ${ }^{6} \mathrm{Li}$ concentration and, hence, the tritium production rate, to reach an equilibrium value. The initial tritium production will be on the order of $5000 \mathrm{Ci} /$ day. For comparison, an LWR produces $\sim 50 \mathrm{Ci} /$ day, and a typical heavy water reactor produces $3500-6000 \mathrm{Ci} /$ day. ${ }^{20}$

The AHTR will contain a cover gas cleanup system and a Brayton cycle gas cleanup system. Both systems will likely include tritium removal capabilities (if required), along with capabilities for the removal of other impurities. Depending upon design choices, a molten-salt gas stripping system may be associated with the cover-gas cleanup system for removal of tritium and other impurities from the coolant. The major escape route for tritium from the primary system is the high-temperature, high-surface-area intermediate heat exchanger. In the MSR, an intermediate coolant was chosen that could trap the tritium in the molten salt. The MSR was designed to use a steam Rankine cycle, where diffusion of tritium through the steam generators needed to be minimized. While an intermediate salt with high tritium trapping capabilities is an option for the AHTR, no experiments have been done in this temperature range. Several other approaches have been partly developed for fusion machines to control migration of tritium or trap the tritium at high temperatures. For an AHTR using a Brayton power cycle, the tritium can be relatively easily recovered in the cooler zones of the power conversion system.

\subsection{RADIOLYSIS OF MOLTEN SALT}

Fluoride salts do not undergo radiolysis in radiation fields when molten, and no fluorine will be generated. Earlier reports ${ }^{21}$ show that no radiolysis was detected in flowing loops of molten salt operated in intense radiation fields of the Materials Testing Reactor. Molten fluoroborate coolant salts (containing $\mathrm{BF}_{3}+$ alkali-fluorides) were also tested for their radiolysis response, and none was found. ${ }^{22}$ In fact, the reverse reaction-recombination-typically counteracts primary radiolysis events far below the melting point of the salt. For solid $2 \mathrm{LiF}-\mathrm{BeF}_{2}$ salt in a radiation field, the temperature that inhibited a net radiolysis response was approximately $150^{\circ} \mathrm{C} .^{23}$ For other solid fluoride salts $\left(\mathrm{ZrF}_{4}\right.$, $)$, no radiolysis response was found above room temperature, and radiolysis at room temperature was not observed for $\mathrm{NaF}-\mathrm{ZrF}_{4}$ salts in the ARE. ${ }^{24}$

\subsection{FISSION PRODUCT RETENTION AND CLEANUP}

A great deal of knowledge has been gained about the behavior of fission products in fluoride salts from the experience with fluid-fueled reactors. This evidence has been gleaned from numerous irradiation 
capsule tests and the operation of two experimental reactors - the ARE in 1954 and the MSRE during 1966-1970.

The report on the disassembly and postoperative examination of the $\mathrm{ARE}^{25}$ pointed to the ease of removal of the noble gases and the deposition of certain noble metal fission products on metallic surfaces. It was also learned that because of the evolution of chemistry that occurs during radioactive decay, it is important to account for the kinetics of noble gas removal from the salt.

The irradiation capsule tests of molten salts that used a purged gas space are the most revealing. ${ }^{26-28}$ Xenon and krypton fission products were detected in these purge-gas samples. Very small amounts of iodine and tellurium were found in a few tests, and these values are consistent with the precursor transport of xenon and krypton.

A 140-page summary repor $\mathrm{t}^{29}$ describing the behavior of fission products in the MSRE is the most complete source of information on fission product behavior in molten fluorides. In all instances, the evidence confirms what basic thermodynamics tells us: "only the noble gases ( $\mathrm{Xe}, \mathrm{Kr}$ ) and tritium are released from the salt." All of the alkali (e.g., Cs), alkaline earth (e.g., Sr), rare earth (e.g., Y, Ln), and most metallic fission products (e.g., $\mathrm{Zr}$ ) are dissolved in the salt as fluorides and are relatively nonvolatile. A few of the metallic fission products (the "noble" group: $\mathrm{Ag}, \mathrm{Pd}, \mathrm{Ru}, \mathrm{Mo}, \mathrm{Tc}, \mathrm{Rh}, \mathrm{Sb}$ ) are not dissolved (or are partially dissolved), but remain as metallic species and tend to deposit on the colder metallic surfaces.

Of particular interest is the behavior of iodine. Fission product iodine exists in the salt in the reduced form-"iodide" - and is not volatile. After proper accounting for precursor transport, this behavior was confirmed in the irradiation tests and during reactor operation. An extensive chemical study showed that iodine can be removed from the salt only by extremely oxidizing conditions that promote iodide to elemental iodine, ${ }^{30,31}$ or by displacement with fluorine under oxidizing conditions. ${ }^{32}$

For the purposes of this study, the importance of the molten salt as an additional barrier for fission product release should be highlighted. The situation for gas-cooled reactors was summarized in the International Atomic Energy Agency's TECDOC-978 (Ref. 33) and is shown in Fig. 4.1. To meet siteboundary release restrictions for HTRs, credit for each fission product barrier is needed. A low-failure fraction fuel is required; only about one particle in $\sim 100,000$ can fail in normal operation or accident conditions and still meet the regulatory requirements. The most mobile radioactive species are Ag-110m, $\mathrm{Cs}$, I, and Sr. The controlling isotopes for site-boundary release are Cs and I, while Ag-110m tends to control the maintenance dose. ${ }^{34}$

The situation for the AHTR, shown in Fig. 4.2, has the potential to be more favorable. The molten salt coolant offers additional fission product containment features and may reduce some licensing barriers. Key features are the low-pressure coolant and gas-trapping system and the retention of the most important radiotoxic fission products in the salt. With a low-pressure coolant, a true containment building is a more practical option than for a high-pressure, gas-cooled system.

There will also likely be a requirement to clean up the coolant salt from any chemical or radioactive impurities. Chemical purification was perfected during the preparation of the salt for the MSRE. Hydrofluorination for the preparation of clean salts was done on a large scale for the production of $\sim 12$ metric tons of high-purity fluoride salts for the MSRE. ${ }^{35,36}$ Prior to the second phase of U-233 operations, the MSRE fuel salt was purified by removal of ${ }^{235} \mathrm{U}$ and selected fission products (H-3, Se, Br, I, Kr, Xe, $\mathrm{Nb}, \mathrm{Mo}, \mathrm{Tc}, \mathrm{Ru}, \mathrm{Np}, \mathrm{Sb}$ ) by fluorination and hydrofluorination/reductive purification $(\mathrm{Cr}, \mathrm{Ni}, \mathrm{Fe}){ }^{37,38}$ Vacuum distillation studies showed that $\mathrm{CsF}$ can be selectively removed from the base-salt. ${ }^{39-42}$ Extensive reductive extraction studies are summarized in Ref. 3. The primary objective of these studies was the removal of rare earth fission product poisons. In the past decade, Argonne National Laboratory examined a complete clean-up of the MSRE fuel salt by other pyrochemical methods (mainly electroseparations) and found this to be feasible route. The most difficult separations are those that involve elements that are in a homologous chemical series, such as $\mathrm{Cs}$ from $\mathrm{Li}$ or $\mathrm{Na}$, and $\mathrm{Sr}$ from $\mathrm{Be}$. The higher volatility of $\mathrm{BeF}_{2}$, $\mathrm{CsF}$, and $\mathrm{ZrF}_{4}$ means that these elements separated more easily during vacuum distillation. 


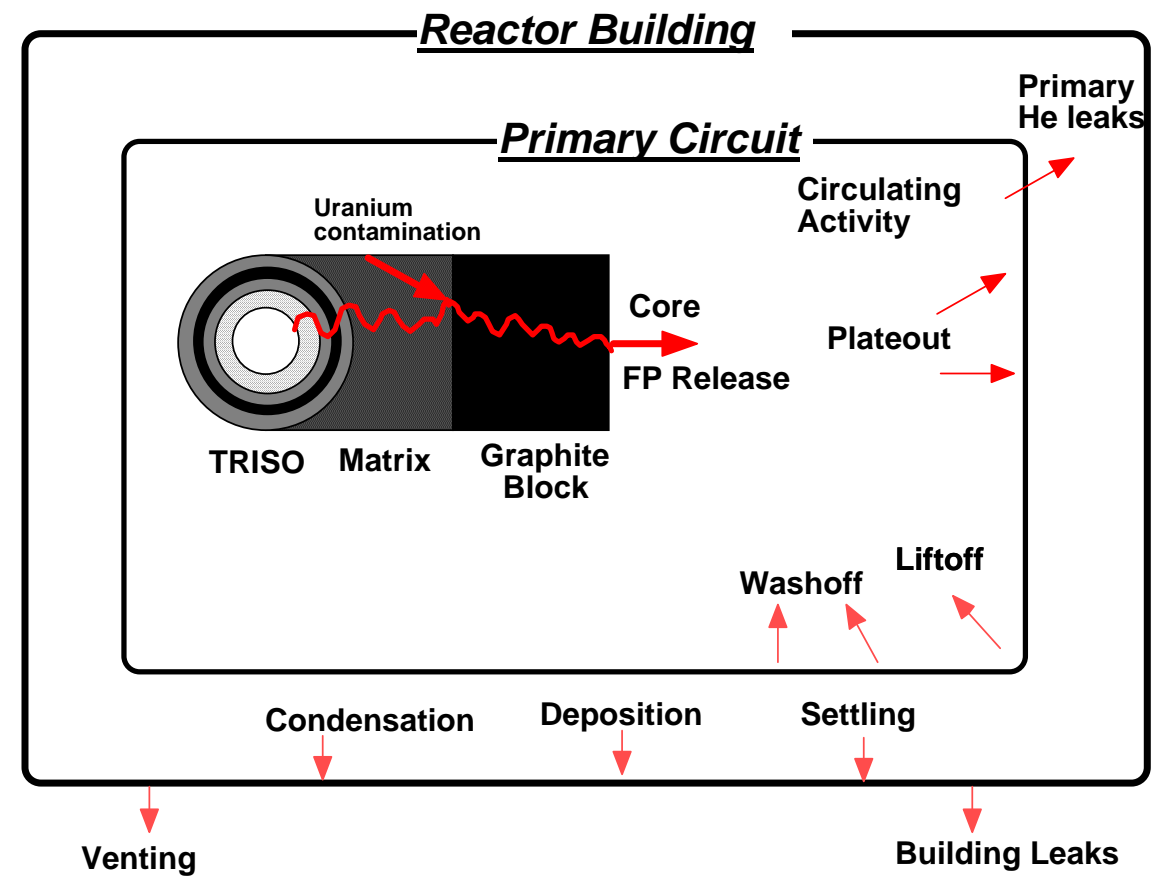

Fig. 4.1. HTR fission product release paths. Source: Ref. 33 .

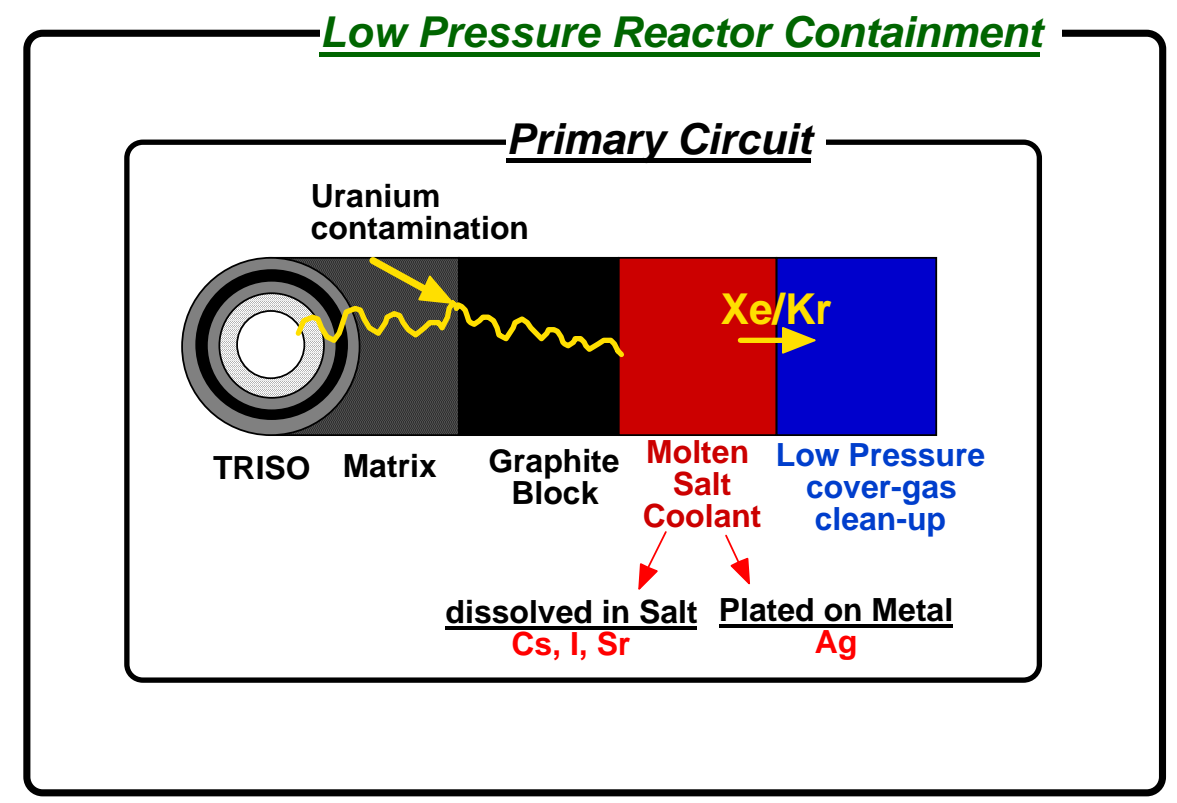

Fig. 4.2. AHTR fission product release paths. 
The MSRE secondary coolant was kept extremely clean during the 4-year operation of the reactor, and no in-line cleaning was required. It is likely that the AHTR will not require a complex clean-up system for the coolant, but that more extensive cleanup may be needed on a period determined by the release of fission products from the fuel. 


\section{STRUCTURAL MATERIALS}

In considering materials performance in the AHTR, the materials were classified into four broad categories: (1) graphite and $\mathrm{C} / \mathrm{C}$ composites; (2) reactor vessel materials; (3) high-temperature metallic components; and (4) high-temperature, melt-infiltrated-composite components. Codification of the materials may be necessary, and the experience base and maturity of the material will influence the applicability of the material within the proposed time frame for reactor demonstration. In general, mechanical properties of irradiated and unirradiated materials in the presence of the chosen molten fluoride salt, high-temperature oxidation behavior, and salt compatibility data need to be generated. For the lower temperature AHTR-IT version, compatible code materials already exist such as Hastelloy-N. However, the $1000^{\circ} \mathrm{C}$ coolant outlet temperature required by the AHTR-VT for the NGNP application will require considerable material testing and qualification.

\subsection{GRAPHITE AND CARBON-CARBON COMPOSITES}

The graphite core, reflector and vessel insulation, and $\mathrm{C} / \mathrm{C}$ composite core supports and control rods will operate in a molten salt environment over a range of temperatures from $500^{\circ} \mathrm{C}$ up to $1100^{\circ} \mathrm{C}$ or higher (peak temperature being selected as a tradeoff between reactor thermal inertia, thermal blanket system performance, and materials properties). Extensive prior work has demonstrated that graphite is compatible with molten fluoride (these are fundamental properties and are not particularly dependent on manufacturing). Fine-grained isotropic, molded, or isostatically pressed high-strength graphite suitable for core support structures (e.g., Carbone USA grade 2020 or Toyo Tanso grade IG-110) is available today. Toyo Tanso grade IG-110 was used in the Japanese High-Temperature Test Reactor for fuel blocks and in the Chinese HTR-10 pebble bed reactor. Past experience has also demonstrated techniques for accommodating any radiation-induced dimensional changes in the graphite reactor vessel insulation. However, a database of properties needs to be developed for design use. It is anticipated that properly designed and manufactured $\mathrm{C} / \mathrm{C}$ composite structures will demonstrate similarly good properties in the presence of molten fluoride salts and better mechanical properties. Carbon-carbon composite heat exchangers are also now being explored under a high-temperature heat exchanger project at the University of Nevada at Las Vegas.

\subsection{REACTOR VESSEL MATERIALS}

The reactor vessel must be capable of operating at $500^{\circ} \mathrm{C}$ and may need to withstand temperature excursions to $800^{\circ} \mathrm{C}$ for 100 hours under accident conditions if a DRACS system is not used to augment RVACS decay heat removal. The vessel must demonstrate adequate strength and creep resistance (long term and short term), good thermal-aging properties, low irradiation degradation, fabricability, good corrosion resistance, and ability to develop and maintain a high-emissivity surface in air. Past experience has demonstrated that nickel-based alloys demonstrated good resistance to molten salts. Therefore, it is proposed that stable, high-strength, high-temperature materials, such as $9 \mathrm{Cr}-1 \mathrm{MoV}$, be coated with a high nickel coat for the reactor vessel application. Should the vessel be required to withstand excessive offnormal temperatures, base materials such as $304 \mathrm{~L}, 316 \mathrm{~L}, 347$, Alloy $800 \mathrm{H}$, or HT may be appropriate. In addition, monolithic materials with adequate corrosion resistance to molten fluoride salts and hightemperature strength may include Alloy $800 \mathrm{H}$ or HT, Hastelloy N, and Haynes 242. The performance of the suggested materials needs to be evaluated, especially at the higher temperatures. Further, the ability to develop and maintain a high-emissivity layer on the surface of the vessel exposed to argon or air must be demonstrated, but this is not considered a major barrier. 


\subsection{HIGH-TEMPERATURE METALS}

High-temperature metallic or composite materials are needed for use at $1000^{\circ} \mathrm{C}$ in the presence of molten fluoride salts on one side and an insulation system in contact with air on the other side. Piping and heat exchanges are examples for the latter conditions. Pumps and other components submerged below the primary salt pool will need to survive higher temperatures for short times or be replaceable at reasonable expense. The metallic materials used in these environments must demonstrate adequate strength (long term and short term), good thermal-aging properties, low-irradiation degradation, fabricability, and good corrosion resistance. Again, based on material maturity and the need for high nickel for fluoride corrosion resistance, stable high-strength, high-temperature metallic materials such as Inconel 617, Haynes 230, Alloy $800 \mathrm{H}$, Hastelloy X or XR, VDM 602CA, and HP modified with high nickel coatings need to be evaluated. Should higher-temperature alloys be required, Haynes 214, cast Ni-based superalloys (for pumps), and ODS MA 754 are possible candidates. Recent experience suggests that should the oxidation potential of the salt be made very reducing, it may be possible to use ODS MA 956 (an iron-based alloy). These monolithic materials will require more testing and data development. For composite materials, LSI composites, with chemical vapor deposition carbon coatings, may be promising for use for pumps, piping, and heat exchangers.

The following tables (Tables 5.1 and 5.2) summarize the properties of the metallic materials selected for further evaluation. 
Table 5.1. Coated F-M or stainless steels, or monolithic alloys potentially suitable for AHTR reactor vessel needs

\begin{tabular}{|c|c|c|c|c|c|c|}
\hline & Candidate materials & $\begin{array}{c}\text { Salt corrosion } \\
\text { resistance }\end{array}$ & $\begin{array}{c}\text { Air corrosion } \\
\text { resistance }\end{array}$ & $\begin{array}{c}\text { Long-term strength at } \\
500^{\circ} \mathrm{C} \\
\end{array}$ & \multicolumn{2}{|c|}{ Highest usage temperature $\left({ }^{\circ} \mathrm{C}\right)$} \\
\hline \multirow[t]{6}{*}{ Coated } & $9 \mathrm{Cr}-1 \mathrm{MoV}$ & Poor & Good & Very good & \multicolumn{2}{|l|}{650} \\
\hline & $21 / 4 \mathrm{Cr}-1 \mathrm{Mo}$ & Poor & Good & Good & \multicolumn{2}{|l|}{650} \\
\hline & 304 & Poor & Good & Very good & \multicolumn{2}{|l|}{815} \\
\hline & 316 & Poor & Good & Very good & \multicolumn{2}{|l|}{815} \\
\hline & 347 & Poor & Good & Very good & \multicolumn{2}{|l|}{815} \\
\hline & Alloy $800 \mathrm{H}$ or HT & Poor-Fair & Good & Very good & \multicolumn{2}{|l|}{980} \\
\hline \multirow[t]{4}{*}{ Monolithic } & Hastelloy $\mathrm{N}$ & Excellent & Good & Very good & \multicolumn{2}{|l|}{730} \\
\hline & Haynes 242 & Very good & Good & Very good & \multicolumn{2}{|l|}{540} \\
\hline & Alloy $800 \mathrm{H}$ or HT & Poor-Fair & Good & Very good & \multicolumn{2}{|l|}{980} \\
\hline & Candidate materials & $\begin{array}{c}\begin{array}{c}\text { Metallurgical } \\
\text { stability }\end{array} \\
\end{array}$ & $\begin{array}{c}\text { Irradiation } \\
\text { resistance }\end{array}$ & Fabricability & Maturity & Codified \\
\hline \multirow[t]{5}{*}{ Coated } & $9 \mathrm{Cr}-1 \mathrm{MoV}$ & Fair & Good & Good & High & Sect. III, VIII \\
\hline & 304 & Good & Good & Good & High & Sect. III, VIII \\
\hline & 316 & Good & Good & Good & High & Sect. III, VIII \\
\hline & 347 & Good & Good & Good & High & Sect. III, VIII \\
\hline & Alloy $800 \mathrm{H}$ or HT & Good & Good & Good & High & Sect. I, III, VIII \\
\hline \multirow[t]{3}{*}{ Monolithic } & Hastelloy $\mathrm{N}$ & Good & Good & Good & High & Sect III,* VIII \\
\hline & Haynes 242 & Good & Adequate & Good & Low & Sect. VIII \\
\hline & Alloy $800 \mathrm{H}$ or HT & Good & Good & Good & High & Sect. III, VIII \\
\hline
\end{tabular}


Table 5.2. Coated high-temperature alloys or monolithic alloys potentially suited for AHTR needs

\begin{tabular}{|c|c|c|c|c|c|c|}
\hline & Candidate materials & $\begin{array}{l}\text { Salt corrosion } \\
\text { resistance }\end{array}$ & $\begin{array}{l}\text { Air corrosion } \\
\text { resistance }\end{array}$ & $\begin{array}{c}\text { Long-term strength at } \\
\qquad 1000^{\circ} \mathrm{C}\end{array}$ & $\begin{array}{l}\text { Highest usage } \\
\text { temperature }\left({ }^{\circ} \mathrm{C}\right)\end{array}$ & $\begin{array}{c}\text { Potential AHTR } \\
\text { component } \\
\text { usage* }\end{array}$ \\
\hline \multirow[t]{6}{*}{ Coated } & Inconel 617 & Needs evaluation & Good & Very good & 1000 & $\mathrm{PM}, \mathrm{P}, \mathrm{V}, \mathrm{HX}$ \\
\hline & VDM 602CA & Needs evaluation & Good & Good & 1000 & $\mathrm{P}, \mathrm{V}, \mathrm{HX}$ \\
\hline & Alloy $800 \mathrm{H}$ & Needs evaluation & Poor & Good & 1000 & $\mathrm{P}, \mathrm{HX}$ \\
\hline & Haynes 230 & Needs evaluation & Marginal & Good & 900 & $\mathrm{P}, \mathrm{HX}$ \\
\hline & Hastelloy X or XR & Needs evaluation & Poor & Good & 900 & $\mathrm{P}, \mathrm{HX}$ \\
\hline & HP modified & Needs evaluation & Good & Excellent & 1100 & $\mathrm{~V}$ \\
\hline \multirow[t]{5}{*}{ Monolithic } & Haynes 214 & Very good & Good & Good & 1000 & $\mathrm{~V}, \mathrm{HX}, \mathrm{CHX}$ \\
\hline & MA 956 & Very good & Good & Good & $?$ & $\mathrm{HX}, \mathrm{CHX}$ \\
\hline & MA 754 & Very good & Good & Good & $?$ & $\mathrm{HX}, \mathrm{CHX}$ \\
\hline & Cast Ni superalloys & Very good & Good & Good & $?$ & $\mathrm{PM}$ \\
\hline & Candidate materials & $\begin{array}{c}\text { Metallurgical } \\
\text { stability }\end{array}$ & $\begin{array}{c}\text { Irradiation } \\
\text { resistance }\end{array}$ & Fabricability & Alloy maturity & Codified \\
\hline \multirow[t]{6}{*}{ Coated } & Inconel 617 & Good & Good & Good & High & Sect. VIII \\
\hline & VDM 602CA & Good & $\mathrm{N} / \mathrm{A}$ & Good & Medium & Sect. VIII \\
\hline & Alloy $800 \mathrm{H}$ & Good & $\mathrm{N} / \mathrm{A}$ & Good & High & Sect. I, III, VIII \\
\hline & Haynes 230 & Good & N/A & Fair-Good & High & Sect. I, VIII \\
\hline & Hastelloy X or XR & Good & $\mathrm{N} / \mathrm{A}$ & Good & High & Sect. I, VIII \\
\hline & HP modified & Good & $\mathrm{N} / \mathrm{A}$ & Cast only & High & API \\
\hline \multirow[t]{4}{*}{ Monolithic } & Haynes 214 & Fair-Poor & $\mathrm{N} / \mathrm{A}$ & Poor-Fair & Low & No \\
\hline & MA 956 & Good & $\mathrm{N} / \mathrm{A}$ & Poor-Fair & Low & No \\
\hline & MA 754 & Good & $\mathrm{N} / \mathrm{A}$ & Poor-Fair & Low & No \\
\hline & Cast Ni superalloys & Good & Adequate & Cast only & High & No \\
\hline
\end{tabular}

*PM-pump
P-piping
V-valves
HX-heat exchanger
CHX_compact HX




\subsection{HIGH-TEMPERATURE MELT-INFILTRATED COMPOSITES}

(LSI C/C composites are a potentially attractive construction material for high-temperature heat exchangers, piping, pumps, and vessels for the AHTR because of their ability to maintain nearly full mechanical strength to high temperatures (up to $1400^{\circ} \mathrm{C}$ ), the simplicity of their fabrication, their low residual porosity, and their moderate cost. ${ }^{9,43}$ Intermediate heat exchangers fabricated from these materials could potentially be located inside the AHTR-VT vessel, eliminating external primary piping and heat exchangers. LSI composites are fabricated from low-modulus carbon fiber that can be purchased in bulk at around $\$ 20$ per kilogram and at lower costs for chopped carbon fibers.

Chopped carbon fiber can provide a particularly attractive material that can be readily formed by pressing with dies and machined using standard milling tools and then assembled into complex parts. In the United States, centrifugal pump impellors and casings are now routinely machined from carbon-fiber reinforced phenolic resin preforms, a machining process that could be readily extended to the machining of $\mathrm{C} / \mathrm{C}$ preform materials prior to LSI processing for use at high temperatures. ${ }^{43}$

LSI C/C-SiC composite heat exchangers, and other components, capable of operating with highpressure helium, molten fluoride salts, and sulfuric acid, could have great value both for thermochemical production of nuclear hydrogen with the sulfur-iodine or hybrid process and for use for components in fusion blanket systems using molten salts as coolants and neutron shielding media (e.g., heat exchangers to transfer heat from molten salts to power-cycle helium).

Three primary materials questions will need to be answered by research to confirm the viability of using these materials for these applications. These include testing for materials compatibility with molten salt and sulfuric acid as a part of these materials compatibility studies now under way in the DOE nuclear hydrogen program, to confirm material corrosion performance, and studies of helium permeation in appropriate small test articles.

Of greatest interest is the potential to fabricate compact plate-type heat exchangers that can provide very high surface-area-to-volume ratios and very small fluid inventories while operating at high temperatures with small temperature drops. Fabrication might be possible using plates a few to several millimeters thick fabricated from chopped fiber $\mathrm{C} / \mathrm{C}$ preform material.

One side of each plate would be die-embossed, or milled, to provide appropriate flow channels, leaving behind fins or ribs that would provide enhanced heat transfer as well as mechanical connection by a reaction bond to the smooth side of the next plate. Typical flow-channel geometries are shown in Fig. 5.1. For the green $\mathrm{C} / \mathrm{C}$ material, milling can be performed readily with standard numerically controlled milling machines, as shown in Fig. 5.2. Alternatively, plates can be molded with the flow channels, as has been demonstrated for $\mathrm{C} / \mathrm{C}$ composite plates fabricated at ORNL for fuel cells (shown in Fig. 5.3). As shown in Fig, 5.1, the channels for the molten salt would have a smaller cross-sectional area than those for the helium because of the much higher volumetric heat capacity of the molten salt. 


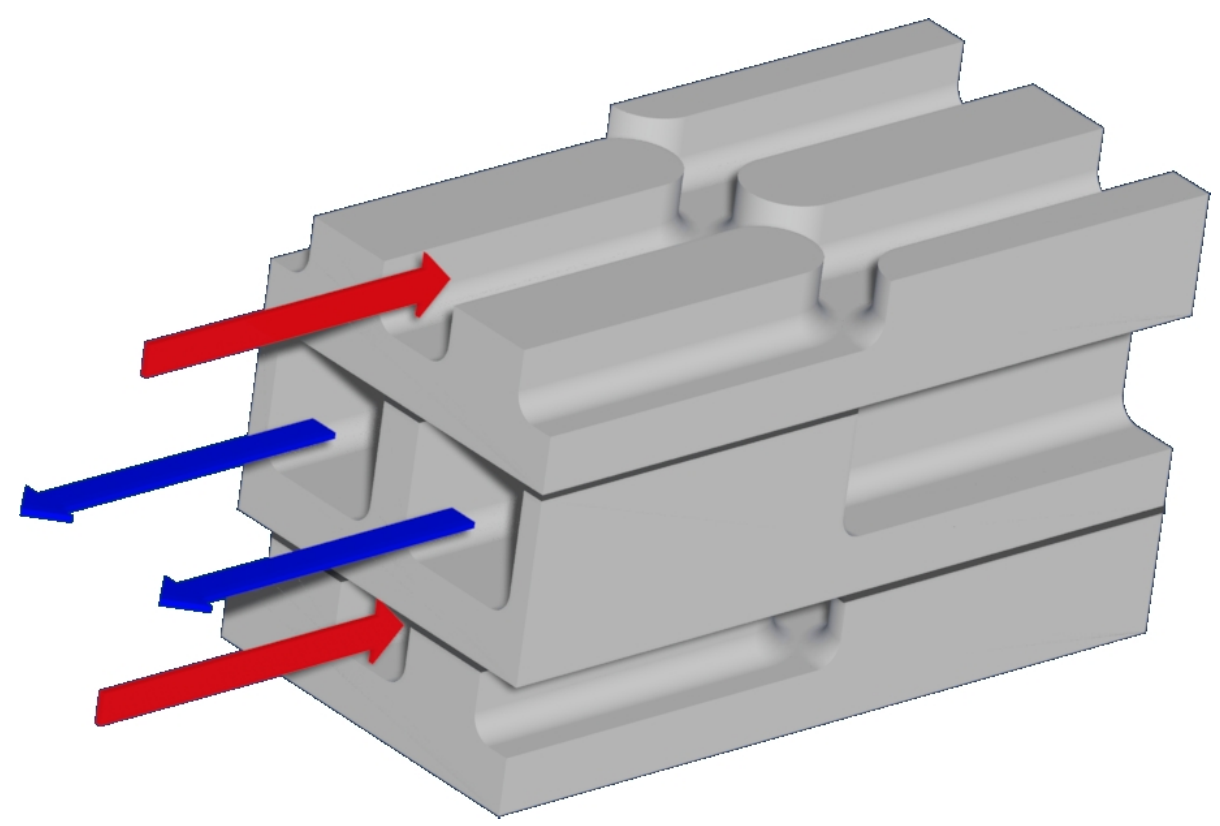

Fig. 5.1. A unit cell of an LSI C/C-SiC plate heat exchanger.
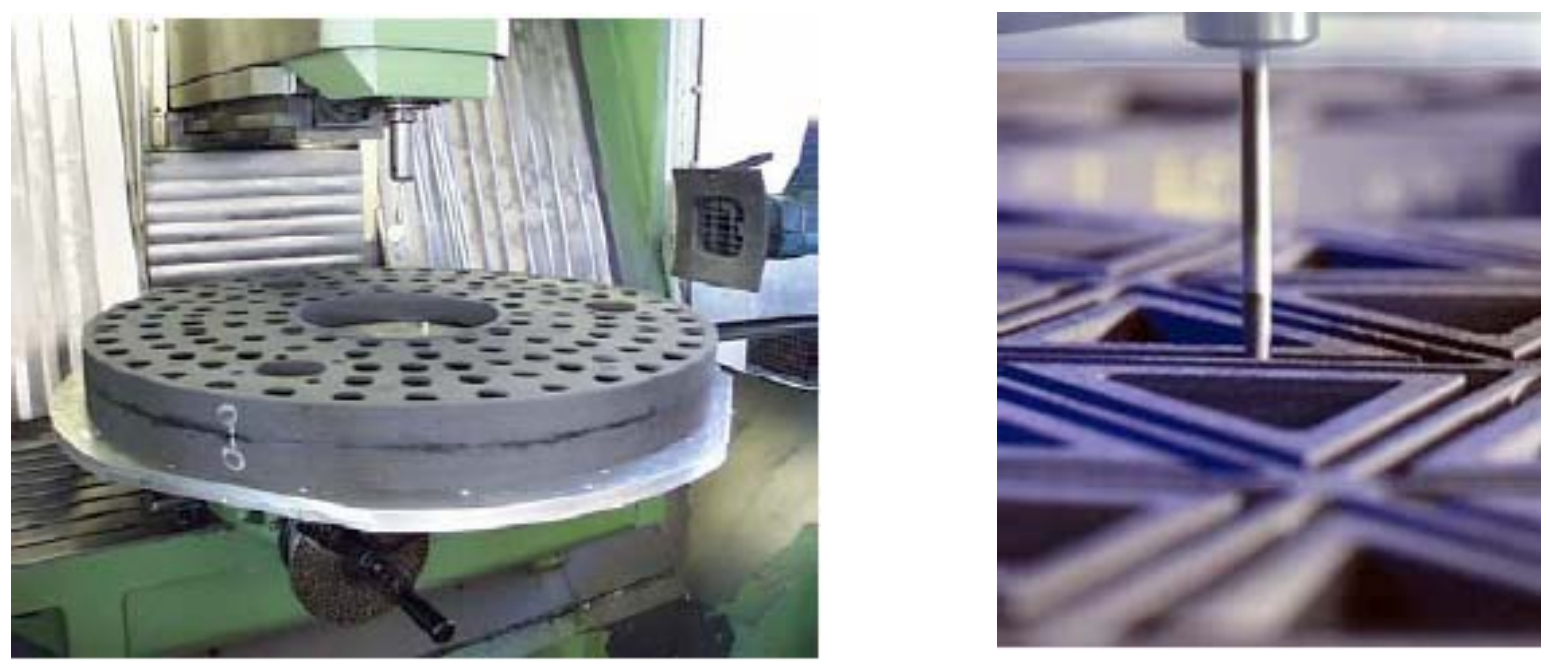

Fig. 5.2. Photos of numerically controlled milling being performed on carbon-carbon green-body material. Source: Ref. 44. 


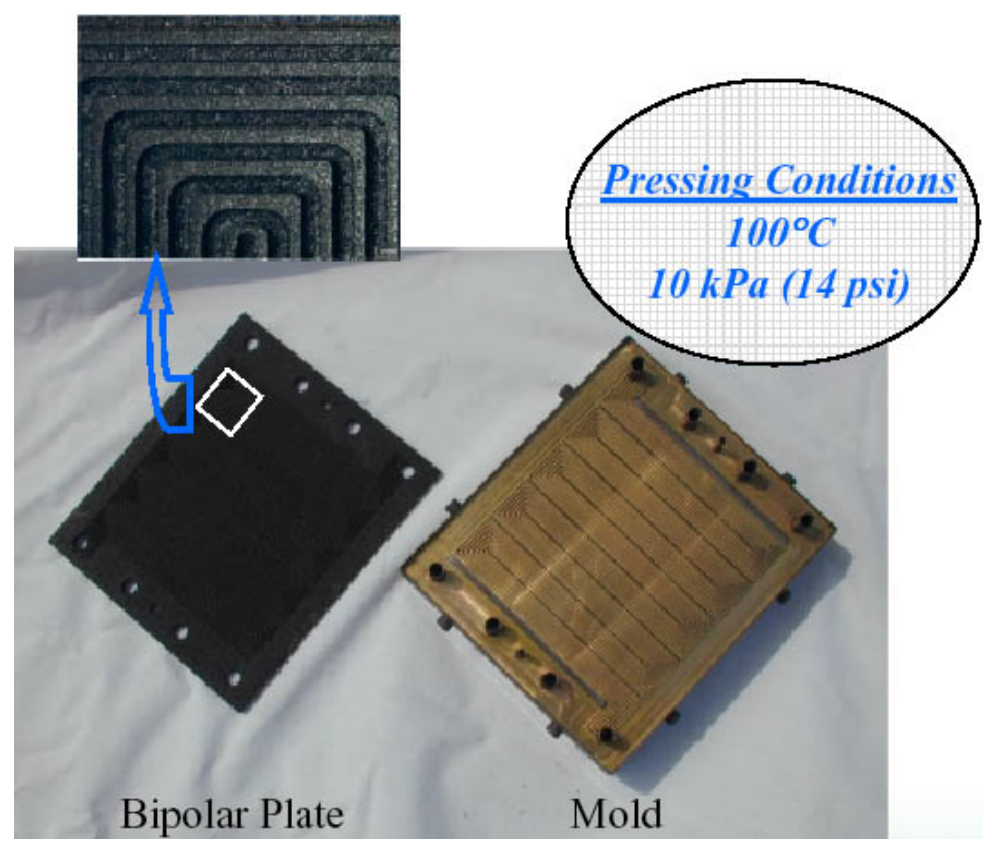

Fig. 5.3. Pressed plate of short-fiber carbon-carbon composites showing the fabrication of flow channels using molds for application to fuel cells. Source: Ref. 45.

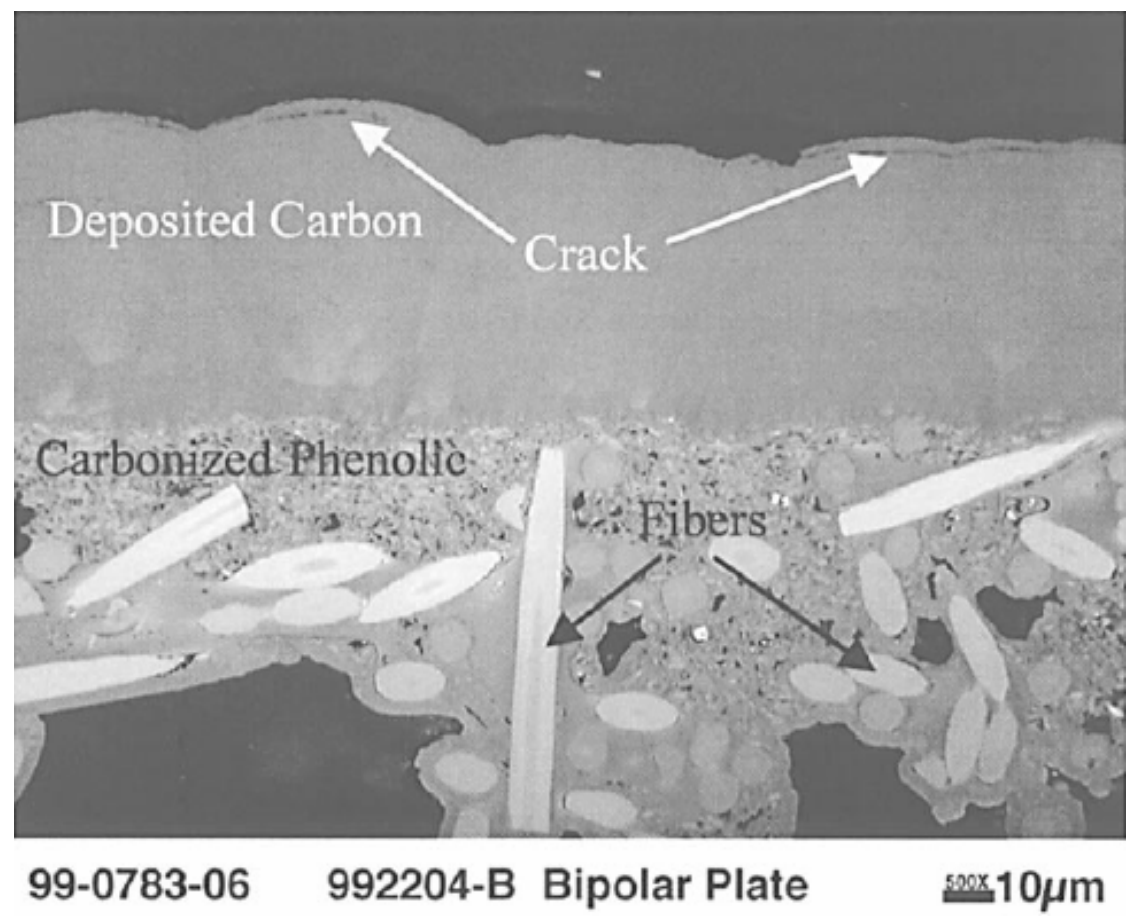

Fig. 5.4. Photo of chemical vapor infiltration-deposited carbon layer on a carbon-carbon composite plate. Source: Ref. 5. 
The flow configuration through the plates would be similar to that of a standard plate heat exchanger, where circular holes at each corner provide flow paths for fluids entering and leaving from between alternating plates. For assembly, the ends of the fins and other remaining unmachined surfaces around the machined flow channels would be coated with phenolic adhesive, the plate stack assembled, header pipes bonded and reinforced, and the resulting monolith pyrolysed under compression. Then liquid silicon would be infiltrated to reaction-bond the plates and headers together, forming a compact heat exchanger monolith.

Optionally, surfaces to be exposed to molten salts could be coated with carbon using chemical vapor infiltration (CVI). Such methods have been developed at ORNL for coating C/C composite plates for fuel cells. ${ }^{45}$ Figure 5.4 shows a $\mathrm{C} / \mathrm{C}$ composite plate coated at ORNL using the CVI method. Methane, potentially with a carrier gas like argon, flows at low pressure $(\sim 8 \mathrm{kPa})$ between the plates at temperatures around $1500^{\circ} \mathrm{C}$ and deposits a graphitic carbon layer with a preferred crystallographic orientation with the $c$ direction of the hexagonal structure normal to the deposition surface. The basal planes then lie parallel to the surface, so that cracks are more likely directed along the surface rather than through the thickness. From the perspective of protecting the substrate material from the molten salt, some porosity of the carbon layer could be acceptable, as is found for nuclear graphite, for which DeVan et al. ${ }^{46}$ have noted, "Completely sealing these pores [in graphite] is impractical, the material will simply 'blow-up' due to internal pressure developed during heat treatment. However, since the molten salts are non-wetting to graphite and possess a high surface tension, it is only necessary to reduce the entrance pore diameter to $<1$ micron to prevent salt intrusion" (p. 485).

ORNL also subjected samples treated by CVI of carbon to $100 \mathrm{MPa}$ stresses in bidirectional bending of plates. ${ }^{45}$ These samples were then tested for hermeticity by pressurizing one side with $206 \mathrm{kPa}$ of hydrogen and measuring the through-thickness gas leakage rate, and it was found that excellent permeation resistance could be achieved.

Activities to fabricate and test LSI test samples are now under way at UCB as a part of the DOE nuclear hydrogen program. 


\section{SAFETY SYSTEMS}

The AHTR has the potential to provide a robust safety case because of various inherent and passive safety characteristics. Inherent safety characteristics include moderate core power density, hightemperature-margin fuel, a high-thermal-inertia core, efficient decay-heat removal based on effective heat transfer of the molten salt (which requires no moving parts or control activation signals), atmospheric pressure operation, and efficient liquid-coolant heat transfer. Reactor power is intrinsically limited by negative temperature feedback (Doppler effect) within the fuel. The reactor physics and kinetics are similar to that of the GT-MHR. A series of systems are designed to remove decay heat and provide protection in beyond-design-basis accidents.

\subsection{AHTR CORE THERMAL INERTIA}

One of the most important safety characteristics of a reactor is its thermal inertia. If a reactor has an appropriately large thermal inertia, it will take days before the decay heat raises the reactor temperature sufficiently to cause fuel failure. This has several advantages: (1) provides time for operator action, (2) reduces the requirements on the decay heat removal system, and (3) provides time for short-lived radionuclides to decay away. The AHTR has a very large thermal inertia because it combines the efficient natural-circulation liquid heat transfer with high-temperature capabilities. The effective utilization of this thermal inertia requires, however, a reliable TBS to maintain the reactor vessel at lower temperatures while the primary salt and core are heated to higher temperatures. For safety analysis, key issues will involve assessing the uncertainty in predictions of the heat transfer rate across the TBS and assessing the effects of TBS component failures in creating potential leakage and thermal bypass across the TBS.

\subsection{RVACS/DRACS DECAY HEAT REMOVAL}

Thermal inertia can slow the temperature rise in the reactor core; however, decay heat removal is ultimately required. The thermal capacity of the $2400 \mathrm{MW}(\mathrm{t})$ AHTR core is more than a factor of four greater than the $600 \mathrm{MW}(\mathrm{t}) \mathrm{GT}-\mathrm{MHR}$, while maintaining a peak core temperature of $1160^{\circ} \mathrm{C}$ at 50 hours in the AHTR. The acceptable thermal power of the AHTR is then limited by the peak decay-heat removal capacity of the RVACS, potentially supplemented by a DRACS. The $600 \mathrm{MW}(\mathrm{t}) \mathrm{GT}-\mathrm{MHR}$ reactor cavity cooling system (RCCS) has a peak capacity that matches the decay heat output at the time of peak core temperature 50 hours after loss of cooling. To achieve the same 50-h duration at $2400 \mathrm{MW}(\mathrm{t})$, the AHTR RVACS/ DRACS system must have a heat removal capacity four times that of the GT-MHR.

The AHTR uses passive RVACS similar to that developed for the General Electric sodium-cooled S-PRISM for decay heat removal. ${ }^{47}$ The reactor and decay heat cooling system is located in a below-grade silo. In this pool reactor, RVAC system decay heat is (1) transferred to the reactor vessel graphite reflector by natural circulation of the molten salts, (2) conducted through the graphite reflector and reactor vessel wall, (3) transferred across an argon gap by radiation to a guard vessel, (4) conducted through the guard vessel, and then (5) removed from outside of the guard vessel by natural circulation of ambient air. The rate of heat removal is controlled primarily by the radiative heat transfer through the argon gas from the reactor vessel. Radiative heat transfer increases by the temperature to the fourth power $\left(\mathrm{T}^{4}\right)$; thus, a small rise in the reactor vessel temperature (as would occur upon the loss of normal decayheat-removal systems) greatly increases heat transfer out of the system. The design allows transfer of the heat by efficient liquid natural convection from the center of the reactor core (hot-spot location) to near the vessel wall. The vessel layout also allows the addition of supplemental DRACS heat exchangers, similar to those used in the EBR-II, to augment decay heat removal by the RVACS.

While the potential for highly effective RVACS heat removal exists for the AHTR, detailed design will be required to optimize and maximize its heat removal capability. There are multiple RVACS cooling options, including operating the reactor vessel at lower temperatures than the molten salt coolant. Scaling of both the thermal inertia and RVACS heat removal capability of the AHTR suggest that reactor thermal 
power greater than $2400 \mathrm{MW}(\mathrm{t})$ should be achievable with a vessel of the same volume as the GT-MHR or S-PRISM. The additional use of a DRACS could further augment the reactor power.

\subsection{BEYOND-DESIGN-BASIS ACCIDENTS}

\subsubsection{Accident Mitigation}

Among solid-fuel reactors, the AHTR has potentially unique accident-mitigation capabilities; that is, characteristics that limit the extent and scope of an accident and potential radioactive releases.

- Fuel. The AHTR uses the same fuel as the GT-MHR. This high-temperature fuel has the same excellent high-temperature fission product retention capabilities.

- Coolant. Most fission products (excluding primary krypton and xenon) and all actinides escaping the fuel are soluble in the molten salt and will remain in the molten salt at very high temperatures. Cesium and iodine remain in the salt. Fluoride salts were chosen for the liquid-fueled molten salt reactor, in part because actinides and fission products dissolve in the molten salt at very high temperatures. ${ }^{3}$

- Low energetics. The chemical inertness and low pressure of the molten-salt coolant eliminate the potential for damage to the confinement structure by rapid chemical energy releases (e.g., sodium) or coolant vaporization (e.g., water).

- Fuel isolation. The molten salt excludes access of air to the solid fuel. This avoids concerns about graphite fuel oxidation and prevents direct transfer of radionuclides from fuel to air.

\subsubsection{Beyond-Design-Basis Accidents with Vessel Failure}

In a beyond-design-basis accident, it is assumed that the air-cooled passive decay-heat-cooling system has failed and that significant structural failures (vessel failure, etc.) have occurred. Decay heat continues to heat the reactor core but decreases with time. To avoid the potential for catastrophic accidents (accidents with significant release of radionuclides), the temperature of the fuel must be kept below that of fuel failure by (1) absorption of decay heat in the reactor and silo structure and (2) transfer of decay heat through the silo walls to the environment. For the modular high-temperature gas-cooled reactor (MHTGR), ${ }^{4}$ the maximum size of reactor that can withstand this accident without major fuel failure is $\sim 600 \mathrm{MW}(\mathrm{t})$.

Work has begun ${ }^{48}$ to define the maximum size AHTR that can withstand this type of accident based on the earlier work on MHTGRs. The choice of (1) a high-temperature fuel and (2) a low-pressure (relatively chemically inert), high-temperature coolant enables construction of larger reactors with this capability. The beyond-design-basis strategy can be understood by following the sequence of expected events and defining the mechanisms to prevent massive fuel failure (Fig. 6.1).

- Reactor vessel heat up. After loss of decay heat cooling, the initial event is heat up of the reactor vessel. The AHTR thermal inertia per megawatt thermal in the reactor vessel exceeds that of the MHTGR; that is, the peak fuel temperatures increase at a slower rate after loss of all cooling. This slower increase occurs despite the fact that the AHTR vessel volume [2400 MW(t), 9.2-m diam, $1260 \mathrm{~m}^{3}$ ] is almost identical to that of the MHTGR [600 MW(t), 8.4-m diam, $1210 \mathrm{~m}^{3}$ ] and reflects the more efficient use of the thermal inertia of materials within the reactor vessel.

Under design-basis depressurization loss-of-cooling conditions in the MHTGR, ${ }^{49}$ large radial and vertical temperature gradients exist within the reactor vessel. Under depressurized conditions, the MHTGR peak fuel temperature reaches $1560^{\circ} \mathrm{C}$ after 60 hours, while the peak temperatures of the reactor vessel are under $600^{\circ} \mathrm{C}$. Large temperature gradients are needed to remove the decay heat by conduction. If the reactor remains pressurized with better heat transfer in the reactor vessel, the core temperature peaks at only $1240^{\circ} \mathrm{C}$ at 50 hours, because of the more uniform core 
temperature caused by natural convection of the high-pressure helium coolant. Most of the mass in the reactor is far below allowable peak temperatures and not efficiently used to maximize the effective thermal inertia.

The larger total thermal inertia of the AHTR is a consequence of (1) the molten salt circulation, which ensures almost isothermal conditions within the reactor core and (2) the higher-heatcapacity reactor core. The conceptual design of the AHTR has a 9.2-m diam, 5-cm vessel with a $0.65-\mathrm{m}$-thick graphite liner and reflector and an effective annular core diameter of $7.8 \mathrm{~m}$.

Conversely, the effective core diameter of the MHTGR is only $4.9 \mathrm{~m}$ because of the 0.22 -m-thick vessel wall, the inner core barrel and shell for helium inlet down flow and vessel thermal conditioning, and the graphite reflector. In both reactors, the centers of the annular cores are filled with graphite that is included in the calculations of core heat capacity. In the vertical direction, the MHTGR heats the 1.6-m-thick graphite reflector, located above the 7.9-m-high core. Conversely, the AHTR provides a 6.8-m-deep molten-salt pool above the core. Thus for the AHTR, the ratio of the active volume to absorb heat relative to that of the MHTGR is 4.1. Furthermore, in the MHTGR a significant fraction of the thermally active volume is occupied by helium, which has negligible heat capacity. Conversely, in the AHTR, all of the active volume is occupied by graphite or by molten salt, which has a larger specific heat capacity than graphite. ${ }^{12}$

- Vessel failure. High temperatures ultimately cause the vessel to fail. Molten salt coolant from the reactor vessel fills the bottom of the silo. The reactor vessel contains sufficient salt to keep the reactor core flooded. The circulating molten salt between the reactor vessel and silo efficiently transfers heat from the reactor vessel to the silo wall. Several different molten salts are being considered as reactor coolants. The freezing points are typically $350^{\circ} \mathrm{C}$ or somewhat higher. When the salt contacts the cold silo wall, it freezes. Unlike water, the salt will not leak out. Furthermore, no major chemical reactions that generate heat or gases will occur, which is not the case with sodium.

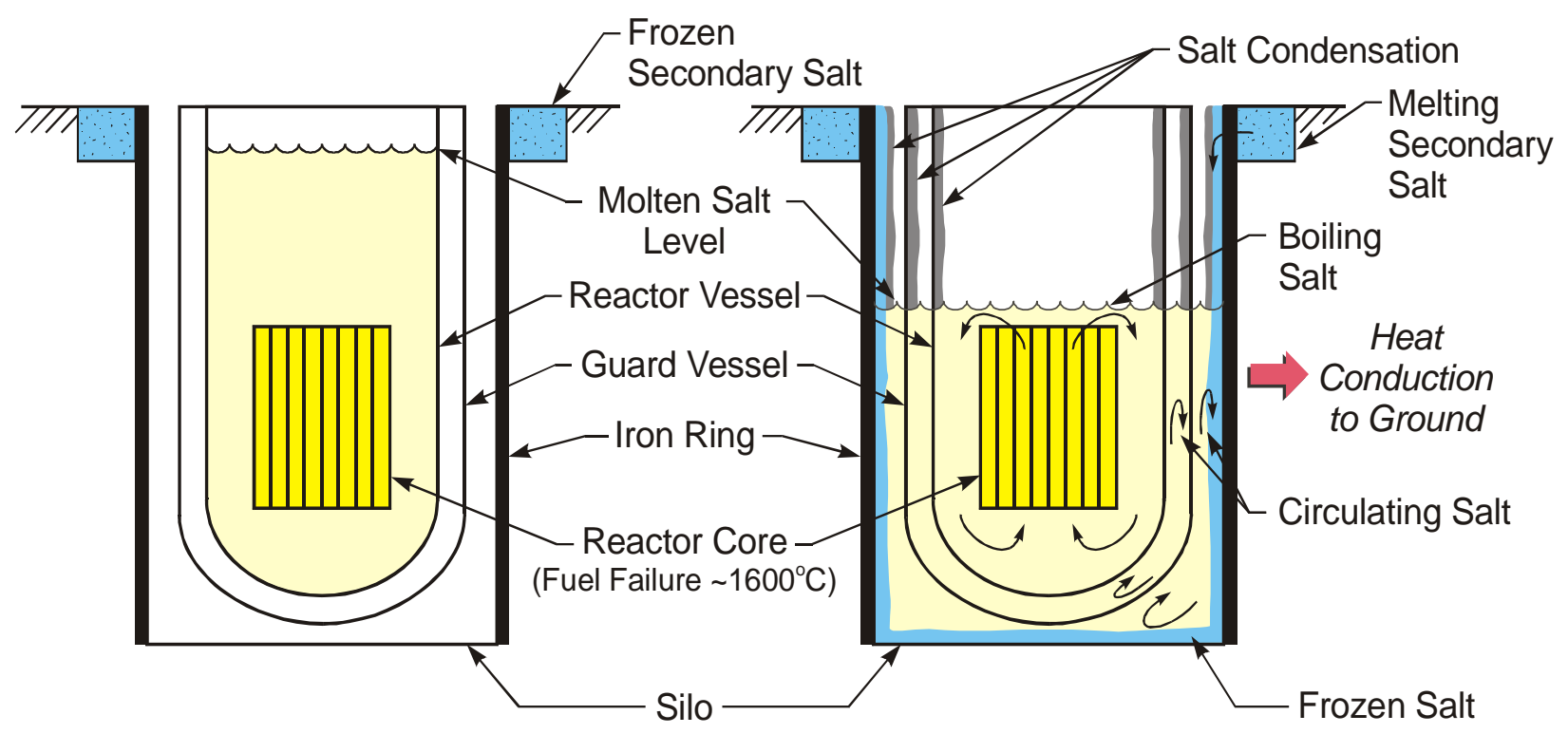

Fig. 6.1. Normal and beyond-design-basis accident states for the AHTR. 
- Silo-wall heat conduction. The silo wall contains low-cost thick steel rings that are similar to those used in the mining industry to line deep mine shafts and prevent their collapse. In the mining industry, these rings are referred to as tubing or "ausbau." The diameter of the AHTR silo is similar to that of large mine shafts, but the depth is only $20 \mathrm{~m}$. Under operating conditions, the rings are cooled by exposure to outside air that is drawn down in the silo and then flows up on the other side of a partition to remove heat from the guard vessel. Following vessel failure, the rings conduct heat up of the silo wall and distribute it above the coolant salt layer.

- Secondary-salt melting. Near the top of the silo is an annular ring of a secondary solidified molten salt. As the temperature of the secondary salt increases, the secondary salt melts, flows into the silo, and floods the silo to a higher level. The melting, heating, and boiling of the secondary salt can provide a significant source of thermal inertia.

- Heat absorption. Typical fluoride salts have a volumetric heat capacity ${ }^{12,50}$ of $\sim 4000$ $\mathrm{kJ} /\left(\mathrm{m}^{3}{ }^{\circ} \mathrm{C}\right)$. If the secondary salt was allowed to be heated to $1000^{\circ} \mathrm{C}$, it would absorb $0.046 \mathrm{MWd} / \mathrm{m}^{3}$. The heat of vaporization for typical fluorides is about $0.16 \mathrm{MWd} / \mathrm{m}^{3}$. Depending upon design, the heat up and selected boil off of secondary salt components can absorb several days of decay heat.

- Salt selection. Unlike the reactor coolant salt, the secondary salt has no requirement for low nuclear cross sections to minimize neutron absorption. A variety of chloride and fluoride salts are potential candidates. Studies have not yet been conducted to define the preferred salt based on cost and performance requirements (compatibility with coolant salt and melting point). If appropriate low-cost salts are found, the option exists for the secondary-salt inventory to absorb days to weeks of decay heat.

- Heat conduction to earth. Heat is conducted to the earth surrounding the silo and ultimately to the environment. The 600-MW(t) MHTR uses the same approach for ultimate heat rejection in a beyond-design-basis accident. However, significant differences are noted between gas-cooled and molten-salt-cooled reactors in their ability to reject heat to the ground.

- Heat transfer area. The flooding of the silo with molten salt increases the effective surface area of heat transfer from the reactor vessel to the silo wall. If the silo is full of molten salt, the entire silo wall, not a small section of the wall, rejects heat to the environment. The placement of the reactor core at the very bottom of the reactor vessel allows full utilization of the complete silo area. Because molten salt heat fluid is used for heat transfer, heat rejection rates can be further increased by (1) increasing silo depth or

(2) designing the top of the silo with its shorter pathway for heat rejection to the environment. The effective heat transfer area is thus doubled.

- Uniform temperatures. Natural circulation of the molten salt results in a relatively uniform temperature throughout the silo. The vertical temperature gradient will be only a few tens of degrees.

- Temperature drops. The peak temperature of the fuel is fixed by the need to avoid fuel failure. Temperature drops occur from the fuel to reactor vessel wall, from the vessel wall to silo wall, and from the silo wall into the earth. Liquid cooling (reactor coolant and secondary salt) minimizes the first two temperature drops. This allows for higher silo temperatures, which, in turn, allow greater heat rejection to the ground.

Extrapolations from the MHTGR (considering heat capacity, effective silo surface area, and available temperature to drive heat from the silo wall to the environment) indicate that a $2400 \mathrm{MW}(\mathrm{t})$ AHTR with beyond-design-basis-accident capabilities could be built. However, major uncertainties remain because such systems imply high temperatures near the silo and reactor facilities. There are many design choices and tradeoffs, ${ }^{51}$ including options that may not require a secondary salt. 
Most fission products (including cesium and iodine) and all actinides escaping the solid AHTR fuel are soluble in the molten salt and will remain in the molten salt at very high temperatures. Fluoride salts were chosen for the liquid-fueled molten-salt reactor because actinides and fission products dissolve in the molten salt at very high temperatures. ${ }^{3}$ This same characteristic applies to the AHTR and provides the reactor with a second, independent beyond-design-basis-accident mitigation system to prevent radionuclide release to the environment.

\subsection{INTERMEDIATE HEAT TRANSPORT LOOP}

If the AHTR is used to produce hydrogen, a key issue is the coupling of the two plants via the intermediate heat transport loop. The intermediate heat transfer system has two sets of safety-related functional requirements: (1) protect the reactor and chemical plant from transients and accidents in either facility and (2) protect the reactor and chemical plant from transients and accidents within the intermediate heat transfer system. Molten salts may offer major safety advantages compared to helium for this application.

The primary hazard associated with thermochemical production of hydrogen is the large inventory of toxic hazardous chemicals. For example, in the sulfur iodine process this includes hydrogen iodine (HI), iodine $\left(\mathrm{I}_{2}\right)$, sulfuric acid $\left(\mathrm{H}_{2} \mathrm{SO}_{4}\right)$, sulfur trioxide $\left(\mathrm{SO}_{3}\right)$, sulfur dioxide $\left(\mathrm{SO}_{2}\right)$, and hydrogen $\left(\mathrm{H}_{2}\right)$. From a chemical perspective, the primary hazards are associated with toxic heavy gases. Chemical industry experience (e.g., Bhopal) shows that the most dangerous materials are those associated with toxic heavy gases that migrate at ground level, go downwind offsite, and come in contact with people. In contrast, the hazards associated with hydrogen are localized to within the chemical plant because hydrogen is a light gas that rapidly rises. Hydrogen is not the primary safety concern in an industrial environment.

There are two types of energy sources that can enable the rapid dispersal of hazardous chemicals as a fine aerosol or gas in an accident-high-pressure gases and highly energetic chemical reactions. Both must be considered in terms of plant safety.

If the heat transfer loop is at pressures in excess of the chemical plant, the compressed heat transfer fluid becomes an energy source to disperse hazardous chemicals if a heat exchanger fails. The chemical industry has traditionally used low pressure, low-energetic liquids as heat transfer agents to avoid this type of accident. This has included various molten salts in traditional applications to $\sim 600^{\circ} \mathrm{C}$. Several chemical companies, such as DOW, produce specialized heat transfer liquids for these applications. Because there has not been a demand, molten salt heat transfer agents for very high temperatures have not been developed or commercialized.

High-pressure helium has not been used for safety, performance, and cost reasons. If helium is allowed, active safety systems with very fast acting valves dumping to atmosphere will be required for rapid depressurization in the event of an accident before the chemical plant is pressurized and disperses hazardous chemicals.

The second type of accident initiator is associated with chemical reactions between the heat transfer fluid and the chemical plant fluids. Helium is chemically inert; thus, is safe in this context. The safety of fluoride molten salts for this application was evaluated using the HSC 5.1 thermodynamics package by Outokoumpu Research of Finland. This preliminary safety evaluation examined chemical reactions between sulfuric acid $\left(\mathrm{H}_{2} \mathrm{SO}_{4}\right)$ and $\mathrm{NaF}-\mathrm{KF}-\mathrm{ZrF}_{4}\left(10-48-42\right.$ mole \%) salt at $1 \mathrm{~atm}$ and $850^{\circ} \mathrm{C}$. The evaluation indicated that the potential chemical reaction was endothermic; that is, the reaction only progresses if heat is applied. The analysis also indicates that if the reaction went to completion, the gas volume of reactants would increase by $15 \%$. The preliminary analysis indicates that there is only a limited potential for safety concerns from mixing the thermochemical plant reagents with the molten salt heat transfer fluid. Accidents are self limiting.

Table 6.1 shows the chemical reagents before mixing and the equilibrium thermodynamic mixture if the reaction goes to completion; that is, sufficient heat is provided to drive the reaction to completion. It is 
noted that the heating of sulfuric acid to $850^{\circ} \mathrm{C}$, as shown in the second column, results in the dissociation of sulfuric acid into various chemical species.

Criteria for selection of a molten salt for transport of heat should include criteria to assure chemical plant safety. In most cases, this criterion is not expected to have a significant impact on the choice of molten salt. The transport of heat imposes two technical criteria on the choice of the salt: (1) thermally stable at very high temperatures and (2) compatible with the materials of construction used for piping and heat exchangers. These criteria require selection of fluoride salts that are thermodynamically very stable. This required characteristic also makes exothermic chemical reactions with chemical process reagents unlikely in practical systems.

Table 6.1. Thermodynamic equilibrium $\left(850^{\circ} \mathrm{C} ; 1 \mathrm{~atm}\right)$ between 200 moles of sulfuric acid $\left(\mathrm{H}_{2} \mathrm{SO}_{4}\right)$ and 100 moles of the molten salt: NaF-KF-ZrF 4 (10-48-42)

\begin{tabular}{|c|c|c|}
\hline Species & Before interaction & At equilibrium \\
\hline $\mathrm{H}_{2} \mathrm{O}(\mathrm{g})$ & 200 & 87.66 \\
$\mathrm{SO}_{2}(\mathrm{~g})$ & 165.4 & 145.09 \\
$\mathrm{O}_{2}(\mathrm{~g})$ & 82.6 & 72.54 \\
$\mathrm{SO}_{3}(\mathrm{~g})$ & 34 & 26.54 \\
$\mathrm{NaF}$ & 10 & 0.06 \\
$\mathrm{KF}$ & 48 & 1.21 \\
$\mathrm{ZrF}$ & 42 & 0.01 \\
$\mathrm{HF}(\mathrm{g})$ & & 224.65 \\
$\mathrm{ZrO}$ & & 41.99 \\
$\mathrm{~K}_{2} \mathrm{SO}_{4}$ & & 23.39 \\
$\mathrm{Na}_{2} \mathrm{SO}_{4}$ & & 4.97 \\
$\mathrm{HSO}_{3}(\mathrm{~g})$ & & 0.011 \\
$\mathrm{SO}_{2} \mathrm{~F}_{2}(\mathrm{~g})$ & & 0.002 \\
\hline
\end{tabular}




\section{ELECTRICITY AND HYDROGEN PRODUCTION}

\subsection{THERMAL CHARACTERISTICS FOR ENERGY CONVERSION}

An important characteristic of the AHTR is the ability to deliver all the heat at high average temperatures without high pumping requirements. Liquid coolants have high-heat capacities and lowpumping power costs in comparison with gas coolants due to their much higher volumetric heat capacities. Liquid-cooled reactors deliver most of their heat at near-constant temperatures, while gascooled reactors deliver their heat over a wide range of temperatures due to pumping power limitations. If a gas-cooled reactor were to deliver most of its heat over a similar small temperature range, the energy consumption in circulating the gas would use a significant fraction of the plant output. The AHTR, as a liquid-cooled reactor, can deliver its heat with small temperature drops $\left(40\right.$ to $\left.100^{\circ} \mathrm{C}\right)$ with low pumping power costs.

\subsection{ELECTRICITY PRODUCTION}

The AHTR has a higher potential efficiency than the GT-MHR at the same reactor coolant exit temperatures, because delivery of most of the heat at near-constant high temperatures allows the use of more-efficient Carnot-like power cycles. The benefit of these advanced cycles is increased efficiency, resulting in up to $20 \%$ increased electrical output for the same thermal power. The cost of this improvement is some increased system complexity. Molten salt coolants present the most promising approach to take advantage of this potential benefit.

The proposed General Atomics GT-MHR, ${ }^{4}$ with a direct recuperative gas-turbine cycle, has an efficiency of $48 \%$ with an exit gas temperature of $850^{\circ} \mathrm{C}$. The AHTR, with an indirect recuperative multireheat gas-turbine cycle (Fig. 2.11), has an efficiency of 54\%-assuming the same temperatures and turbomachinery parameters. ${ }^{7}$ Current materials may allow molten salt temperatures of $\sim 750^{\circ} \mathrm{C}$. At these temperatures, the AHTR matches the efficiency of the GT-MHR with its exit helium temperature of $850^{\circ} \mathrm{C}$. At $1000^{\circ} \mathrm{C}$ turbine inlet temperature that might be obtained with advanced materials, using the same fuel that currently limits the GT-MHR to an exit helium gas temperature of $850^{\circ} \mathrm{C}$, and taking advantage of the improved heat transfer properties of the molten salt (see above), the efficiency of the AHTR can exceed 59\%.

The reference AHTR design employs a recuperated helium Brayton cycle with three stages of reheat and three stages of intercooling. ${ }^{52}$ The helium pressure is reduced through three turbines in series, with reheating of the helium to its maximum temperature with hot molten salt before each turbine. Such power cycles are viable only with (1) indirect power cycles to deliver heat before each turbine and (2) liquidcooled reactors, in which most of the heat from the reactor can be delivered with low-pressure drops at near-constant high temperatures. Calculations have shown that for the same reactor outlet temperatures, the multiple-reheat Brayton cycle increases the thermal efficiency of the AHTR by between 5 to $6 \%$ above that of the GT-MHR with a traditional Brayton cycle. The potential reduction in the reactor vessel conditioning heat load, due to the low-pressure operation of the AHTR, potentially increases the AHTR thermal efficiency by an additional 1 to $2 \%$ relative to that achieved with reactors operated at high pressures.

The differences in pressures between the power cycle and the primary system require appropriate design features to ensure that no overpressurization of the reactor occurs. These include (1) use of an intermediate salt heat transfer loop, (2) minimization of the helium inventory in the power cycle, (3) pressure relief valves for small leaks, and (4) burst relief valves for large leaks. 


\subsection{HYDROGEN PRODUCTION}

The world uses 50 million tons of $\mathrm{H}_{2}$ per year, ${ }^{53,54}$ primarily for fertilizer production and the conversion of lower-grade crude oil into transport fuels. The demand is growing rapidly. Many oil refineries, other $\mathrm{H}_{2}$ users, and merchant $\mathrm{H}_{2}$ plants are now connected by pipelines. The projected market for traditional $\mathrm{H}_{2}$ applications is sufficient to support the development of nuclear methods to produce $\mathrm{H}_{2}$. Furthermore, large-scale R\&D efforts are under way to develop $\mathrm{H}_{2}$ fueled vehicles. The energy required to produce a sufficient amount of $\mathrm{H}_{2}$ for transportation purposes would be approximately equivalent to that used currently to produce electricity.

The largest $\mathrm{H}_{2}$ plants that are under construction ${ }^{55}$ have capacities of 200 million standard cubic feet per day and operate on natural gas. Hydrogen can be produced from water and high-temperature heat (see below). A 1600-MW(t) reactor would be required to produce the energy to manufacture 200 million standard cubic feet per day-assuming 50\% efficient conversion of thermal energy to $\mathrm{H}_{2}$. By the time the AHTR could be deployed, its proposed size $[2000+\mathrm{MW}(\mathrm{t})]$ will match the production capacity requirements of a conventional $\mathrm{H}_{2}$ plant.

There are several methods currently being considered to produce emission-free hydrogen from nuclear energy. The primary candidates ${ }^{56-58}$ are thermochemical cycles and electrolysis, including hightemperature electrolysis. The thermochemical production of $\mathrm{H}_{2}$ involves a series of chemical reactions with the net result of heat plus water yields $\mathrm{H}_{2}$ and oxygen. The incentive for thermochemical production of $\mathrm{H}_{2}$ is that the potential economics of scaling may be significantly better than those for electrolysis of water with electricity. The Japanese estimates ${ }^{58}$ are that the cost of nuclear thermochemical $\mathrm{H}_{2}$ production could be as low as $60 \%$ of that for nuclear $\mathrm{H}_{2}$ production by the electrolysis of water. At the most fundamental level, thermochemical $\mathrm{H}_{2}$ production involves conversion of thermal energy to chemical energy $\left(\mathrm{H}_{2}\right)$ while electrolysis involves conversion of thermal energy to electricity and subsequent conversion of electricity to chemical energy. The additional conversion step adds cost and introduces additional inefficiencies. Efficient $\mathrm{H}_{2}$ production places severe requirements on the reactor, which the AHTR is designed to meet.

Many types of thermochemical processes for $\mathrm{H}_{2}$ production exist. ${ }^{59}$ All of the competitive processes require heat input at temperatures above $750^{\circ} \mathrm{C}$. The sulfuric acid processes (sulfur-iodine and Westinghouse hybrid) are the leading candidates. In each of these processes, the high-temperature, lowpressure endothermic (heat-absorbing) reaction is the catalytic thermal decomposition of sulfuric acid to produce oxygen:

$$
\mathrm{H}_{2} \mathrm{SO}_{4} \rightarrow \mathrm{H}_{2} \mathrm{O}+\mathrm{SO}_{2}+1 / 2 \mathrm{O}_{2}
$$

Based on current technology, temperatures in the range of 800 to $1000^{\circ} \mathrm{C}$ are needed to drive the sulfuric acid decomposition reaction sufficiently to completion for efficient $\mathrm{H}_{2}$ production. (There is research under way that may lower these temperatures to $700^{\circ} \mathrm{C}$ ). After oxygen separation, additional chemical reactions are required to produce $\mathrm{H}_{2}$ and recycle all of the chemical reagents.

The sulfur-iodine process for thermochemical $\mathrm{H}_{2}$ generation has two additional chemical reactions:

$$
\mathrm{I}_{2}+\mathrm{SO}_{2}+2 \mathrm{H}_{2} \mathrm{O} \rightarrow 2 \mathrm{HI}+\mathrm{H}_{2} \mathrm{SO}_{4}\left(\sim 120^{\circ} \mathrm{C}\right)
$$

and the $\mathrm{H}_{2}$-producing step

$$
2 \mathrm{HI} \rightarrow \mathrm{H}_{2}+\mathrm{I}_{2}\left(\sim 450^{\circ} \mathrm{C}\right) .
$$

The hybrid sulfur process (also known as Westinghouse GA-22 and Ispra Mark 11) has a single electrochemical step that completes the cycle: 


$$
\left.\mathrm{SO}_{2}(\mathrm{aq})+2 \mathrm{H}_{2} \mathrm{O}(\mathrm{l}) \rightarrow \mathrm{H}_{2} \mathrm{SO}_{4}(\mathrm{aq})+\mathrm{H}_{2}(\mathrm{~g}) \text { (Electrolysis: } 80^{\circ} \mathrm{C}\right)
$$

The design of the interface between the reactor system and the $\mathrm{H}_{2}$ plant is significantly different from that for heat transfer to the high-pressure helium power conversion system. For the $\mathrm{H}_{2}$ plant, the heat is transferred to a chemical reactor for the disassociation of $\mathrm{H}_{2} \mathrm{SO}_{4}$. The high-temperature step is an equilibrium process. Low pressures and high temperatures yield dissociation products, while high pressures and low temperatures favor formation of $\mathrm{H}_{2} \mathrm{SO}_{4}$; thus, the chemical reactor must operate at high temperatures and relatively low pressure. Chemical dissociation is a near-constant-temperature process that requires that heat be supplied at a near-constant temperature. Because large quantities of lowertemperature heat are not useful for $\mathrm{H}_{2}$ production, the use of liquid-cooled reactors, rather than gas-cooled reactors, is favored. If the heat is needed at $750^{\circ} \mathrm{C}$, the maximum temperature of the molten salt may be as low as $800^{\circ} \mathrm{C}$. In contrast, if a gas coolant is used to provide the heat to the sulfuric acid dissociation step, the maximum temperature of the coolant may exceed $1000^{\circ} \mathrm{C}$ to limit costs of pumping the gas coolant through the reactor and chemical plant. Considerations involving process, safety (potential release of hazardous chemicals in the $\mathrm{H}_{2}$ production system), and materials (reduced strength of materials at high temperatures) all indicate that an optimized chemical reactor (heat transfer equipment) should operate at relatively low pressures and at temperatures only slightly above those needed for the chemical reactions. These high-temperature and low-pressure requirements match the AHTR capabilities.

The production of $\mathrm{H}_{2}$ requires isolation of the reactor from the chemical plant, probably using an intermediate heat transfer loop between the primary reactor coolant and the thermochemical cycle. Efficient heat transfer is required in this intermediate loop to minimize temperature loses and pumping power requirements. The high heat transfer and low pressures characteristics of the molten salts are among the best coolant choices to meet these requirements.

Another candidate for $\mathrm{H}_{2}$ production from nuclear energy is high-temperature electrolysis (up to $\sim 900^{\circ} \mathrm{C}$ ). In this process, ${ }^{60,61}$ thermal energy is used to produce high-temperature steam. Electrolysis of the steam yields $\mathrm{H}_{2}$ and oxygen. High-temperature heat significantly reduces the quantities of the more expensive electricity required for electrolysis by providing high-temperature steam and additional heat directly to the electrolytic cells. Equally important, the high temperatures may result in better chemical kinetics within the electrolyzer, which reduces (1) equipment size and (2) inefficiencies. The reactor requirements for delivery of heat (temperature, pressure, isolation) are similar to those of the abovedescribed thermochemical cycles. The currently projected costs for high-temperature electrolysis are higher than those for other methods of $\mathrm{H}_{2}$ production, but future research may result in significant improvements. 


\section{ECONOMICS}

\subsection{COMPARISON-BASED CAPITAL COST ESTIMATE}

The potential cost of the AHTR is estimated based upon cost information for the S-PRISM ${ }^{62}$ and the GT-MHR. ${ }^{63}$ The reference AHTR design produces $2400 \mathrm{MW}(\mathrm{t})$ from a reactor vessel with the same diameter as the $1000 \mathrm{MW}(\mathrm{t}) \mathrm{S}-\mathrm{PRISM}$ and slightly larger diameter than the $600 \mathrm{MW}(\mathrm{t}) \mathrm{GT}-\mathrm{MHR}$.

This economic study considered two variations of the AHTR - an AHTR-IT version with a core outlet temperature of $800^{\circ} \mathrm{C}$ and an electrical power output of $1145 \mathrm{MW}(\mathrm{e})$, and an AHTR-VT version with an outlet temperature of $1000^{\circ} \mathrm{C}$ and an electrical power output of $1300 \mathrm{MW}(\mathrm{e})$. Table 8.1 summarizes the results of the cost analysis, showing the relative cost of the AHTR compared with the S-PRISM and GT-MHR.

From the perspective of an economist, the potential for improved economics is an expected consequence of the economy of scale. The AHTR electrical output is approximately four times that of the other reactors but with similar physical size and complexity. The potential for improved economics compared with LWRs, for a plant of the same size, is a consequence of higher efficiencies, higher power cycle power density, a low-pressure containment, and the complete elimination of active safety equipment.

Table 8.2 provides key parameters for the AHTR-VT, AHTR-IT, S-PRISM, and GT-MHR reactors used here as the basis for cost scaling assumptions. There are two major assumptions and a number of additional assumptions used in the cost comparisons that are summarized in the following sections. Detailed comparisons at a subsystem level are given in Table 8.3.

Table 8.1. Comparison of the estimated overnight capital cost (2002 \$) of the AHTR-IT and AHTR-VT, as a percentage of the costs of the S-PRISM ${ }^{62}$ and GT-MHR [with 1145 MW(e) output]

\begin{tabular}{|lccc|}
\hline & & $\begin{array}{c}\text { S-PRISM } \\
\mathbf{1 6 8 1} \mathbf{\$} / \mathbf{k W h}(\mathbf{e})\end{array}$ & $\begin{array}{c}\text { GT-MHR } \\
\mathbf{1 5 2 8} \$ \mathbf{k W h}(\mathbf{e})\end{array}$ \\
\hline AHTR-IT & $930 \$ / \mathrm{kWh}(\mathrm{e})$ & $55 \%$ & $61 \%$ \\
AHTR-VT & $816 \$ / \mathrm{kWh}(\mathrm{e})$ & $49 \%$ & $53 \%$ \\
\hline
\end{tabular}

\subsection{CAPITAL COST ASSUMPTIONS}

There are two major assumptions used in the cost analysis:

1. Reactor vessel and building: The $2400 \mathrm{MW}(\mathrm{t})$ AHTR reactor building and vessel are assumed to have the same size as a single S-PRISM reactor vessel and building. The most important assumption for this cost estimate is that an AHTR can produce $2400 \mathrm{MW}(\mathrm{t})$ with an S-PRISM size vessel and building, and deliver it to heat helium to temperatures between 750 and $900^{\circ} \mathrm{C}$.

2. High-temperature, compact heat exchangers: It is assumed that compact, high-temperature, platetype salt-to-salt and salt-to-helium heat exchangers will be developed by the NGNP project. For an NGNP with helium primary coolant, helium-to-salt intermediate heat exchanger will be developed at engineering scale only if salt is selected as the NGNP intermediate coolant. As shown in Table 8.2 , these plate heat exchangers have much higher power density than the coiled tube heat exchangers in the S-PRISM. For the AHTR-IT, these compact heat exchangers are assumed to be fabricated from metal with a design similar to that of the Heatric heat exchanger or the proprietary 
100\% welded GT-MHR recuperator heat exchanger design. Table 7.2 shows the power density for the GT-MHR recuperator for helium-to-helium use; its design based on thin plates may have better thermal shock resistance than the Heatric heat exchanger. For the AHTR-VT, a silicon-melt infiltrated, reaction-bonded composite plate heat exchanger has been assumed. ${ }^{43}$ Because the power density of the AHTR heat exchangers is much higher than the power density of the S-PRISM steam generator, and hence they are expected to be much smaller and cheaper, the cost of the S-PRISM steam generator is not included in the AHTR cost estimate.

Table 8.2. Comparison of parameters for AHTR-VT, AHRT-IT, S-PRISM, and GT-MHR

\begin{tabular}{|c|c|c|c|c|}
\hline & $\begin{array}{l}\text { Very high- } \\
\text { temperature } \\
\text { AHTR-VT }\end{array}$ & $\begin{array}{c}\text { Intermediate } \\
\text { temperature } \\
\text { AHTR-IT }\end{array}$ & S-PRISM & GT-MHR \\
\hline Thermal power & $2400 \mathrm{MW}(\mathrm{t})$ & $2400 \mathrm{MW}(\mathrm{t})$ & $1000 \mathrm{MW}(\mathrm{t})$ & $600 \mathrm{MW}(\mathrm{t})$ \\
\hline Electrical power & $1300 \mathrm{MW}(\mathrm{e})$ & $1145 \mathrm{MW}(\mathrm{e})$ & $380 \mathrm{MW}(\mathrm{e})$ & $286 \mathrm{MW}(\mathrm{e})$ \\
\hline Number of PCUs & 3 & 3 & $\mathrm{~N} / \mathrm{A}$ & 1 \\
\hline PCU working fluid & Helium & Helium & Steam & Helium \\
\hline Primary maximum temperature & $1000^{\circ} \mathrm{C}$ & $800^{\circ} \mathrm{C}$ & $510^{\circ} \mathrm{C}$ & $850^{\circ} \mathrm{C}$ \\
\hline $\begin{array}{l}\text { Intermediate maximum } \\
\text { temperature }\end{array}$ & $920^{\circ} \mathrm{C}$ & $770^{\circ} \mathrm{C}$ & $485^{\circ} \mathrm{C}$ & $\mathrm{N} / \mathrm{A}$ \\
\hline Intermediate minimum temperature & $860^{\circ} \mathrm{C}$ & $715^{\circ} \mathrm{C}$ & $325^{\circ} \mathrm{C}$ & $\mathrm{N} / \mathrm{A}$ \\
\hline Intermediate flow rate & $8.9 \mathrm{~m}^{3} / \mathrm{s}$ & $9.7 \mathrm{~m}^{3} / \mathrm{s}$ & $6.3 \mathrm{~m}^{3} / \mathrm{s}$ & $\mathrm{N} / \mathrm{A}$ \\
\hline Turbine inlet temperature & $900^{\circ} \mathrm{C}$ & $750^{\circ} \mathrm{C}$ & $462^{\circ} \mathrm{C}$ & $848^{\circ} \mathrm{C}$ \\
\hline Compressor inlet temperature & $35^{\circ} \mathrm{C}$ & $35^{\circ} \mathrm{C}$ & $\mathrm{N} / \mathrm{A}$ & $26.4^{\circ} \mathrm{C}$ \\
\hline PCU pressure & $10 \mathrm{MPa}$ & $10 \mathrm{MPa}$ & $\mathrm{N} / \mathrm{A}$ & $7.24 \mathrm{MPa}$ \\
\hline IHX power density $\left[\mathrm{m}^{3} / \mathrm{MW}(\mathrm{t})\right]$ & $120 \mathrm{MW}(\mathrm{t}) / \mathrm{m}^{3}$ & $45 \mathrm{MW}(\mathrm{t}) / \mathrm{m}^{3}$ & $4 \mathrm{MW}(\mathrm{t}) / \mathrm{m}^{3}$ & $\mathrm{~N} / \mathrm{A}$ \\
\hline $\begin{array}{l}\text { Heaters/steam } \\
\text { generator/recuperator power } \\
\text { density }\end{array}$ & $\begin{array}{c}100 \mathrm{MW}(\mathrm{t}) / \mathrm{m}^{3} \\
\text { (heater) }\end{array}$ & $\begin{array}{l}82 \mathrm{MW}(\mathrm{t}) / \mathrm{m}^{3} \\
\text { (heater) }\end{array}$ & $\begin{array}{l}3 \mathrm{MW}(\mathrm{t}) / \mathrm{m}^{3} \\
\text { (steam gen.) }\end{array}$ & $\begin{array}{l}43 \mathrm{MW}(\mathrm{t}) / \mathrm{m}^{3} \\
\text { (recuperator) }\end{array}$ \\
\hline Overall cycle efficiency & 0.54 & 0.48 & 0.38 & 0.48 \\
\hline PCU power density & $\begin{array}{c}360 \\
\mathrm{kWh}(\mathrm{e}) / \mathrm{m}^{3}\end{array}$ & $305 \mathrm{kWh}(\mathrm{e}) / \mathrm{m}^{3}$ & $\mathrm{~N} / \mathrm{A}$ & $\begin{array}{c}230 \\
\mathrm{kWh}(\mathrm{e}) / \mathrm{m}^{3}\end{array}$ \\
\hline
\end{tabular}

In addition, the following assumptions are applied in the cost analysis:

1. S-PRISM blocks cost scaling. S-PRISM scaling exponents relative to the number of advanced liquid-metal-cooled reactor blocks, varying from 1 to 3, were derived from GEFR-00940 1994 Capital and Busbar Cost Estimates. These derived scaling exponents were applied in calculating costs of single modules and components, based on the four-block costs. For reactor equipment, the derived scaling exponent is 0.86 . The S-PRISM cost is taken from Ref. 62, which gives an estimate for a two-block, four-reactor plant.

2. Nth of a kind. The costs given in Table 8.3 are Nth of a kind, as opposed to first of a kind.

3. Comparability of costs. It is assumed that similar cost estimating guidelines were used by GE and by GA for the S-PRISM and GT-MHR cost estimates, from which the AHTR cost estimate is derived. 
Table 8.3. Detailed results for AHTR comparative cost estimate

\begin{tabular}{|c|c|c|c|c|c|c|c|c|c|}
\hline & $\begin{array}{c}\text { S-PRISM } \\
\text { ICONE-9 } \\
\text { two blocks } \\
1000 \text { MW(t) } \\
\text { per reactor } \\
\text { indirect cycle }\end{array}$ & $\begin{array}{c}\text { Block } \\
\text { scaling } \\
\text { exponents } \\
\text { derived } \\
\text { from } \\
\text { ALMR }^{a} \\
\text { 1-3 blocks }\end{array}$ & $\begin{array}{l}\text { S-PRISM one } \\
\text { block two } \\
\text { reactors } 1000 \\
\text { MW(t) per } \\
\text { reactor indirect } \\
\text { cycle }\end{array}$ & $\begin{array}{c}\text { Estimated } \\
\text { cost factors } 2 \\
\text { to } 1 \text { reactors } \\
\text { in same } \\
\text { block }\end{array}$ & $\begin{array}{c}\text { S-PRISM } \\
\text { 1/2 block } \\
\text { one reactor } \\
2400 \\
\text { MW(t) }\end{array}$ & $\begin{array}{c}\text { GT-910720/1 } \\
\text { target costs } \\
4 \times 600 \mathrm{MW}(\mathrm{t}) \\
{[1145 \mathrm{MW}(\mathrm{e})]} \\
\text { direct cycle }\end{array}$ & $\begin{array}{c}\text { AHTR-IT } \\
2400 \text { MW(t) } \\
{[1145} \\
\text { MW(e)] } \\
\text { indirect } \\
\text { cycle }\end{array}$ & $\begin{array}{c}\text { AHTR-VT } \\
2400 \text { MW(t) } \\
{[1300} \\
\text { MW(e)] } \\
\text { indirect } \\
\text { cycle }\end{array}$ & Cost basis \\
\hline Number of reactor vessels & 4 vessels & & 2 vessels & & 1 vessel & 4 vessels & 1 vessel & 1 vessel & \\
\hline $\begin{array}{l}\text { Scaled thermal output } \\
{[\mathrm{MW}(\mathrm{t})]}\end{array}$ & 4,000 & & 2,000 & & 2,400 & 2,400 & 2,400 & 2,400 & \\
\hline Electrical output [MW(e)] & 1,520 & & 760 & & 380 & 1,145 & 1,145 & 1,300 & \\
\hline Description & $1996 \mathrm{KS}$ & & $1996 \mathrm{KS}$ & & $1996 \mathrm{KS}$ & $1994 \mathrm{KS}$ & $1996 \mathrm{KS}$ & $1996 \mathrm{KS}$ & \\
\hline Land & 0 & & 0 & & & 2,000 & 0 & 0 & S-PRISM \\
\hline Structures and improvements & 232,000 & 0.82 & 131,166 & 0.65 & 85,058 & 149,000 & 85,058 & 85,058 & S-PRISM \\
\hline Reactor plant equipment & 900,000 & 0.86 & 497,025 & 0.66 & 328,761 & 353,000 & 328,761 & 328,761 & S-PRISM \\
\hline Turbine plant equipment & 236,500 & 0.99 & 118,674 & 1.20 & 142,408 & 211,000 & 155,177 & 150,081 & GT \\
\hline Electric plant equipment & 128,000 & 0.85 & 70,981 & 1.20 & 85,178 & 65,000 & 47,803 & 46,233 & GT \\
\hline $\begin{array}{l}\text { Miscellaneous plant } \\
\text { equipment }\end{array}$ & 39,000 & 0.51 & 27,464 & 0.80 & 21,971 & 31,000 & 32,291 & 32,291 & GT \\
\hline Main heat rejection system & 38,500 & 0.88 & 20,976 & 1.00 & 20,976 & 35,000 & 28,479 & 32,464 & GT \\
\hline Special materials & 20,000 & 1.0 & 10,000 & 1.00 & 10,000 & & 10,000 & 10,000 & S-PRISM \\
\hline Total direct cost & $1,594,000$ & & 876,286 & & 694,353 & 864,000 & 687,570 & 684,888 & \\
\hline Construction services & 138,000 & 0.71 & 84,365 & & 66,849 & 107,000 & 66,196 & 65,938 & S-PRISM \% \\
\hline $\begin{array}{l}\text { Home office engineering and } \\
\text { services }\end{array}$ & 69,000 & 0.34 & 54,383 & & 43,092 & 68,000 & 42,671 & 42,505 & S-PRISM \% \\
\hline $\begin{array}{l}\text { Field office engineering and } \\
\text { services }\end{array}$ & 79,000 & 0.71 & 48,402 & & 38,353 & 52,000 & 37,978 & 37,830 & S-PRISM \% \\
\hline Owner's cost & 290,000 & 0.83 & 163,017 & & 129,171 & 150,000 & 127,090 & 127,411 & S-PRISM \% \\
\hline Total direct cost & 576,000 & & 350,167 & & 277,466 & 377,000 & 274,755 & 273,683 & \\
\hline Base construction cost & $2,170,000$ & & $1,226,452$ & & 971,818 & $1,223,000$ & 962,325 & 958,571 & \\
\hline Contingency & 0 & & 0 & & 0 & 295,000 & 0 & 0 & S-PRISM \% \\
\hline Overnight cost & $2,170,000$ & & $1,226,452$ & & 971,818 & $1,518,000$ & 962.325 & 958.57 & \\
\hline Electrical power $[\mathrm{MW}(\mathrm{e})]$ & 1,520 & 1,145 & 760 & & 380 & 1,145 & 1,145 & 1,300 & GT \\
\hline$\$ / \mathrm{kWh}(\mathrm{e})$, overnight & 1,428 & & 1,614 & & 2,557 & 1,326 & 840 & 737 & \\
\hline 2002_\$kWh(e), overnight & 1,580 & 1,681 & 1,786 & N/A & & 1,528 & 930 & 816 & \\
\hline $\begin{array}{l}\text { Relative_\$kWh(e), overnight } \\
\text { [relative to } 1145 \mathrm{MW}(\mathrm{e}) \\
\text { S-PRISM] }\end{array}$ & 0.94 & 1.00 & 1.06 & N/A & & 0.91 & 0.55 & 0.49 & \\
\hline
\end{tabular}

${ }^{a} \mathrm{ALMR}=$ advanced liquid-metal reactor. 
4. Reactor building. The cost for a single S-PRISM reactor building is estimated from the cost of the reactor building for a two-reactor module using a cost scaling of $(0.5)^{0.82}=0.57$. The two-unit S-PRISM building has some shared equipment, which would suggest a somewhat larger scaling factor. Conversely, the AHTR does not have a pressurization source comparable to the sodium/air chemical reaction that the S-PRISM reactor building is designed to contain, so the design pressure of the AHTR building is lower than that of the S-PRISM, suggesting a somewhat lower scaling factor. The value that was selected was, therefore, considered a reasonable compromise.

5. Reactor vessel. The higher density of molten salt creates larger hydrostatic loads than sodium. While the AHTR will have smaller loads from reactor internals, because the fuel will be close to neutrally buoyant, it is anticipated that the AHTR will still require a thicker vessel. Thus the cost of the AHTR vessel cost is assumed to be equal to the cost of two S-PRISM vessels to account for a 10 -cm-thick wall vs the 5 -cm-thick S-PRISM vessel.

6. Reactor internals and control rod drives. The AHTR and S-PRISM vessels have the same diameter, so the reactor internals for the AHTR are assumed to have the same cost as the internals for a single S-PRISM vessel. Because the AHTR core is larger than the S-PRISM core, it is assumed that the cost of the AHTR control rod drives cost is double the cost for an S-PRISM reactor.

7. Primary and intermediate heat transport systems. The cost of the primary pumping and ducting systems, intermediate heat exchangers, and intermediate loop piping is assumed to scale with thermal power from the S-PRISM values by a factor of $(2400 / 1000)^{0.86}=2.12$, using the 0.86 scaling exponent derived for S-PRISM reactor plant equipment. This estimate may be conservative because the volumetric flow of sodium in the $1000 \mathrm{MW}(\mathrm{t}) \mathrm{S}$-PRISM is $6.3 \mathrm{~m}^{3} / \mathrm{s}$, compared with only $8.9 \mathrm{~m}^{3} / \mathrm{s}$ in the $2400 \mathrm{MW}(\mathrm{t})$ AHTR because of salt's much higher volumetric thermal capacity, and the AHTR heat exchangers have much higher power density than those of the S-PRISM intermediate heat exchanger.

8. Backup heat removal system. The cost of the decay-heat removal system (reactor-cavity cooling system and variations) is assumed to scale with thermal power from the S-PRISM values by a factor of $(2400 / 1000)^{0.86}=2.12$.

9. Steam generators. The AHTR has no steam generators, so the S-PRISM cost for steam generators is set to zero. The AHTR intermediate loop transfers energy to heaters inside the PCUs that are included in the PCU cost estimate. These heaters will be either metal, with a welded design like that of the current GT-MHR Russian-designed recuperators (AHTR-IT), or compact LSI composite plate heat exchangers (AHTR-VT), and will have much smaller size and much less complexity than sodium-to-boiling-water steam generators (see Table 8.2 for power density comparison).

10. Salt makeup and chemistry control system. These are required and are assumed to be $75 \%$ of the cost of similar systems for a two-reactor S-PRISM module.

11. Turbine building. The turbine building for the AHTR will be much more compact than a steamcycle turbine building. Here the AHTR turbine building cost is assumed to be $50 \%$ of the cost of the 2000 MW(t) S-PRISM turbine building.

12. Other structures. All other miscellaneous structures are assumed to have the same cost as those for a two-reactor S-PRISM module, except the control room and maintenance building, which have a 0.75 scaled cost.

13. Power conversion system. The cost of the AHTR power conversion system is scaled based on PCU power densities from detailed UCB design studies shown in Table 8.2, from the cost of a set of GTMHR PCUs capable of producing $1145 \mathrm{MW}(\mathrm{e})$, using a scaling exponent of 0.86 . The PCU costs are scaled further by a factor of 0.9 to account for the fact that they are not nuclear-grade equipment in the AHTR. The costs of the electrical plant and the heat rejection equipment are scaled with electrical power ( 0.86 exponent) and thermal heat rejection (also 0.86 exponent), respectively. 
14. Power conversion system cost. The costs of the power conversion system were estimated from Ref. 49. Costs are reported only at the two-digit code of account level. In addition, the turbine plant equipment, account 23 , was combined with the reactor plant equipment, account 22 , as GA contended that all this equipment was part of the reactor system. In order to estimate the portion of these combined costs that applied to power conversion, cost partition factors were estimated by utilizing an earlier direct cycle MHTGR document. ${ }^{63}$

15. Indirect costs. Indirect cost accounts 91-94 for AHTR were calculated based on the indirect cost account percentage taken from S-PRISM and applied to the direct cost of AHTR. No discrete value of contingency was applied to the AHTR, consistent with the S-PRISM estimate. S-PRISM indirect cost account percentages and contingency are used since the S-PRISM is the primary benchmark for the AHTR.

16. Additional cost information. There is a more recent (2002) cost of the GT-MHR, presented as a near-term deployment option (GA-A23952). Very few cost values are presented, only total direct, total indirect, and a combined contingency plus owner's cost. An overnight value of $974 \$ / \mathrm{kWh}(\mathrm{e})$ is shown, which is substantially lower than the 1994 GT-MHR overnight cost of $1326 \$ / \mathrm{kWh}(\mathrm{e})$ used as the basis for this AHTR capital cost estimate. As the AHTR power conversion system is currently $\sim 40 \%$ of the total cost, the implied cost reduction from the more recent GT-MHR study would result in a further reduction of the estimated AHTR cost relative to that presented in Table 8.3. 


\section{TECHNOLOGY DEVELOPMENT REQUIREMENTS}

\subsection{RELATIONSHIP TO OTHER PROGRAMS}

The development of a new high-temperature reactor will be a major undertaking. As referenced throughout this report, however, the AHTR shares similarities and features with several other reactor designs. Because the fuel, molten-salt coolant, decay-heat removal systems, plant layout, and powerconversion technologies have been partly or fully developed as part of these other reactor concepts, the major AHTR R\&D needs are greatly reduced to a few key areas. In particular, further development of an AHTR design can draw heavily on recent or ongoing activities in the following related programs:

- GT-MHR and helium-cooled VHTR. The AHTR R\&D needs are strongly dependent on the development of the GT-MHR since they share the same fuel, moderator, and helium gas-turbine technology. This includes the domestic GT-MHR design being proposed for NGNP and the design being investigated by Russia for the disposition of weapons-grade plutonium. For the same reasons, the AHTR will share several development needs with the Generation IV VHTR development program independent of whether the VHTR has a prismatic or pebble core design.

- Sodium fast reactor. Sodium-cooled fast reactors are low-pressure, high-temperature reactors. Because these characteristics are similar to the AHTR, the AHTR plant design shares many features with this class of reactors, and specifically the General Electric S-PRISM, for which a considerable R\&D investment has already been expended. These features include overall facility design and decay heat removal systems.

- Nuclear hydrogen production. Nuclear hydrogen production requires transfer of large quantities of heat from the VHTR to the thermochemical or high-temperature electrolysis hydrogen production plant. Regardless of the primary coolant, molten salt is an attractive candidate for transport of heat in the intermediate heat transport loop. The development of a heat transport system will require development of related molten salt technology, including materials, heat exchangers, pumps, and valves.

- Lead-cooled fast reactor and accelerator transmutation of wastes. The AHTR requires highertemperature refueling and maintenance operations compared with sodium-cooled reactors to avoid freezing of the salt. The refueling temperatures are closer to those required for lead-cooled reactors and accelerator-based machines to destroy nuclear wastes. Russian experience with leadcooled reactors and the large European program examining lead-cooled accelerator-driven systems must address the same refueling and maintenance issues as will the AHTR.

- Fusion. Molten salts are a leading candidate for cooling the first wall of fusion energy machines. Hence there are similar technological development requirements for this program.

Because of these relationships, some components of the AHTR are already at a commercial stage of development while others are very early in development.

\subsection{DEVELOPMENT STRATEGY}

The development of the AHTR requires three overlapping steps leading to a full scale demonstration plant or first-of-a-kind plant: concept development and evaluation, research and development, and integrated demonstration test. These are described in more detail below in thecontext of AHTR deployment. 


\subsubsection{Concept Development and Evaluation}

Concept development and evaluation requires the establishment of a "point" design with sufficient detail to understand key performance features and uncertainties, technical viability, and testing requirements. Also, a detailed economic analysis should be performed to assess commercial viability. The effort described in this report was an initial step toward achieving a point design, but significant additional work is needed. Detailed system designs must be developed, possibly with supporting experimental work, to understand the trade-offs between high-temperature performance, reliability, and various design choices (molten salt composition, core power density, etc.). Key items needing further development and evaluation are the following.

- Salt selection. Selection of a coolant salt is critical to moving forward with an AHTR design since the salt choice dictates many other design features such as: operational temperature limits (upper and lower), core design, structural material options, salt chemistry and cleanup systems, and balance of plant dose levels.

- Structural material selection. The AHTR requires high-temperature corrosion resistant materials. Materials are the greatest challenge for all high-temperature reactors, including the AHTR. Materials have been identified that allow operation with molten salts to $750^{\circ} \mathrm{C}$ (Hastelloy-N). New nickel superalloys (e.g., Hastelloy-X) possess adequate strength at higher temperatures, but tests to confirm compatibility with molten fluorides will be required. Operating temperatures much above $800^{\circ} \mathrm{C}$ will require improved materials of construction. The excellent chemical compatibility of carbon with molten salts creates new materials options, but these will need to be evaluated for nuclear applications.

- Power level. Preliminary analyses indicate that $2400 \mathrm{MW}(\mathrm{t})$ is an achievable power level for an AHTR while maintaining the capability for passive safety. Additional evaluations are needed to establish the optimum power level for the AHTR considering core size, passive safety, and size of the reactor vessel. Because the economics are strongly tied to the reactor size, and the reactor size is tied to the passive decay heat cooling system, detailed design and heat transfer optimizations are needed to maximize the potential for passive safety performance.

- Nuclear design. Preliminary core nuclear analysis has been performed to establish conceptual core sizing and enrichments; however, only a very limited number of design options using relatively homogenous core designs have been examined under a limited set of conditions. Additional studies of performance, the fuel cycle, and alternative core designs are required to understand the reactor core options for the AHTR. For example, heterogeneous core options have not been examined but may offer superior performance, especially regarding the coolant void coefficient. The optimum power density needs to be evaluated since it impacts core size, fuel lifetime, core transient behavior, etc.

- Thermal hydraulic design. The preliminary core thermal hydraulic design reported here needs to be continued using multidimensional methods to establish the heat removal capability and coolant pump sizing for the target power level and for assessing the reactor's performance in anticipated transients.

- Beyond-design-basis-accident analyses. Because of passive safety features, the designers of the modular HTGR make the case for a $600 \mathrm{MW}(\mathrm{t})$ reactor that one can walk away from the reactor in an accident without serious offsite consequences. The same safety case should exist for the AHTR even at the higher power rating. System modeling and analyses are needed to demonstrate the potential for the AHTR to meet the passive safety criteria for the target power level. The AHTR case will involve natural circulation of coolant and conduction/radiation heat transfer to the environment. 
- Power conversion cycle. Preliminary work on the power conversion cycle has been completed, but a detailed evaluation of alternative designs is required. Included within the power cycle activities are the associated heat exchangers and related system components.

- Concept design description. Evaluation of the AHTR will require preparation of concept-level drawings including:

- flow diagrams to illustrate the reactor system processes and parameters;

- overall reactor and plant arrangement for hydrogen productions including the intermediate heat exchanger for transfer of the high-temperature heat from the reactor to an intermediate loop for transport to the hydrogen plant;

- reactor vessel and internals arrangement illustrating the location and support of the primary in-vessel components, including the core, core support, control rods, control rod drives, coolant circulators, and thermal blanket system.

- proposed refueling approach and concept for storage of spent fuel; and

- design descriptions of the primary coolant pumps, motors and siphon breaks.

\subsubsection{Research and Development}

Technical viability requires understanding of basic phenomenology (material behavior under irradiation, salt-graphite interactions, etc.) and development of key technologies so that an integrated demonstration test can be constructed with high confidence of success. This requires a variety of analysis studies, laboratory research, and supporting experimental test facilities. Some of the R\&D requirements that have been identified include

- experimental study of thermo-mechanical properties of metallic alloys in molten salt environments such as creep and embrittlement;

- measurement of corrosion rates of candidate structural materials in hot primary and secondary salts;

- study of long-term compatibility of salts with $\mathrm{C} / \mathrm{C}$ composites and melt-infiltrated composites;

- development and demonstration of techniques for tritium capture and fission product clean-up in molten salts;

- experimental verification of molten salt thermal properties;

- evaluation of chemical reactions of molten salts with water/steam and process chemicals for hydrogen production;

- development and demonstration of monitoring and diagnostic instruments for high ambient temperatures;

- study of heat transfer data at high temperatures where radiative transfer dominates; and

- development of compact, high-efficiency heat exchangers for salt-to-salt and salt-to-gas heat transfer.

Several test facilities will be needed to develop the science and technology base for an AHTR, while other test facilities will be needed for engineering tests. Many of these facilities will also be required for the development of a gas-cooled VHTR. Except for the reactor test loop, all of these facilities are nonnuclear facilities. A partial list of these facilities is included below. The facilities are identified as supporting either research or engineering. 
- Materials test loops (research). These are high-temperature materials corrosion test loops to help researchers understand and validate corrosion mechanisms of different materials of construction under expected operating conditions.

- Molten salt purification and chemistry control (research). Molten salt coolant will require cleanup systems to remove impurities from the salt and to control the salt chemistry. A facility to enable researchers to understand, develop, demonstrate, and test alternative cleanup and coolant chemistry control systems is required to ensure effective control of salt chemistry.

- RVACS/DRACS test loop (research). RVACS and DRACS decay heat removal systems have been developed and tested for sodium-cooled fast reactors. However, the AHTR RVACS/DRACS will operate at significantly higher temperatures. Test loops are required to provide integrated experimental data to qualify design codes for higher temperatures.

- Valve and pump test loops (research). The reactor primary coolant system and power conversion system will require valves and pumps to operate at very high temperatures. A test facility is required to test small components, including siphon breaks. In the development of the molten salt reactor, there were two types of test facilities to consider-large facilities for large-scale tests using water or other fluids for hydraulic testing, and smaller facilities to test salt-lubricated bearings, valves, and other components that operate in the molten salt environment. Commercial facilities are available for large-scale hydraulic testing, and some laboratory facilities exist for the small-scale component testing.

- Thermal blanket system test facility (engineering). The AHTR requires a thermal blanket system to insulate the reactor vessel from the elevated core and coolant salt. Appropriate hightemperature tests for a variety of transient conditions are required to test alternative insulation system capabilities.

- Inspection, refueling, and maintenance test facility (engineering). Reactor inspection, maintenance, and refueling operations will occur at high temperatures relative to sodium-cooled reactors. At the same time, molten salts are transparent and allow for the use of optical systems. There has been limited experience with lead-cooled reactors in the chemical industry at these temperatures. A facility is required to develop the technology and test designs for these operations.

- Fuel test facility (engineering). This is a flow loop in a test reactor to test fuel under realistic operating and transient conditions.

- Heat exchanger test facility (engineering). The high-temperature heat exchangers are beyond the normal temperature range of industrial experience. Testing of heat exchangers that are smaller (but with prototypic design) will be required. Such testing is to confirm both performance and behavior under transient conditions. It is noted that the radiation heat transfer in these heat exchangers will become a significant factor, something that is generally not important at lower temperatures.

\subsubsection{Integrated Demonstration Test}

Ultimately, the development of the AHTR will require a test reactor to integrate and test the entire system. Important system tests include startup, shutdown, refueling, maintenance, and various transients that a power reactor is expected to experience. The test reactor will also be used to test design margins and performance beyond the normal operating range, something that cannot be done with a commercial reactor. Although a study has not been conducted yet to determine the optimum size of a test reactor, the likely range of size is between 50 and $200 \mathrm{MW}(\mathrm{t})$. The reactor must be able to provide at a minimum $50 \mathrm{MW}(\mathrm{t})$ to a thermochemical hydrogen production pilot plant. The reactor must be of sufficient size to 
require a suitably sized Brayton power cycle to realistically test system behavior under all expected transient conditions that will be found in a commercial reactor. This includes power transients such as loss of electrical load (grid failure). This is especially important for very high-temperature systems, because control under transient operations is critical in order to avoid thermal spikes that may damage equipment.

\subsection{ECONOMIC EVALUATION}

The economics of the AHTR are dependent upon dramatically reducing the plant size by using the higher temperature to improve efficiency and the lower pressure to reduce plant size. The preliminary economic assessment based on comparisons with similar reactor concepts indicates potentially excellent economics. A more detailed "bottoms up" cost analysis based on components and systems that are specific to the AHTR will be required when a complete preconceptual plant design exists.

\subsection{UNIVERSITY AND INDUSTRY PARTICIPATION}

A broad collaboration of universities, national laboratories, and industry is needed to fully develop and mature the AHTR design. University and laboratory involvement is essential to support the R\&D needs of the concept and to conduct fundamental tests of material and system performance. Initial contacts have been made with several national universities, including the University of Tennessee, Ohio State University, Purdue University, the University of Wisconsin, and Oregon State University, in addition to UCB. Additional universities need to be contacted, and specific roles for those who wish to participate need to be negotiated.

Nuclear industry participation early in the development is a requirement to address the many engineering aspects of the design, and to provide a long-term path forward. Interest in the AHTR has already been expressed by two reactor vendors, and these need to be pursued. Also, international interest in the AHTR, and molten salt (fueled) reactors in general, has been expressed by France and other countries. Collaborations should be pursued through the Generation IV International Forum to leverage the investments of these other countries. 


\section{CONCLUSIONS}

As a new member to the family of high-temperature reactors, the AHTR is defined by two characteristics: (1) a high-temperature fuel and (2) a low-pressure liquid coolant. Our studies indicate that a reactor with these characteristics has the potential for significantly improved economics for the production of electricity and hydrogen while meeting the top-level functional requirements of the NGNP project. Because heat is delivered at temperatures and pressures that match process requirements, the reactor may have unique potential for the thermochemical production of $\mathrm{H}_{2}$. As with all new reactor concepts, there are major uncertainties (materials, performance, engineering, etc.) and many alternative design possibilities. Significant work will be required before the characteristics of and potential for the AHTR can be realized. 


\section{REFERENCES}

1. P. E. Macdonald, NGNP Point Design-Results of the Initial Neutronics and Thermal-Hydraulics Assessments During FY-03, INEEL/EXT-03-00870, Rev. 1, Idaho Nuclear Energy and Engineering Laboratory (2003).

2. A. P. Fraas and A. W. Savolainen, Design Report on the Aircraft Reactor Test, ORNL-2095, Oak Ridge National Laboratory (Dec. 7, 1956).

3. A.M. Weinberg et al., "The Status and Technology of Molten Salt Reactors-A Review of Work at the Oak Ridge National Laboratory", Nucl. Appl. Tech. 8(2) (February 1970).

4. M. P. LaBar, "The Gas Turbine-Modular Helium Reactor: A Promising Option for Near Term Deployment," presented at the International Congress on Advanced Nuclear Power Plants, Embedded Topical American Nuclear Society 2002 Annual Meeting, Hollywood, FL, June 9-13, 2002, GA-A23952 (2002).

5. C. E. Boardman et al., "A Description of the S-Prism Plant," presented at the $8^{\text {th }}$ Int. Conf. on Nucl. Eng., Baltimore, MD, April 2-6, 2000, ICONE-8168 (2002).

6. R. C. Robertson, Conceptual Design Study of a Single-Fluid Molten Salt Breeder Reactor, ORNL4541, Oak Ridge National Laboratory (June 1971).

7. P. F. Peterson, "Multiple-Reheat Brayton Cycles for Nuclear Power Conversion with Molten Coolants," Nuclear Technology, 144, 279-288 (2003).

8. H. Zhao and Per F. Peterson, A Reference 2400 MW(t) Power Conversion System Point Design for Molten Salt Cooled Fission and Fusion Energy Systems, University of California-Berkeley, Department of Nuclear Engineering Report UCB TH-03-002 (Nov. 20, 2003).

9. P. F. Peterson, C. Forsberg, and P. Pickard, “Advanced CSiC Composites for High-Temperature Nuclear Heat Transport with Helium, Molten Salts, and Sulfur-Iodine Thermomchemical Hydrogen Process Fluids," presented at the Second Information Exchange Meeting on Nuclear Production of Hydrogen Argonne National Laboratory, IL, October 2-3, 2003 (2003).

10. E. J. Parma, P. S. Pickard, and A. J. Suo-Anttil, Very High Efficiency Reactor (VHER) Concepts for Electric Power Generation and Hydrogen Production, Sandia National Laboratory (2003).

11. S. J. Ball and D. J. Nypaver, GRSAC Users Manual, ORNL/TM-13697, Oak Ridge National Laboratory (February 1999).

12. C. W. Forsberg, P. Pickard, and P. F. Peterson, "Molten-Salt-Cooled Advanced High-Temperature Reactor for Production of Hydrogen and Electricity," Nuclear Technology, 144, 289-302 (2003).

13. G. D. Del Cul, D. F. Williams, L. M. Toth, and J. Caja, "Redox Potential of Novel Electrochemical Buffers Useful for Corrosion Prevention in Molten Fluorides," published in the Proc. $13^{\text {th }}$ International Symposium on Molten Salts, $201^{\text {st }}$ Meeting of the Electrochemical Society, Philadelphia, PA, May 12-17, 2002 (2002).

14. X. X. Keiser, The Corrosion Resistance of Type 316 Stainless Steel to $\mathrm{Li}_{2} \mathrm{BeF}_{4}$, ORNL/TM-5782, and Compatibility Studies of Potential Molten Salt Breeder Materials in Molten Fluoride Salts, ORNL/TM-5783, Oak Ridge National Laboratory (1977).

15. C. Poinssot et al., "Expected Evolution of Spent Nuclear Fuel in Long Term Dry Storage and Geological Disposal: Major Outcomes of the French R\&D Program PRECCI," presented at the Fifth Topical Meeting on DOE Spent Nuclear Fuel and Fissile Materials Management, Charleston, SC, September 17-20, 2002 (2002).

16. W. R. Grimes, "Molten Salt Reactor Chemistry," Nucl. Appl. Technol., 8, 137-155 (February 1970).

17. H. E. McCoy and B. McNabb, Postirradiation Examination of the Materials from the MSRE, ORNL/TM-4174, Oak Ridge National Laboratory (December 1972). 
18. C. F. Weaver and R. G. Ross, "High-Temperature Fuel Salt-Graphite Compatibility Experiment", Section 10.3 in MSR Program Semiannual Progress Report for Period Ending August 31,1968, ORNL-4344, Oak Ridge National Laboratory (1969).

19. A. Sagara et al., "Design and Development of the FLIBE Blanket for Helical-Type Fusion Reactor FFHR," Fusion Eng. Design, 49-50, 661-666 (2000).

20. R. B. Briggs, Molten Salt Reactor Program Semiannual Progress Report for the Period Ending July 31, 1963, ORNL-3529, p.125, Oak Ridge National Laboratory (1963).

21. MSR Semi-Annual Report, July-December 1964, ORNL-3708, Oak Ridge National Laboratory (1964).

22. E. L. Compere, H. C. Savage, and J. M. Baker, "High Intensity Gamma Irradiation of Molten Salt Fluoroborate-Sodium Fluoride Eutectic Salt," J. of Nuclear Materials, 34(1), 97 (1970).

23. L. M. Toth and L. K. Felker, "Fluorine Generation by Gamma-Radiolysis of a Fluoride Salt Mixture," Radiation Effects and Defects in Solids, 112(4), 201-210 (1990).

24. MSR Semi-Annual Report, January-July 1963, ORNL-3626, Oak Ridge National Laboratory (1963).

25. W. B Cottrell et al, The Disassembly and Postoperative Examination of the Aircraft Reactor Experiment, ORNL-1868, Oak Ridge National Laboratory (1958).

26. W. R. Grimes, Radiation Chemistry of the MSR System, ORNL/TM-500, Oak Ridge National Laboratory (1963).

27. W. R. Grimes, Reactor Chemistry Division Annual Progress Report, ORNL-3789, Oak Ridge National Laboratory (1965).

28. R. B. Briggs, Molten Salt Reactor Program Semiannual Progress Report for the Period Ending February 28, 1965, ORNL-3812, Oak Ridge National Laboratory (1965).

29. E. L. Compere et al., Fission Product Behavior in the Molten Salt Reactor Experiment, ORNL4865, Oak Ridge National Laboratory (1975).

30. R. B. Briggs, Molten Salt Reactor Program Semiannual Progress Report for the Period Ending August 31, 1961, ORNL-3215, Oak Ridge National Laboratory (1961).

31. W. R. Grimes, Reactor Chemistry Division Annual Progress Report, ORNL-3262, Oak Ridge National Laboratory (1962).

32. C. F. Baes, et al, "Removal of Iodide From LiF-BeF2 Melts by HF-H2 Sparging - Application to Iodine Removal From Molten-Salt Breeder Reactor Fuel," Nuc. Sci. and Eng. 56(4), p. 399 (April 1975).

33. Fuel Performance and Fission Product Behaviour in Gas Cooled Reactors, IAEA-TECDOC-978, International Atomic Energy Agency, Vienna, Austria (1997).

34. R. Moormann et al., "Source Term Estimation for Small-Sized HTRs: Status and Further Needs, Extracted from German Safety Analyses” Nucl. Tech. 135(3), 183-193 (September 2001).

35. J. H. Shaffer, Preparation and Handling of Salt Mixtures for the Molten Salt Reactor Experiment, ORNL-4616, Oak Ridge National Laboratory (1971).

36. R. E. Thoma, Chemical Aspects of MSRE Operations, ORNL-4658, Oak Ridge National Laboratory (1971).

37. R. B. Lindauer, MSRE Design and Operations Report, Part VII, Handling and Processing Plant, ORNL/TM-907R, Oak Ridge National Laboratory (1968).

38. R. B. Lindauer, Processing of the MSRE Flush and Fuel Salts, ORNL/TM-2578, Oak Ridge National Laboratory (1969). 
39. M. W. Rosenthal, R. B. Briggs, and P. R. Kasten, Molten Salt Reactor Program Semiannual Progress Report for Period Ending February 29, 1968, ORNL-4254, Oak Ridge National Laboratory (1968).

40. M. W. Rosenthal, R. B. Briggs, and P. R. Kasten, Molten Salt Reactor Program Semiannual Progress Report for Period Ending August 31, 1968, ORNL-4344, Oak Ridge National Laboratory (1968).

41. M. W. Rosenthal, R. B. Briggs, and P. R. Kasten, Molten Salt Reactor Program Semiannual Progress Report for Period Ending August 31, 1969, ORNL-4449, Oak Ridge National Laboratory (1969).

42. J. R. Hightower, "Relative Volatilities of Fluorides of Ce, La, Pr, Nd, Sm, Eu, Ba, Sr, Y, and Zr in Molten Mixteruns of $\mathrm{LiF}$ and $\mathrm{BeF}_{2}$ at $1000^{\circ} \mathrm{C}$," J. Chem. Eng. Data 17(3), 342 (1972).

43. P. F. Peterson, Development of Liquid-Silicon-Impregnated C/C-SiC Composites for HighTemperature Heat Transport," University of California Berkeley Department of Nuclear Engineering Report UCBTH-03-001 (Oct. 1, 2003).

44. M. Krödel et al., "Short Carbon-Fiber Reinforced Ceramic-CeSiC-for Optomechanical Applications," presented at the SPIE Optomechanical Design and Engineering Conference, Seattle, WA, July 7-9, 2002 (2002).

45. T. M. Besmann et al., "Carbon/Carbon Composite Bipolar Plate for Proton Exchange Membrane Fuel Cells," Journal of The Electrochemical Society, 147(11), 4083-4086 (2000).

46. J. H. Devan, J. R. Distefano, W. P. Eartherly, J. R. Keiser, and R. L. Klueh, "Materials Considerations for Molten Salt Accelerator-Based Plutonium Conversion Systems," published in the Proc. International Conference on Accelerator-Driven Transmutation Technologies and Applications, Las Vegas, NV. July 1994, AIP Conference Proceedings 346, LA-UR-95-1792, Woodbury, New York (1995).

47. C. E. Boardman et al., "Optimizing the Size of the Super-Prism Reactor," presented at the $8^{\text {th }}$ Int. Conf. on Nucl. Eng., Baltimore, MD, April 2-6, 2000, ICONE-8003, (2000).

48. C. W. Forsberg and P. Peterson, "Making Core Melt Accidents Impossible in a Large 2400-MW(t) Reactor," presented at Global 2003, embedded topical within 2003 American Nuclear Society Winter Meeting November 16-20, 2003, New Orleans, LA, (2003).

49. GT-MHR Conceptual Design Description Report, Report 910720, General Atomics (1996).

50. S. Cantor et al., Physical Properties of Molten Salt Reactor Fuel, Coolant, and Flush Salts, ORNLTM-2316, Oak Ridge National Laboratory (August 1968).

51. P. Hejzlar, N. E. Todreas, and M. J. Driscoll, Passive Decay Heat Removal in Advanced Reactor Concepts, MIT-ANP-TR-003, Massachusetts Institute of Technology, Cambridge, MA (May 1991).

52. M. M. El-Wakil, Nuclear Energy Conversion, International Textbook Company, San Francisco (1971).

53. C. W. Forsberg, "Hydrogen, Electricity, and Nuclear Power," Nuclear News, 45(10) (September 2002).

54. R. E. Stoll and F. Von Linde, "Hydrogen-What Are the Costs?" Hydrocarbon Process., 79(12), 42-46 (December 2000).

55. G. Parkinson, "The Utility of Hydrogen," Chemical Engineering, 108(10), 29-36 (September 2001).

56. C. W. Forsberg and K. L. Peddicord, "Hydrogen Production as a Major Nuclear Energy Application," Nucl. News, 44(10), 41-45 (September 2001).

57. C. W. Forsberg, "Hydrogen, Nuclear Energy, and the Advanced High Temperature Reactor," International Journal of Hydrogen (in press). 
58. OECD-NEA Nuclear Science Committee, First International Exchange Meeting on Nuclear Production of Hydrogen, Paris, October 2-3, 2000 (2000).

59. C. L. Brown, J. F. Funk, and S. K. Showalter, High Efficiency Generation of Hydrogen Fuels Using Nuclear Power, GA-A23451, General Atomics (July 2000).

60. J. Sheffield et al., "A Study of Options for the Deployment of Large Fusion Power Plants," presented at the JIEE 2000-06, Joint Institute for Energy and Environment, University of Tennessee, Knoxville, TN (June 2000).

61. R. Hino et al., Study on Hydrogen Production by High-Temperature Electrolysis of Steam, 97-064, Japan Atomic Energy Research Institute, Oarai-machi, Japan (September 1997).

62. C. Boardman, M. Hui, D. G. Carroll, and A. E. Dubberley, "Economic Assessment of S-PRISM Including Development and Generating Costs," Proceedings of the 9th International Conference on Nuclear Engineering, Nice, France, April 8-12, 2001 (2001).

63. Modular High Temperature Gas-Cooled Reactor Commercialization and Generation Cost Estimates, DOE-HTGR 90365, Gas Cooled Reactor Associates (November 1993). 
ORNL/TM-2004/104

\section{INTERNAL DISTRIBUTION}

1. S. J. Ball (ballsj@ornl.gov)

2. J. L. Binder (binderi1@ornl.gov)

3. W. R. Corwin (corwinwr@ornl.gov)

4. G. D. Del Cul (delculgd@ornl.gov)

5. C. W. Forsberg (forsbergcw@ornl.gov)

6. J. C. Gehin (gehinjc@ornl.gov)

7. D. J. Hill (hilldj@ornl.gov)

8. G. E. Kulynych (kulynychge@ornl.gov)

9. G. T. Mays (maysgt@ornl.gov)

10. G. E. Michaels (michaelsge@ornl.gov)

11. D. L. Moses (mosesdl@ornl.gov)
12. L. J. Ott (ottlj@ornl.gov)

13. C. V. Parks (parkscv@ornl.gov)

14. R. L. Reid

15. J. P. Renier (renierjp@ornl.gov)

16. J. E. Rushton (rushtonje@ornl.gov)

17. D. F. Williams (williamsdf2@ornl.gov)

18. D. F. Wilson (wilsondf@ornl.gov)

19. G. L. Yoder Jr. (yodergljr@ornl.gov)

20. ORNL Central Research Library (conradre@ornl.gov)

21. ORNL Laboratory Records-RC (hamrindr@,ornl.gov)

\section{EXTERNAL DISTRIBUTION}

22. T. L. Cook, NE-20/Germantown Building, U.S. Department of Energy, 1000 Independence Ave., S.W., Washington, DC 20585-1290 (trevor.cook@,hq.doe.gov).

23. M. A. Feltus, NE-20/Germantonw Building, U.S. Department of Energy, 1000 Independence Ave., S.W., Washington, DC 20585-1290 (madeline.feltus@hq.doe.gov).

24. P. E. MacDonald, Idaho National Engineering and Environmental Laboratory, Mailstop 3870, 2525 N. Fremont Avenue, P. O. Box 1625, Idaho Falls, ID 83415 (pem@inel.gov).

25. E. J. Parma, Jr., Sandia National Laboratories, P. O. Box 5800, Albuquerque, NM 87185-1141 (ejparma@sandia.gov).

26. P. F. Peterson, University of California, Berkeley, Nuclear Engineering Department, 4153 Etcheverry Hall, Berkeley, CA 94720-1730 (peterson@nuc.berkeley.edu).

27. P. S. Pickard, Sandia National Laboratories, P. O. Box 5800, Albuquerque, NM 87185-1136 (pspicka@sandia.gov).

28. J. M. Ryskamp, Idaho National Engineering and Environmental Laboratory, Mailstop 3860, 2525 N. Fremont Avenue, P. O. Box 1625, Idaho Falls, ID 83415 (jmr@inel.gov).

29. A. C. Taylor, NE-40/Germantown Building, U.S. Department of Energy, 1000 Independence Ave., S.W., Washington, DC 20585-1290 (amy.taylor@hq.doe.gov).

30. M. Vernon, Sandia National Laboratories, P. O. Box 5800, Albuquerque, NM 87185-1146 (meverno@sandia.gov).

31. R. M. Versluis, NE-20/Germantown Building, U.S. Department of Energy, 1000 Independence Ave., S.W., Washington, DC 20585-1290 (rob.versluis@hq.doe.gov). .

32. H. Zhao, University of California, Berkeley, Nuclear Engineering Department, 4153 Etcheverry Hall, Berkeley, CA 94720-1730 (zhaohh@nuc.berkeley.edu). 